This item was submitted to Loughborough's Research Repository by the author.

Items in Figshare are protected by copyright, with all rights reserved, unless otherwise indicated.

\title{
A comprehensive proton exchange membrane fuel cell system model integrating various auxiliary subsystems
}

PLEASE CITE THE PUBLISHED VERSION

https://doi.org/10.1016/j.apenergy.2019.113959

PUBLISHER

Elsevier BV

VERSION

AM (Accepted Manuscript)

PUBLISHER STATEMENT

This paper was accepted for publication in the journal Applied Energy and the definitive published version is available at https://doi.org/10.1016/j.apenergy.2019.113959

LICENCE

CC BY-NC-ND 4.0

\section{REPOSITORY RECORD}

Yang, Zirong, Qing Du, Zhiwei Jia, Chunguang Yang, Jin Xuan, and Kui Jiao. 2019. "A Comprehensive Proton Exchange Membrane Fuel Cell System Model Integrating Various Auxiliary Subsystems”. figshare. https://hdl.handle.net/2134/10855409.v1. 
A comprehensive proton exchange membrane fuel cell

\title{
system model integrating various auxiliary subsystems
}

\author{
Zirong Yang ${ }^{\mathrm{a}}$, Qing Du ${ }^{\mathrm{a}, *}$, Zhiwei Jia ${ }^{\mathrm{b}}$, Chunguang Yang ${ }^{\mathrm{b}}$, Jin Xuan ${ }^{\mathrm{c}}$, Kui Jiao ${ }^{\mathrm{a}, *}$ \\ a. State Key Laboratory of Engines, Tianjin University, 135 Yaguan Road, Tianjin, 300350, China \\ b. Zhengzhou Yutong Bus CO., LTD, Yutong Industry Park, Zhengzhou, 450016, China \\ c. Department of Chemical Engineering, Loughborough University, Loughborough, LE11 3TU, \\ United Kingdom \\ *Corresponding authors: duqing@tju.edu.cn (Q. Du); kjiao@tju.edu.cn (K. Jiao)
}

\begin{abstract}
A comprehensive proton exchange membrane fuel cell (PEMFC) system model is developed, including a pseudo two-dimensional transient multiphase stack model, a one-dimensional transient multiphase membrane humidifier model, a one-dimensional electrochemical hydrogen pump model, an air compressor model with proportion-integral-derivative control and a ribbon-tubular fin radiator model. All sub-models have been rigorously validated against experimental data to guarantee the system model accuracy. The effects of stack operating temperature, gas flow pattern and humidifier structural design are investigated to cast insights into the interaction among stack and auxiliary subsystems. The results indicate that the stack is successfully maintained at required operating temperatures $\left(60^{\circ} \mathrm{C}, 70{ }^{\circ} \mathrm{C}, 80{ }^{\circ} \mathrm{C}\right)$ with help of the radiator when the whole system starts from ambient temperature $\left(25^{\circ} \mathrm{C}\right)$. However, the stack is likely to suffer from membrane dehydration when operated at $70{ }^{\circ} \mathrm{C}$, and the problem becomes more severe at $80{ }^{\circ} \mathrm{C}$, causing significant performance deterioration. The water and temperature distribution inside the system are further demonstrated. The co-current flow pattern contributes to better water utilization of the whole system which may lead to higher output performances. But the counter-current flow pattern has positive effects on parameter distribution uniformity inside fuel cell, which is beneficial for the stack durability. As regards the membrane dehydration, it is found that optimizing membrane humidifier area does not fundamentally solve the problem. Increasing humidifier area contributes to higher water vapor transfer rate, however, it results in much slower humidification responses.
\end{abstract}




\section{Nomenclature}

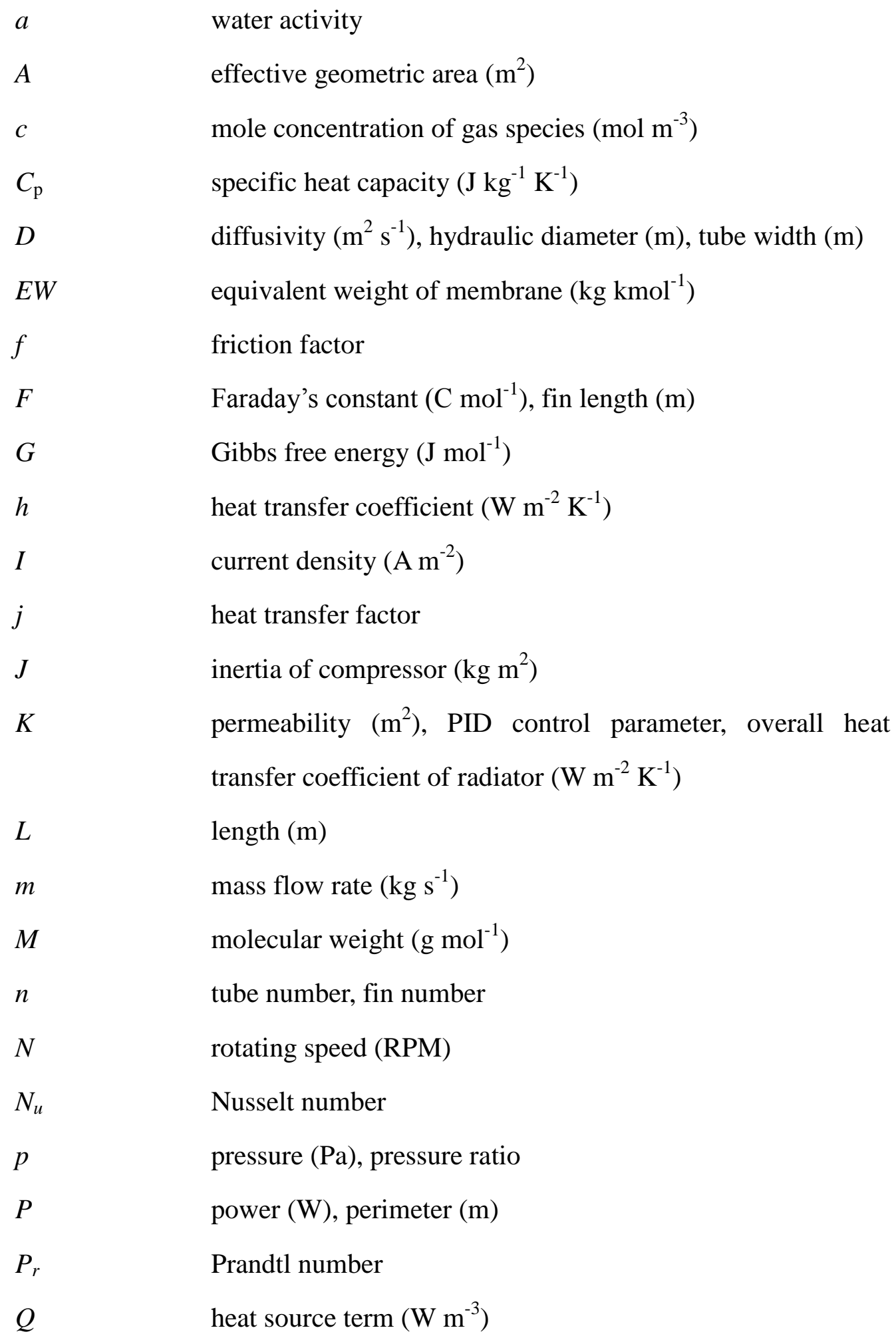


area ratio

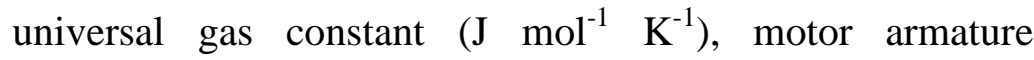
resistance $(\Omega)$

$R e$

S

$S$

Sher

\section{$t$}

$\Delta t$

$\Delta t_{\mathrm{m}}$

T

$u$

V

Greek letters

$\varepsilon$

$\zeta$

$\lambda$

$\xi$

$\mu$

$\rho$

$\omega$

$\sigma$

$\delta$

$\psi$

$\eta$

$\gamma$

Reynolds number

volume fraction in pore structures

source terms $\left(\mathrm{kmol} \mathrm{m}^{-3} \mathrm{~s}^{-1}, \mathrm{~kg} \mathrm{~m}^{-3} \mathrm{~s}^{-1}, \mathrm{~W} \mathrm{~m}^{-3}\right)$, entropy ( $\mathrm{mol}^{-1} \mathrm{~K}^{-1}$ )

Sherwood number

time (s)

time step size (s)

average temperature difference $(\mathrm{K})$

temperature $(\mathrm{K})$, tube length $(\mathrm{m})$

velocity $\left(\mathrm{m} \mathrm{s}^{-1}\right)$, velocity ratio

voltage $(\mathrm{V})$

porosity

water transfer rate $\left(\mathrm{s}^{-1}\right)$

membrane water content

stoichiometry ratio

dynamic viscosity $\left(\mathrm{kg} \mathrm{m}^{-1} \mathrm{~s}^{-1}\right)$

density $\left(\mathrm{kg} \mathrm{m}^{-3}\right)$

volume fraction of ionomer, rotation angular frequency (rad $\left.\mathrm{s}^{-1}\right)$

surface tension $\left(\mathrm{N} \mathrm{m}^{-1}\right)$

thickness (m), pressure calibration factor

water volume fraction in hydrated membrane

efficiency

compressibility coefficient 
contact angle $\left({ }^{\circ}\right)$, temperature calibration factor, louver angle

$\left({ }^{\circ}\right)$

torque $(\mathrm{N} \mathrm{m})$

conductivity $\left(\mathrm{S} \mathrm{m}^{-1}\right)$, motor torque constant

motor terminal voltage $(\mathrm{V})$

Subscripts and superscripts

a

act

atm

BP

c

$\mathrm{CH}$

CL

$\mathrm{cm}$

conc

cond

cool

$\mathrm{cp}$

cr

D

dry

eff

EOD

eq

f

FPD

fusn

g anode

activation

atmosphere

bipolar plate

cathode, capillary

flow channel

catalyst layer

compressor motor

concentration

condensation

coolant

compressor

corrected

derivative

dry channel

effective

electro-osmotic drag

equilibrium

fin

freezing point depression

fusion

gas phase 


$\begin{array}{ll}\text { GDL } & \text { gas diffusion layer } \\ \mathrm{H}_{2} & \text { hydrogen } \\ \mathrm{HP} & \text { hydrogen pump } \\ \mathrm{I} & \text { integral } \\ \text { ice } & \text { ice } \\ \text { in } & \text { inlet } \\ \text { 1 } & \text { liquid phase } \\ \text { lq } & \text { liquid water } \\ \mathrm{MEM} & \text { membrane } \\ \mathrm{MH} & \text { membrane humidifier } \\ \mathrm{mw} & \text { membrane water } \\ \mathrm{MPL} & \text { micro-porous layer } \\ \mathrm{N} & \text { standard condition } \\ \mathrm{N}_{2} & \text { nitrogen } \\ \mathrm{Nernst} & \text { Nernst } \\ \mathrm{O}_{2} & \text { oxygen } \\ \text { ohmic } & \text { ohmic } \\ \text { out } & \text { output, outlet } \\ \mathrm{P} & \text { proportion } \\ \text { pc } & \text { phase change } \\ \text { per } & \text { permeation } \\ \text { react } & \text { reaction } \\ \text { ref } & \text { reference state } \\ \text { req } & \text { requested } \\ \text { sat } & \text { saturation } \\ \text { suplq } & \text { super-cooled water } \\ \text { surr } & \text { surroundings } \\ \text { wet } & \text { water vapor } \\ \text { wet channel }\end{array}$


m-1 membrane water to super-cooled liquid water

$\mathrm{m}-\mathrm{v} \quad$ membrane water to water vapor

1-i super-cooled water to ice

v-1 water vapor to super-cooledVliquid water 
The schematic diagram of a comprehensive PEMFC system is shown in Fig.1, including stack, reactant gases supply subsystem, humidification subsystem, and heat management subsystem. After exiting the high-pressure hydrogen tank, hydrogen is regulated at the requested pressure and mass flow rate through solenoid valves, which is subsequently supplied to the stack to generate electricity. To improve fuel utilization, there usually exists a recirculation loop in fuel cell vehicles (FCVs). There are different types of hydrogen recirculation pump such as motor-driven pump, ejector, and electrochemical hydrogen pump [8-11]. For the air intake, an air filter is engaged to eliminate impurities, which is of great importance for component lifetime in PEMFC systems [12-14]. A compressor or blower is indispensable to increase the stack operating pressure. To avoid carbon corrosion in cathode catalyst layer, solenoid valves are placed before and after the stack to prevent the residual air in manifolds from entering after shutdown. Humidification subsystem is responsible for humidifying reactant gases since fuel cell is likely to suffer from the membrane dehydration without sufficient gas humidification $[15,16]$. However, excessive humidification may lead to liquid water flooding, which also deteriorates fuel cell performances [17-19]. Spray humidifier, membrane humidifier and enthalpy wheel 


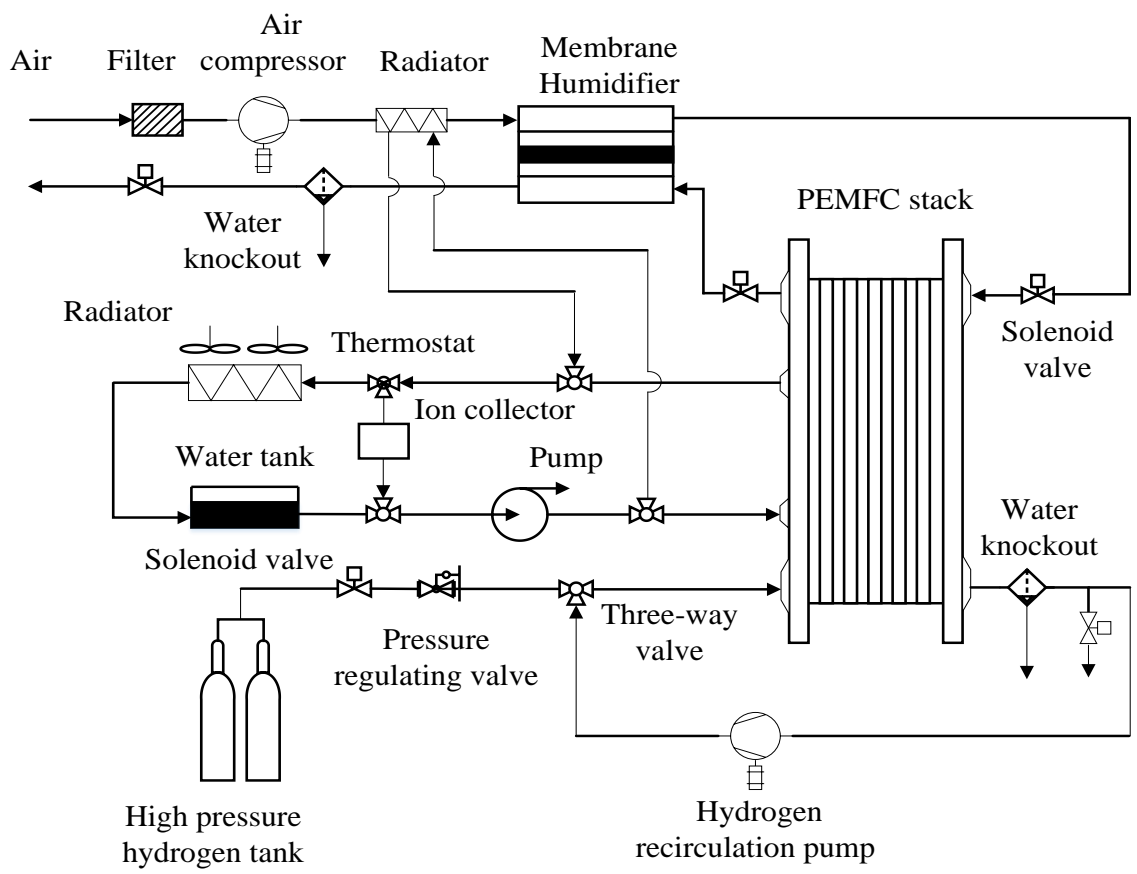

Fig. 1. Schematic diagram of a comprehensive proton exchange membrane fuel cell system.

In the past decades, a large number of experimental and numerical studies have been 
conducted towards fuel cells and stacks. Effects of operating conditions such as relative humidity, temperature, and pressure have been investigated [15-18,24-27] to optimize fuel cell performances. Much attention has also been paid to the structural design and optimization, such as the catalyst [28-30], porous electrode [31,32] and flow channel [33]. Through steady-state polarization curves, transient response and electrochemical impedance spectroscopy (EIS) techniques, Yan et al. [17] found that the cathode inlet gas humidification had significant influences on output performances. Besides, $75{ }^{\circ} \mathrm{C}$ was found to be the best operating temperature among five temperatures ranging from $65^{\circ} \mathrm{C}$ to $85^{\circ} \mathrm{C}$ under full humidification conditions. Similar investigations were conducted by Kim [24], Iranzo [25] and Ozen [27]. It was further observed that single fuel cell or stack performances were more affected by the cathode humidification than the anode humidification. To cast more insights, visualization studies such as neutron imaging [34,35], scanning electron microscopy (SEM) [36], infrared radiation imaging [37] and other high-tech methods [38] have been adopted. In addition to experiments, many theoretical or numerical models have been developed with focuses on operating conditions and structural designs [39-46]. Jiao et al. [39] developed a three-dimensional multiphase transient model to investigate gas humidification influences during cold start process. It was found that the relative humidity had negligible effects since the saturated water vapor pressure was small at subzero temperatures. Tolj et al. [45] developed a pseudo 2D model to investigate the possibility of using product water to internally humidify reactant gases. However, auxiliary equipment such as air compressor, humidifier, and hydrogen pump was hardly taken into consideration in the aforementioned studies. The operation conditions were realized by simply assuming the boundary conditions, which was not coupled with real performances of auxiliary subsystems. The interaction among PEMFC stack and various subsystems needs further investigation because it provides practical suggestions about heat and water management at a system level.

Although comprehensive system studies are rarely presented in literature, numerous researches have been conducted on individual auxiliary subsystems. As regards the 
hydrogen supply subsystem, studies were mainly aimed at eliminating anode nitrogen accumulation and improving fuel utilization [47-54]. He et al. [48] developed a control-oriented model of the fuel delivery system to investigate effective control strategies. Peomislow et al. [49] presented an analytic model to investigate the anode nitrogen accumulation phenomenon. The nitrogen crossover and purging strategies were also studied by Rabbani [50] and Chen [51]. Hwang [52] compared three different hydrogen supply schemes to investigate the PEMFC system efficiency, including flow-through mode, dead-end mode, and recirculation mode. However, much less attention has been paid to hydrogen pump such as ejector and electrochemical hydrogen pump [56-58]. When it comes to the air supply subsystem, improving compressor dynamic responses and decreasing its parasitic power consumption were the main concerns [59-62]. Wang et al. [61] studied the air flow control for preventing cathode starvation when operating conditions were changed. Liu et al. [62] established a semi-mechanical semi-imperial air supply model to investigate the dynamic control of a centrifugal compressor. The control method was further validated in a $150 \mathrm{~kW}$ PEMFC engine system. The researches on humidification subsystem have concentrated on effects of operating conditions and structural designs [63-68]. Yu et al. [64] developed a static model based on planar heat exchanger to investigate effects of geometric parameters and operating parameters. Divesh et al. [65] developed a steady-state analytical model in counter-current flow mode, which could be applied for both plate-and-frame humidifier and shell-and-tube humidifier. However, the aforementioned humidifier models were developed based on either water-to-gas humidification or gas-to-gas humidification while both may happen in real PEMFC subsystems, making it necessary to consider different humidification methods simultaneously. There also existed some researches about the heat management subsystem, which mainly focused on cold startup techniques and cooling strategies [69-73]. Guo et al. [72] studied the hydrogen-oxygen catalytic reaction with a three-dimensional multiphase cold start model. Detailed unassisted and assisted cold start strategies have been summarized by Luo and Jiao [73]. Despite aforementioned studies, modeling of the whole PEMFC system with detailed 
information about auxiliary subsystems is rarely presented in literature. The system model not only reveals heat and mass transport processes inside each individual subsystem but also exhibits the coupled water and heat management at a system level. Water management and optimization of the whole system is supposed to give valuable advice for PEMFC applications.

In the present study, a comprehensive PEMFC system model is developed, including stack, membrane humidifier, hydrogen pump, air compressor and radiator. Detailed methodologies about the five subsystems are presented. After rigorous model validation, the effects of stack operating temperature, gas flow pattern, and humidifier structural design on system performances are investigated. The output voltage, membrane water content, water vapor and temperature distribution are compared to cast insights into the interaction among stack and auxiliary subsystems.

\section{Model development}

A typical proton exchange membrane fuel cell (PEMFC) system consists of stack, gas supply subsystems, humidification subsystem, and heat management subsystem as shown in Fig. 1. The governing equations of stack, membrane humidifier, electrochemical hydrogen pump, air compressor, and radiator are explained in the following subsections.

\subsection{PEMFC stack model}

The schematic diagram of a pseudo two-dimensional PEMFC stack model is illustrated in Fig.2, including bipolar plate (BP), gas channel (CH), gas diffusion layer (GDL), micro-porous layer (MPL), catalyst layer (CL) and proton exchange membrane (MEM). The stack properties and operating conditions are given in Table 1. The designed power is around $50 \mathrm{~kW}$. The coupled heat and water transport as well as sophisticated phase changes are all considered. Besides, the nitrogen crossover phenomenon is also taken into consideration. Instead of solving implicit conservation equations, the explicit formulation calculation method is adopted to enhance 
simulation efficiency. The membrane water, super-cooled/liquid water, ice, gas species, and temperature are calculated at the center of each layer with no further nodes divided. To better reflect water and temperature distribution along the flow direction, the single cell is further divided into several lumps. Gas temperature, concentration and velocity in flow channels are transmitted from the prior node to the posterior node. Heat exchange between adjacent cells is achieved by heat conduction and heat loss between endplate and surroundings is caused by heat convection. Besides, several important assumptions have been made as follows.

1. Reactant gases are assumed to be uniformly distributed into each individual fuel cell $[72,74,75]$.

2. Gas species are considered as ideal gas.

3. Mass transport process inside porous layer is assumed to be dominated by diffusion $[4,5]$.

4. Electrochemically generated water is assumed to be membrane water and it transforms into water vapor, super-cooled/liquid water through phase changes [76].

5. Homogeneous mist flow assumption is adopted in flow channels.

6. Coolant is assumed to flow through cooling channels uniformly in every bipolar layer.

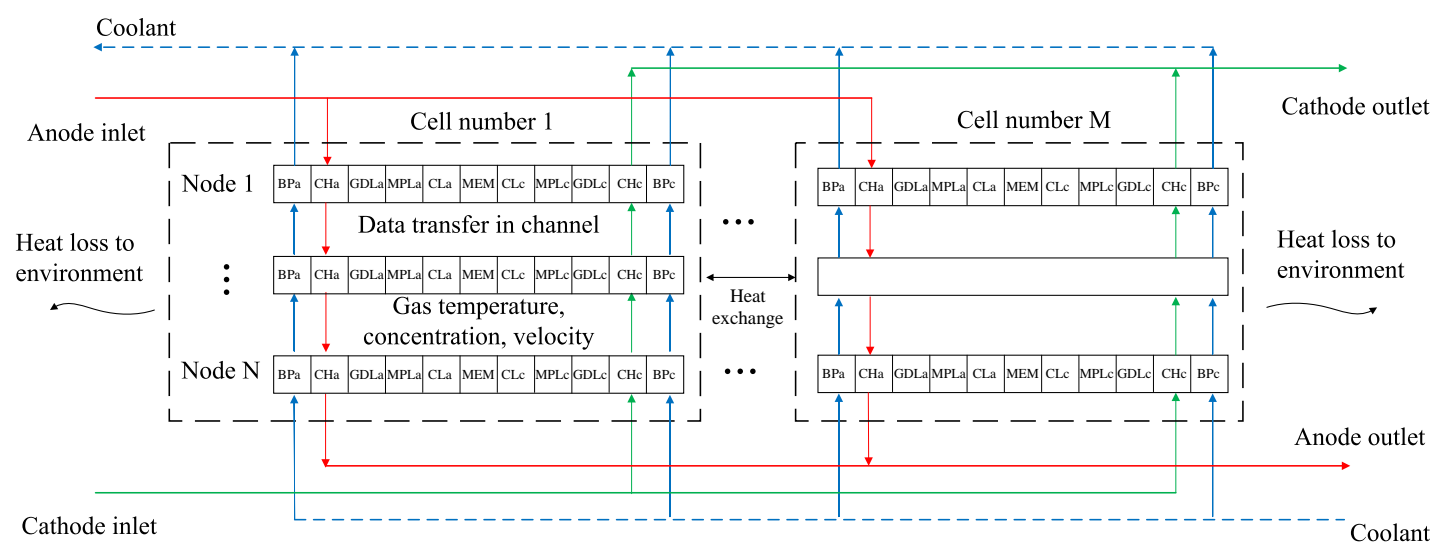

Fig. 2. Schematic diagram of a pseudo two-dimensional PEMFC stack model.

Table 1. Stack properties and operating conditions.

\begin{tabular}{ll}
\hline Parameter & Value \\
\hline
\end{tabular}


Number of single fuel cell

Effective area of single cell

Thickness of BP

Channel length, width, depth, rib width

Thickness of membrane, CL, MPL, $0.050 ; 0.01 ; 0.03 ; 0.2 \mathrm{~mm}$

GDL

Densities of membrane, CL, MPL, $\rho_{\text {mem,CL,MPL,GDL,BP }}=1980 ; 1000 ; 1000$;

GDL, BP $1000 ; 1000 \mathrm{~kg} \mathrm{~m}^{-3}$

Specific heat capacities of membrane, $\left(C_{\mathrm{p}}\right)_{\mathrm{mem}, \mathrm{CL}, \mathrm{MPL}, \mathrm{GDL}, \mathrm{BP}}=833 ; 3300 ; 568$;

CL, MPL, GDL, BP $2000 ; 1580 \mathrm{~J} \mathrm{~kg}^{-1} \mathrm{~K}^{-1}$

Thermal conductivities of membrane, $0.95 ; 1.0 ; 1.0 ; 1.0 ; 20 \mathrm{~W} \mathrm{~m}^{-1} \mathrm{~K}^{-1}$

CL, MPL, GDL, BP

Electric conductivities of CL, MPL, $\kappa_{\mathrm{CL}, \mathrm{MPL}, \mathrm{GDL}, \mathrm{BP}}=5000 ; 5000 ; 5000$;

GDL, BP $20000 \mathrm{~S} \mathrm{~m}^{-1}$

Ionomer volume fraction in $\mathrm{CL}$

$\omega=0.4$

Contact angles of CL, MPL, GDL

$\theta_{\mathrm{CL}, \mathrm{MPL}, \mathrm{GDL}}=100^{\circ} ; 120^{\circ} ; 120^{\circ}$

Porosities of CL, MPL, GDL

$\varepsilon_{\mathrm{CL}, \mathrm{MPL}, \mathrm{GDL}}=0.3 ; 0.4 ; 0.7$

Phase change rates

$\zeta_{\mathrm{m}-\mathrm{v}}, \zeta_{\mathrm{m}-\mathrm{l}}, \zeta_{\mathrm{l}-\mathrm{i}}, \zeta_{\mathrm{i}-\mathrm{l}}=1.0 \mathrm{~s}^{-1} ; \zeta_{\mathrm{v}-1}, \zeta_{\mathrm{l}-\mathrm{v}}=1000$ $\mathrm{s}^{-1}$

Requested stoichiometry ratio

$S T_{\mathrm{a}}^{\mathrm{eq}}=1.2, S T_{\mathrm{c}}^{\mathrm{rq}}=2.0$

Requested operating pressure

$p_{\mathrm{a}, \mathrm{c}}^{\mathrm{req}}=1.5 \mathrm{~atm}$

Heat transfer coefficient between $20 \mathrm{~W} \mathrm{~m}^{-2} \mathrm{~K}^{-1}$

endplate and surrounding

Heat transfer coefficient between fuel $200 \mathrm{~W} \mathrm{~m}^{-2} \mathrm{~K}^{-1}$

cell and coolant

Using the explicit formulation calculation method, membrane water contents at the center of anode CL, membrane, and cathode CL are updated directly at each time step. After discretization and transformation, the calculation equations are expressed as: 
where $\lambda_{\mathrm{CLa}}^{t-\Delta t}, \lambda_{\mathrm{MEM}}^{t-\Delta t}, \lambda_{\mathrm{CLc}}^{t-\Delta t}$ are the membrane water content at last time step, $\lambda_{\mathrm{CLa}}^{t}$, $\lambda_{\text {MEM }}^{t}, \lambda_{\text {CLe }}^{t}$ are the membrane water content at next time step, $D_{\text {MEM_CL }}^{\lambda, \text { eff }}\left(\mathrm{m}^{2} \mathrm{~s}^{-1}\right)$ represents the effective membrane water diffusivity between CL and membrane, $S_{\mathrm{mw}}$ $\left(\mathrm{kmol} \mathrm{m}^{-3} \mathrm{~s}^{-1}\right)$ is the membrane water source term (given in Table 2), $\Delta t$ (s) is the time step.

$$
D_{\mathrm{MEM} \_\mathrm{CL}}^{\lambda, \text { eff }}=\frac{\frac{\delta_{\mathrm{CL}}}{2}+\frac{\delta_{\mathrm{MEM}}}{2}}{\frac{\delta_{\mathrm{CL}}}{2} / D_{\mathrm{CL}}^{\lambda, \text { eff }}+\frac{\delta_{\mathrm{MEM}}}{2} / D_{\mathrm{MEM}}^{\lambda, \text { eff }}}
$$

During the cold start process, super-cooled water freezing mechanism is adopted which has been explained in the previous study [41]. The phase change functions, correlations for transport and electrochemical properties can be found in previous studies $[7,41]$.

Table 2. Source terms.

\begin{tabular}{ll}
\hline Source terms. & Unit \\
$S_{\mathrm{mw}}= \begin{cases}S_{\text {react }}-S_{\mathrm{m}-\mathrm{v}}-S_{\mathrm{m}-1}+S_{\mathrm{EOD}} & (\text { in CLc }) \\
-S_{\mathrm{m}-\mathrm{v}}-S_{\mathrm{m}-1}-S_{\mathrm{EOD}} & \text { (in CLa) }\end{cases}$ & $\mathrm{kmol} \mathrm{m}^{-3} \mathrm{~s}^{-1}$
\end{tabular}


$\mathrm{kg} \mathrm{m}^{-3} \mathrm{~s}^{-1}$ $\mathrm{kmol} \mathrm{m}^{-3} \mathrm{~s}^{-1}$ $\mathrm{kg} \mathrm{m}^{-3} \mathrm{~s}^{-1}$ $\mathrm{kg} \mathrm{m}^{-3} \mathrm{~s}^{-1}$ $\mathrm{kmol} \mathrm{m}^{-3} \mathrm{~s}^{-1}$ $\mathrm{kg} \mathrm{m}^{-3} \mathrm{~s}^{-1}$

(in CLa) (in CLc) (in MEM) (in GDL) $\quad \mathrm{W} \mathrm{m}^{-3}$ (in MPL) (in $\mathrm{CH}$ ) (in BP)

Liquid pressure is assumed to be continuous among porous layers since water saturation jump is observed at the interface of adjacent layers [41-44]. Liquid pressure at the center of CL, MPL and GDL are calculated in a similar way. 


$$
\begin{aligned}
& p_{1, \mathrm{CL}}^{t}=p_{1, \mathrm{CL}}^{t-\Delta t}+\frac{d p_{1}}{d s_{\mathrm{lq}}}\left[-\frac{\left(p_{1, \mathrm{LC}}^{t-\Delta t}-p_{1, \mathrm{MPL}}^{t-\Delta t}\right) D_{\mathrm{CL}, \mathrm{MPL}}^{\mathrm{lq}, \mathrm{eff}}}{\left(\frac{\delta_{\mathrm{CL}}}{2}+\frac{\delta_{\mathrm{MPL}}}{2}\right) \delta_{\mathrm{CL}}}+S_{\mathrm{lq}}\right] \frac{\Delta t}{\rho_{\mathrm{lq}} \varepsilon_{\mathrm{CL}}} \\
& p_{1, \mathrm{MPL}}^{t}=p_{1, \mathrm{MPL}}^{t-\Delta t}+\frac{d p_{1}}{d s_{\mathrm{lq}}}\left[\frac{\left(p_{1, \mathrm{CL}}^{t-\Delta t}-p_{1, \mathrm{MPL}}^{t-\Delta t}\right) D_{\mathrm{CL}, \mathrm{MPL}}^{\mathrm{lq}, \text { eff }}}{\left(\frac{\delta_{\mathrm{CL}}}{2}+\frac{\delta_{\mathrm{MPL}}}{2}\right) \delta_{\mathrm{MPL}}}-\frac{\left(p_{1, \mathrm{MPL}}^{t-\Delta t}-p_{1, \mathrm{GLL}}^{t-\Delta t}\right) D_{\mathrm{MPL}-\mathrm{GDL}}^{\mathrm{lq}, \text { eff }}}{\left(\frac{\delta_{\mathrm{MPL}}}{2}+\frac{\delta_{\mathrm{GDL}}}{2}\right) \delta_{\mathrm{MPL}}}+S_{\mathrm{lq}}\right] \frac{\Delta t}{\rho_{\mathrm{lq}} \varepsilon_{\mathrm{MPL}}}
\end{aligned}
$$

$$
p_{1, \mathrm{GDL}}^{t}=p_{1, \mathrm{GDL}}^{t-\Delta t}+\frac{d p_{1}}{d s_{\mathrm{lq}}}\left[\frac{\left(p_{1, \mathrm{MPL}}^{t-\Delta t}-p_{1, \mathrm{GDL}}^{t-\Delta t}\right) D_{\mathrm{MPL}-\mathrm{GDL}}^{\mathrm{lq}, \text { eff }}}{\left(\frac{\delta_{\mathrm{MPL}}}{2}+\frac{\delta_{\mathrm{GDL}}}{2}\right) \delta_{\mathrm{GDL}}}-\frac{r_{\mathrm{CH}}\left(p_{1, \mathrm{GDL}}^{t-\Delta t}-p_{1, \mathrm{CH}}^{t-\Delta t}\right) D_{\mathrm{GL}}^{\mathrm{lq}, \mathrm{eff}}}{\left(\frac{\delta_{\mathrm{GDL}}}{2}\right) \delta_{\mathrm{GDL}}}+S_{\mathrm{lq}}\right] \frac{\Delta t}{\rho_{\mathrm{lq}} \varepsilon_{\mathrm{GDL}}}
$$

where $p_{1, \mathrm{CL}}^{t-\Delta t}, p_{1, \mathrm{MPL}}^{t-\Delta t}, p_{1, \mathrm{GDL}}^{t-\Delta t}(\mathrm{~Pa})$ are the liquid pressure of CL, MPL, GDL at last time step, $p_{\mathrm{l}, \mathrm{CL}}^{t}, p_{\mathrm{l}, \mathrm{MPL}}^{t}, p_{\mathrm{l}, \mathrm{GDL}}^{t}(\mathrm{~Pa})$ are that of CL, MPL, GDL at next time step, $s_{\mathrm{lq}}$ is the water volume fraction in porous layers, $D_{\mathrm{CL} \_\mathrm{MPL}}^{\mathrm{lq} \text {, eff }}\left(\mathrm{m}^{2} \mathrm{~s}^{-1}\right)$ is the effective liquid water diffusivity between $\mathrm{CL}$ and MPL, $r_{\mathrm{CH}}$ is the ratio between channel area and cell area. If the channel width and the rib width are identical, $r_{\mathrm{CH}}$ is equal to $0.5 . S_{\mathrm{lq}}$ $\left(\mathrm{kg} \mathrm{m}^{-3} \mathrm{~s}^{-1}\right)$ is the source term. $S_{\text {per }}\left(\mathrm{kg} \mathrm{m}^{-3} \mathrm{~s}^{-1}\right)$ represents the source term of hydraulic permeation caused by liquid pressure difference between anode CL and cathode CL. It should be noted that $S_{\text {lqfflow }}\left(\mathrm{kg} \mathrm{m}^{-3} \mathrm{~s}^{-1}\right)$ represents the amount of liquid water staying in flow channel, which is calculated by the difference of liquid water flowing in and flowing out. $A_{\text {in }}\left(\mathrm{m}^{2}\right)$ is cross-sectional area of channel. $\zeta_{\text {ratio }}$ is the velocity ratio between liquid water and gas in flow channels.

The water volume fraction can be obtained by Leverett-J function once the liquid pressure and the gas pressure are solved. 
$p_{\mathrm{c}}=p_{\mathrm{g}}-p_{1}$

$s_{\mathrm{lq}}^{t}=\frac{1}{1.417}\left[\frac{p_{\mathrm{c}}^{t}}{\sigma \cos (\theta)\left(\frac{\varepsilon}{K^{0}}\right)^{0.5}}+2.12\left(s_{\mathrm{lq}}^{t-\Delta t}\right)^{2}-1.26\left(s_{\mathrm{lq}}^{t-\Delta t}\right)^{3}\right]$

To illustrate liquid water removal process, it is necessary to consider the water volume fraction in flow channels. The capillary pressure in channel is also calculated based on Leverett-J function and it is used to calculate the diffusion term between GDL and channel to guarantee mass conservation. Detailed information about data exchange at GDL/channel interface can be found in previous studies [42-44].

$$
\begin{aligned}
& p_{\mathrm{c}, \mathrm{CHc}}^{t-\Delta t}=\sigma \cos (\theta)\left(\frac{\varepsilon}{K^{0}}\right)^{0.5}\left[1.42 s_{\mathrm{lq}, \mathrm{CHc}}^{t-\Delta t}-2.12\left(s_{\mathrm{lq}, \mathrm{CHc}}^{t-\Delta t}\right)^{2}+1.26\left(s_{\mathrm{lq}, \mathrm{CHc}}^{t-\Delta t}\right)^{3}\right] \\
& s_{\mathrm{lq}, \mathrm{CH}}^{t}=s_{\mathrm{lq}, \mathrm{CH}}^{t-\Delta t}+\left[\frac{\left(p_{1, \mathrm{GDL}}^{t-\Delta t}-p_{1, \mathrm{CH}}^{t-\Delta t}\right) D_{\mathrm{GDL}}^{\mathrm{lq}, \mathrm{eff}}}{\left(\frac{\delta_{\mathrm{GDL}}}{2}\right) \delta_{\mathrm{CH}}}+S_{\mathrm{lq}}\right] \frac{\Delta t}{\rho_{\mathrm{lq}}}
\end{aligned}
$$

It is known that super-cooled/liquid water freezes under subzero temperatures, which will decrease effective reaction area and block gas transport passages, resulting in fuel cell performance degradation. During the cold start process, ice volume fraction in porous layers and gas channel are calculated as:

$$
s_{\text {ice }}^{t}=s_{\text {ice }}^{t-\Delta t}+\frac{S_{\text {ice }}}{\varepsilon \rho_{\text {ice }}} \Delta t
$$

where $s_{\text {ice }}^{t-\Delta t}$ is the ice volume fraction at last time step, $s_{\text {ice }}^{t}$ is the ice volume fraction at next time step, $S_{\text {ice }}\left(\mathrm{kg} \mathrm{m}^{-3} \mathrm{~s}^{-1}\right)$ is the source term (given in Table 2).

The gas species include water vapor, hydrogen, oxygen, and nitrogen, which are also updated using the explicit formulation calculation method.

$$
c_{\mathrm{i}, \mathrm{CL}}^{t}=c_{\mathrm{i}, \mathrm{CL}}^{t-\Delta t}+\left[-\frac{\left(c_{\mathrm{i}, \mathrm{CL}}^{t-\Delta t}-c_{\mathrm{i}, \mathrm{MPL}}^{t-\Delta t}\right) D_{\mathrm{CL} \_\mathrm{MPL}}^{\mathrm{i}, \text { eff }}}{\left(\frac{\delta_{\mathrm{CL}}}{2}+\frac{\delta_{\mathrm{MPL}}}{2}\right) \delta_{\mathrm{CL}}}+S_{\mathrm{i}}\right] \frac{\Delta t}{\varepsilon_{\mathrm{CL}}}
$$


where $c_{\mathrm{i}, \mathrm{CL}}^{t-\Delta t}, c_{\mathrm{i}, \mathrm{MPL}}^{t-\Delta t}, c_{\mathrm{i}, \mathrm{GDL}}^{t-\Delta t}, c_{\mathrm{i}, \mathrm{CH}}^{t-\Delta t}\left(\mathrm{~mol} \mathrm{~m}{ }^{-3}\right)$ represent the gas concentration of CL, MPL, GDL, CH at last time step, $c_{\mathrm{i}, \mathrm{CL}}^{t}, c_{\mathrm{i}, \mathrm{MPL}}^{t}, c_{\mathrm{i}, \mathrm{GDL}}^{t}, c_{\mathrm{i}, \mathrm{H}}^{t}\left(\mathrm{~mol} \mathrm{~m}^{-3}\right)$ represent that of CL, MPL, GDL, CH at next time step (i $=\mathrm{H}_{2}, \mathrm{O}_{2}, \mathrm{~N}_{2}$, water vapor), $S_{\mathrm{i}}\left(\mathrm{mol} \mathrm{m}^{-3}\right.$ $\mathrm{s}^{-1}$ ) is the source term of gas species. The effective gas diffusivity between GDL and gas channel $D_{\mathrm{GDL} \_ \text {CH }}^{\mathrm{i} \text { eff }}\left(\mathrm{m}^{2} \mathrm{~s}^{-1}\right)$ is calculated as:

$$
D_{\mathrm{GDL} \_\mathrm{CH}}^{\mathrm{i} \text {,eff }}=\frac{\frac{\delta_{\mathrm{GDL}}}{2}+\frac{\delta_{\mathrm{CH}}}{2}}{\left(\frac{\delta_{\mathrm{GDL}}}{2}\right) / D_{\mathrm{GDL}}^{\mathrm{i} \text {,eff }}+\left(\frac{\delta_{\mathrm{CH}}}{2}\right) /\left(\text { Sher } \cdot D_{\mathrm{CH}}^{\mathrm{i}, \text { eff }}\right)}
$$

where Sher refers to Sherwood number.

Nitrogen crossover phenomenon results from the partial pressure gradient between cathode side and anode side, which may decrease fuel cell performances after long-term operation [49-52]. The nitrogen crossover rate $D_{\mathrm{N}_{2}, \mathrm{MEM}}\left(\mathrm{mol} \mathrm{m}^{-1} \mathrm{~s}^{-1} \mathrm{~Pa}^{-1}\right)$ is calculated as [53]:

$$
D_{\mathrm{N}_{2}, \mathrm{MEM}}=\alpha_{N_{2}}\left(0.0295+1.21 \psi-1.93 \psi^{2}\right) \exp \left[\frac{19830}{R}\left(\frac{1}{303}-\frac{1}{T_{\mathrm{MEM}}}\right)\right]
$$




$$
\psi=\frac{\lambda_{\mathrm{MEM}} V_{\mathrm{H}_{2} \mathrm{O}}}{V_{\mathrm{MEM}}+\lambda_{\mathrm{MEM}} V_{\mathrm{H}_{2} \mathrm{O}}}
$$

where $\psi$ is the water volume fraction in the hydrated membrane. The coefficient $\alpha_{N_{2}}\left(\mathrm{~mol} \mathrm{~m}^{-1} \mathrm{~s}^{-1} \mathrm{~Pa}^{-1}\right)$ is set as $1 \times 10^{-15}$ after validating against the experimental data [54].

Since an air compressor is considered in the system model, it is essential to describe pressure drops in every component. The pressure drop in stack consists of two parts: pressure drop of gas distribution passage inside stack manifolds and pressure drop of straight flow channels in single cell [77].

$$
\frac{\mathrm{d} p}{\mathrm{~d} x}=\frac{4}{D_{h}} f \frac{1}{2} \rho \bar{u}^{2}=\frac{4}{D_{h}} \frac{f \mathrm{Re}_{h}}{\frac{\rho \bar{u} D_{h}}{\mu}} \frac{1}{2} \rho \bar{u}^{-2}=\frac{2}{D_{h}^{2}} f \operatorname{Re}_{h} \mu \bar{u}
$$

where $\mathrm{d} x(\mathrm{~m})$ is the channel length, $D_{h}(\mathrm{~m})$ is the hydraulic diameter, $\bar{u}\left(\mathrm{~m} \mathrm{~s}^{-1}\right)$ is the average velocity, $f$ is the friction factor, $\mathrm{Re}_{h}$ is the Reynolds number. For rectangular flow channels, $f \operatorname{Re}_{h}$ can be calculated as [55]:

$$
f \cdot \operatorname{Re}_{h}=24\left(1-1.3553 \alpha+1.9467 \alpha^{2}-1.7012 \alpha^{3}+0.9564 \alpha^{4}-0.2537 \alpha^{5}\right)
$$

where $\alpha$ represents the length-width ratio of the cross-sectional area.

The temperatures at the center of all layers are updated at each time step.

$$
\begin{aligned}
& T_{\mathrm{BP}}^{t}=T_{\mathrm{BP}}^{t-\Delta t}+\left[\frac{\left(T_{\mathrm{CH}}^{t-\Delta t}-T_{\mathrm{BP}}^{t-\Delta t}\right) k_{\mathrm{BP} \_\mathrm{CH}}^{\text {eff }}}{\left(\frac{\delta_{\mathrm{BP}}}{2}+\frac{\delta_{\mathrm{CH}}}{2}\right) \delta_{\mathrm{BP}}}-\frac{h_{\text {cool }}\left(T_{\mathrm{BP}}^{t-\Delta t}-T_{\text {cool }}\right)}{\delta_{\mathrm{BP}}}+S_{\mathrm{T}}\right] \frac{\Delta t}{\rho c_{\mathrm{p}}} \\
& T_{\mathrm{CH}}^{t}=T_{\mathrm{CH}}^{t-\Delta t}+\left[\frac{\left(T_{\mathrm{GDL}}^{t-\Delta t}-T_{\mathrm{CH}}^{t-\Delta t}\right) k_{\mathrm{GDL} \_\mathrm{CH}}^{\text {eff }}}{\left(\frac{\delta_{\mathrm{CH}}}{2}+\frac{\delta_{\mathrm{GDL}}}{2}\right) \delta_{\mathrm{CH}}}-\frac{\left(T_{\mathrm{CH}}^{t-\Delta t}-T_{\mathrm{BP}}^{t-\Delta t}\right) k_{\mathrm{BP} \_\mathrm{CH}}^{\text {eff }}}{\left(\frac{\delta_{\mathrm{BP}}}{2}+\frac{\delta_{\mathrm{CH}}}{2}\right) \delta_{\mathrm{CH}}}+S_{\mathrm{T}}\right] \frac{\Delta t}{\rho c_{\mathrm{p}}}
\end{aligned}
$$


where $T_{\mathrm{BP}}^{t-\Delta t}, T_{\mathrm{CH}}^{t-\Delta t}, T_{\mathrm{MEM}}^{t-\Delta t}(\mathrm{~K})$ are the temperature of $\mathrm{BP}, \mathrm{CH}, \mathrm{MEM}$ at last time step, $T_{\mathrm{BP}}^{t}, T_{\mathrm{CH}}^{t}, T_{\mathrm{MEM}}^{t}(\mathrm{~K})$ are the temperature of $\mathrm{BP}, \mathrm{CH}, \mathrm{MEM}$ at next time step, $k_{\mathrm{BP} \_\mathrm{CH}}^{\text {eff }}\left(\mathrm{W} \mathrm{m}^{-1} \mathrm{~K}^{-1}\right)$ is the effective thermal conductivity between $\mathrm{BP}$ and flow channel, $h_{\text {cool }}\left(\mathrm{W} \mathrm{m} \mathrm{m}^{-2} \mathrm{~K}^{-1}\right)$ is the heat transfer coefficient between BP and coolant, $S_{\mathrm{T}}\left(\mathrm{W} \mathrm{m}^{-3}\right)$ is the heat source term. $Q_{\text {flow }}\left(\mathrm{W} \mathrm{m}^{-3}\right)$ is the heating/cooling effect since the inlet gas temperature may differ from the fuel cell temperature.

$Q_{\text {flow }}=\frac{A_{\text {in }} \sum_{\mathrm{i}}\left(c_{p} u_{\text {in }} c_{\text {in }} M\left(T_{\mathrm{CH}}-T_{\text {in }}\right)\right)_{\mathrm{i}}}{A_{\text {cell }} \delta_{\mathrm{CH}}}\left(\mathrm{i}=\mathrm{H}_{2}, \mathrm{O}_{2}, \mathrm{~N}_{2}, \mathrm{vp}\right)$

where $u_{\text {in }}\left(\mathrm{m} \mathrm{s}^{-1}\right)$ is the inlet gas velocity, $T_{\text {in }}(\mathrm{K})$ is the inlet gas temperature. It should be noted that the gas temperature is assumed identical as the local layer temperature.

Instead of solving ionic and electronic conservations, the output voltage is calculated based on Tafel equations for simplification. Detailed calculation equations for polarization losses can be found in the reference [7].

$$
\begin{aligned}
& V_{\text {out }}=V_{\text {Nernst }}+V_{\text {act }}+V_{\text {ohmic }}+V_{\text {conc }} \\
& V_{\text {Nernst }}=\frac{\Delta G}{2 F}+\frac{\Delta S}{2 F}\left(T-T_{\text {ref }}\right)+\frac{R T}{2 F}\left[\ln \left(\frac{c_{\mathrm{H}_{2}, \text { CLa }}}{c_{\mathrm{H}_{2}, \text { ref }}}\right)+\frac{1}{2} \ln \left(\frac{c_{\mathrm{O}_{2}, \text { CLC }}}{c_{\mathrm{O}_{2}, \text { ref }}}\right)\right]
\end{aligned}
$$

\subsection{Membrane humidifier model}

The schematic diagram of a planar membrane humidifier is illustrated in Fig.3, consisting of wet/dry channel and proton exchange membrane. Hot and wet exhausted gases from the stack flow into the wet channel while cold and dry reactant gases flow into the dry channel. Water contents on two sides of membrane are influenced by 
water vapor concentration and phase changes. However, phase changes are rarely considered in previous numerical studies [63-65,67], which is important for predicting humidification performances when the inlet vapor concentration is changed. The water transport is coupled with the heat transport, and it is found that the heat transport contributes to the water transport [63,64]. The membrane humidifier properties are given in the Appendix A, Table A.1. The governing equations include membrane water, water vapor, and temperature, which are solved using the same method as the PEMFC stack model.

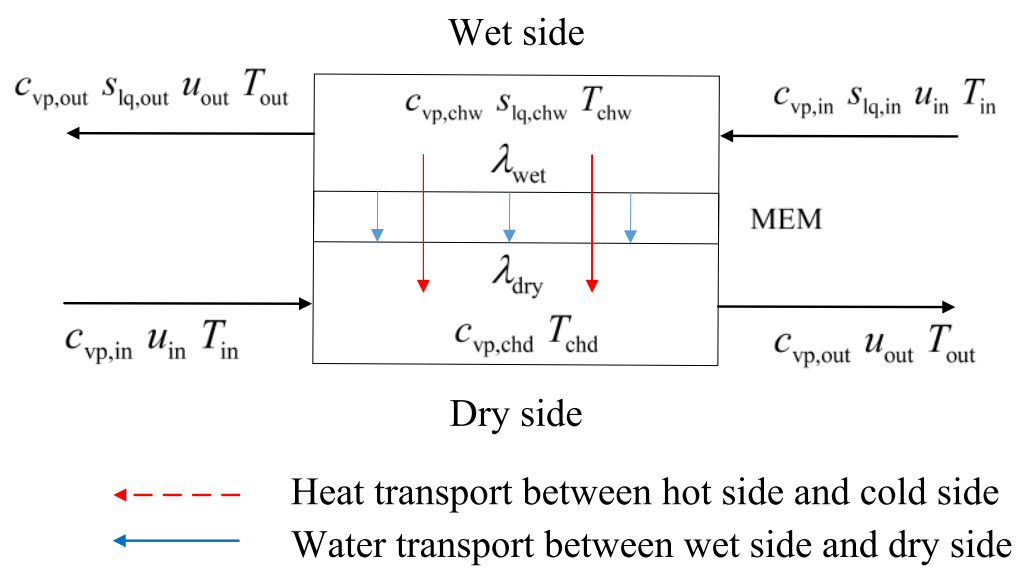

Fig. 3. Schematic diagram of a planar membrane humidifier model.

After discretization and transformation, the membrane water contents at two sides of membrane are calculated as:

$$
\begin{aligned}
& \lambda_{\mathrm{wet}}^{t}=\lambda_{\mathrm{wet}}^{t-\Delta t}+\left[-\frac{\left(\lambda_{\mathrm{wet}}^{t-\Delta t}-\lambda_{\mathrm{dry}}^{t-\Delta t}\right) D_{\mathrm{m}}^{\mathrm{eff}}}{\left(\frac{\delta_{\mathrm{MEM}}}{2}\right) \frac{\delta_{\mathrm{MEM}}}{2}}+S_{\mathrm{MH}, \mathrm{mw}} \frac{E W}{\rho_{\mathrm{MEM}}}\right] \Delta t \\
& \lambda_{\mathrm{dry}}^{t}=\lambda_{\mathrm{dry}}^{t-\Delta t}+\left[\frac{\left(\lambda_{\mathrm{wet}}^{t-\Delta t}-\lambda_{\mathrm{dry}}^{t-\Delta t}\right) D_{\mathrm{m}}^{\mathrm{eff}}}{\left(\frac{\delta_{\mathrm{MEM}}}{2}\right) \frac{\delta_{\mathrm{MEM}}}{2}}+S_{\mathrm{MH}, \mathrm{mw}} \frac{E W}{\rho_{\mathrm{MEM}}}\right] \Delta t
\end{aligned}
$$

where $\lambda_{\text {wet }}^{t-\Delta t}, \lambda_{\text {dry }}^{t-\Delta t}$ are the membrane water content at last time step, $\lambda_{\text {wet }}^{t}, \lambda_{\text {dry }}^{t}$ are membrane water content at next time step, $D_{\mathrm{m}}^{\text {eff }}\left(\mathrm{m}^{2} \mathrm{~s}^{-1}\right)$ is the effective membrane water diffusivity. $S_{\mathrm{MH}, \mathrm{mw}}\left(\mathrm{kmol} \mathrm{m}^{-3} \mathrm{~s}^{-1}\right)$ is the source term (see Appendix A, Table 
The water vapor concentrations in channels are calculated as:

$c_{\mathrm{vp}}^{t}=c_{\mathrm{vp}}^{t-\Delta t}+\left(S_{\mathrm{MH}, \mathrm{vp}}\right) \Delta t$

where $c_{\mathrm{vp}}^{t-\Delta t}\left(\mathrm{~mol} \mathrm{~m}^{-3}\right)$ is the water vapor concentration at last time step, $c_{\mathrm{vp}}^{t}\left(\mathrm{~mol} \mathrm{~m}^{-3}\right)$ is that at next time step, $S_{\mathrm{MH}, \mathrm{vp}}\left(\mathrm{mol} \mathrm{m}^{-3} \mathrm{~s}^{-1}\right)$ is the water vapor source term (see Appendix A, Table A.2).

The liquid water volume fraction in the wet channel is calculated as:

$s_{\mathrm{lq}, \mathrm{CHw}}^{t}=s_{\mathrm{lq}, \mathrm{CHw}}^{t-\Delta t}+\left(S_{\mathrm{MH}, \mathrm{lq}}\right) \frac{\Delta t}{\rho_{\mathrm{lq}}}$

where $s_{\mathrm{lq}, \mathrm{CHw}}^{t-\Delta t}$ is the liquid water volume fraction in wet channel at last time step, $s_{\mathrm{lq}, \mathrm{CHw}}^{t}$ is that of the wet channel at next time step, $S_{\mathrm{MH}, \mathrm{lq}}\left(\mathrm{kg} \mathrm{m}^{-3} \mathrm{~s}^{-1}\right)$ is the source term (see Appendix A, Table A.2). It should be noted that the liquid water in dry channel is not considered since the water vapor concentration is hard to reach saturation.

The temperatures at center of channels and membrane are calculated as:

$$
\begin{aligned}
& T_{\mathrm{CHw}}^{t}=T_{\mathrm{CHw}}^{t-\Delta t}+\left(-\frac{\left(T_{\mathrm{CHw}}^{t-\Delta t}-T_{\mathrm{MEM}}^{t-\Delta t}\right) k_{\mathrm{CHw} \_\mathrm{MEM}}^{\text {eff }}}{\left(\frac{\delta_{\mathrm{CHw}}}{2}+\frac{\delta_{\mathrm{MEM}}}{2}\right) \delta_{\mathrm{CHw}}}-\frac{h_{\text {surr }}\left(T_{\mathrm{CHw}}^{t-\Delta t}-T_{\text {surr }}\right)}{\delta_{\mathrm{CHw}}}+S_{\mathrm{T}}\right) \frac{\Delta t}{\rho c_{\mathrm{p}}} \\
& T_{\mathrm{MEM}}^{t}=T_{\mathrm{MEM}}^{t-\Delta t}+\left(\frac{\left(T_{\mathrm{CHw}}^{t-\Delta t}-T_{\mathrm{MEM}}^{t-\Delta t}\right) k_{\mathrm{CHw} \_\mathrm{MEM}}^{\text {eff }}}{\left(\frac{\delta_{\mathrm{CHw}}}{2}+\frac{\delta_{\mathrm{MEM}}}{2}\right) \delta_{\mathrm{MEM}}}-\frac{\left(T_{\mathrm{MEM}}^{t-\Delta t}-T_{\mathrm{CHd}}^{t-\Delta t}\right) k_{\mathrm{MEM} \_\mathrm{CHd}}^{\text {eff }}}{\left(\frac{\delta_{\mathrm{MEM}}}{2}+\frac{\delta_{\mathrm{CHd}}}{2}\right) \delta_{\mathrm{MEM}}}+S_{\mathrm{T}}\right) \frac{\Delta t}{\rho c_{\mathrm{p}}} \\
& \left.T_{\mathrm{CHd}}^{t}=T_{\mathrm{CHd}}^{t-\Delta t}+\left(\frac{\left(T_{\mathrm{MEM}}^{t-\Delta t}-T_{\mathrm{CHd}}^{t-\Delta t}\right) k_{\mathrm{MEM} \_\mathrm{CHd}}^{\mathrm{eff}}}{\left(\frac{\delta_{\mathrm{MEM}}}{2}+\frac{\delta_{\mathrm{CHd}}}{2}\right) \delta_{\mathrm{CHd}}}\right) \frac{h_{\text {surr }}\left(T_{\mathrm{CHd}}^{t-\Delta t}-T_{\text {surr }}\right)}{\delta_{\mathrm{CHd}}}+S_{\mathrm{T}}\right) \frac{\Delta t}{\rho c_{\mathrm{p}}}
\end{aligned}
$$


where $T_{\mathrm{CHw}}^{t-\Delta t}, T_{\mathrm{MEM}}^{t-\Delta t}, T_{\mathrm{CHd}}^{t-\Delta t}(\mathrm{~K})$ are the temperature of wet channel, membrane and dry channel at last time step, $T_{\mathrm{CHw}}^{t}, T_{\mathrm{MEM}}^{t}, T_{\mathrm{CHd}}^{t}(\mathrm{~K})$ are the temperature at next time step, $S_{\mathrm{T}}\left(\mathrm{W} \mathrm{m}^{-3}\right)$ is the heat source term (see Appendix A, Table A.2), $h_{\text {surr }}\left(\mathrm{W} \mathrm{m}^{-2}\right.$ $\mathrm{s}^{-1}$ ) is the heat transfer coefficient between membrane humidifier and surroundings.

\subsection{Electrochemical hydrogen pump model}

The structure of electrochemical hydrogen pump is similar to PEMFC, consisting of BP, CH, GDL, CL, and membrane. The low concentration hydrogen from the stack anode exhausted gases turns into protons and electrons at the three-phase boundary in anode CL. By applying extra voltage, protons are driven to cross the membrane. Subsequently, protons combine with electrons from the external circuit to generate hydrogen in cathode CL. The water vapor is also recirculated owing to phase changes between membrane water and water vapor. The corresponding structural properties are set identical as the stack, and the explicit formulation calculation method is adopted. The governing equations include membrane water, hydrogen, water vapor, and temperature. Detailed calculation methods are given in Appendix B.

The drive voltage of electrochemical hydrogen pump is calculated as:

$$
\begin{aligned}
& V_{\mathrm{HP}, \mathrm{Nernst}}=\frac{R T}{2 F} \ln \left(\frac{p_{\mathrm{HP}, \mathrm{c}}}{p_{\mathrm{HP}, \mathrm{a}}}\right) \\
& V_{\mathrm{HP}}=V_{\mathrm{HP}, \text { Nernst }}+V_{\mathrm{HP}, \mathrm{act}}+V_{\mathrm{HP}, \mathrm{ohmic}}
\end{aligned}
$$

where $\frac{p_{\mathrm{HP}, \mathrm{c}}}{p_{\mathrm{HP}, \mathrm{a}}}$ is the hydrogen pressure ratio between cathode and anode. The real drive voltage is higher than Nernst voltage since activation voltage loss and ohmic voltage loss are inevitable [57,58].

\subsection{Centrifugal air compressor model}

The centrifugal air compressor is commonly adopted in real PEMFC systems owing 
to its high specific power and efficiency. The compressor model consists of two parts: characteristics of compressor and inertance of drive motor. The Rotrex C15-16 centrifugal air compressor is adopted, and the corresponding parameters are taken from reference [62]. Note that the compressor characteristics from the manufacturer is tested at specific operating conditions which may differ from real working conditions, making it necessary to conduct calibrations for better accuracy (see Appendix C).

It is known that the air mass flow rate is determined by both rotating speed and pressure ratio. By applying polynomial fitting method, the function among mass flow rate, pressure ratio, and rotating speed is derived based on a large number of sample data. The multinomial coefficients are given in Appendix C, Table C.1.

$$
\begin{aligned}
& x=\frac{N_{\mathrm{cp}}-1.444 \times 10^{5}}{4.808 \times 10^{4}}, y=\frac{p_{\text {ratio }}-1.726}{0.4504} \\
& m_{\mathrm{air}}=\mathrm{p}_{00}+\mathrm{p}_{10} x+\mathrm{p}_{01} y+\mathrm{p}_{20} x^{2}+\mathrm{p}_{11} x y+\mathrm{p}_{02} y^{2}+\mathrm{p}_{30} x^{3}+\mathrm{p}_{24} x^{2} y+\mathrm{p}_{12} x y^{2}+\mathrm{p}_{03} y^{3} \\
& +\mathrm{p}_{40} x^{4}+\mathrm{p}_{31} x^{3} y+\mathrm{p}_{22} x^{2} y^{2}+\mathrm{p}_{13} x y^{3}+\mathrm{p}_{04} y^{4}+\mathrm{p}_{50} x^{5}+\mathrm{p}_{41} x^{4} y+\mathrm{p}_{32} x^{3} y^{2}+\mathrm{p}_{23} x^{2} y^{3}+\mathrm{p}_{14} x y^{4}+\mathrm{p}_{05} y^{5}
\end{aligned}
$$

However, the surging region and the region exceeding maximum flow rate are also included. Using the same method, the surging line and the maximum flow rate line are acquired.

$$
\begin{aligned}
& p_{\text {surging }}=1.009 \times 10^{4} m_{\text {air }}{ }^{3}+264.5 m_{\text {air }}{ }^{2}+2.469 m_{\text {air }}+1.032 \\
& p_{\text {maxrate }}=445.9 m_{\text {air }}{ }^{3}-68.58 m_{\text {air }}{ }^{2}+5.975 m_{\text {air }}+0.9028
\end{aligned}
$$

The compressor is driven by motor and the inertance of drive motor is calculated as:

$$
\begin{aligned}
& J_{\mathrm{cp}} \frac{d \omega_{\mathrm{cp}}}{d t}=\tau_{\mathrm{cm}}-\tau_{\mathrm{cp}} \\
& \tau_{\mathrm{cm}}=\eta_{\mathrm{cm}} \frac{\kappa_{\mathrm{t}}}{R_{\mathrm{cm}}}\left(v_{\mathrm{cm}}-\kappa_{\mathrm{v}} \omega_{\mathrm{cm}}\right) \\
& \tau_{\mathrm{cp}}=\frac{P_{\mathrm{cp}}}{\omega_{\mathrm{cp}}}
\end{aligned}
$$


$P_{\mathrm{cp}}=c_{\mathrm{p}} \frac{T_{\mathrm{p} p, \text { in }}}{\eta_{\mathrm{cp}}}\left[\left(\frac{p_{\mathrm{cp}, \text { out }}}{p_{\mathrm{cp}, \text { in }}}\right)^{\frac{\gamma-1}{\gamma}}-1\right] m_{\mathrm{cp}}$

where $J_{\mathrm{cp}}\left(\mathrm{kg} \mathrm{m}^{2}\right)$ is the inertia of compressor, $\omega_{\mathrm{cp}}\left(\mathrm{rad} \mathrm{s}^{-1}\right)$ is the compressor rotation angular frequency, $\tau_{\mathrm{cm}}(\mathrm{N} \mathrm{m})$ is the drive torque, $\tau_{\mathrm{cp}}(\mathrm{N} \mathrm{m})$ is load torque, $\omega_{\mathrm{cm}}\left(\mathrm{rad} \mathrm{s}^{-1}\right)$ is the rotation angular frequency of drive motor, $v_{\mathrm{cm}}(\mathrm{V})$ is the drive terminal voltage, $P_{\mathrm{cp}}(\mathrm{W})$ is the compressor power consumption.

A simple proportion-integral-derivative (PID) control strategy is adopted to satisfy the required mass flow rate under both steady-state and transient operating conditions. Detailed information about the control strategy and the corresponding calculation procedure is presented in Appendix C. One group of PID parameters is adopted by trial and error: $K_{\mathrm{p}}=1.2, K_{\mathrm{I}}=20, K_{\mathrm{D}}=20$, which shows good performances under both steady-state and transient operating conditions.

\subsection{Ribbon-tubular fin radiator model}

The schematic diagram of a ribbon-tubular fin radiator is shown in Fig. D.1, and the detailed radiator structural properties are given in Appendix D and Table D.1. The effectiveness-NTU method is adopted to calculate outlet temperature since it requires less iteration than the logarithmic mean temperature method. It should be noted that the radiator is simplified into a zero-dimensional model, which focuses on heat transfer processes. The same method has been widely adopted when it comes to the energy analysis of complicated thermal systems $[79,80]$.

The amount of heat released by coolant is equal to that absorbed by air when the radiator is under steady-state operating condition.

$Q=m_{\mathrm{lq}}\left(c_{p}\right)_{\mathrm{lq}}\left(T_{\mathrm{lq}, \mathrm{in}}-T_{\mathrm{lq}, \text { out }}\right)=m_{\mathrm{air}}\left(c_{p}\right)_{\text {air }}\left(T_{\text {ar, out }}-T_{\text {air,in }}\right)=A K \Delta t_{\mathrm{m}}$

where $m_{\mathrm{lq}}\left(\mathrm{kg} \mathrm{s}^{-1}\right)$ represents the coolant flow rate, $m_{\text {air }}\left(\mathrm{kg} \mathrm{s}^{-1}\right)$ represents the air 
flow rate, $T_{\mathrm{lq}, \mathrm{in}}(\mathrm{K}), T_{\mathrm{lq}, \mathrm{out}}(\mathrm{K})$ are the inlet and outlet temperature of coolant, $A$ $\left(\mathrm{m}^{2}\right)$ is the overall heat transfer area, $K\left(\mathrm{~W} \mathrm{~m}{ }^{-2} \mathrm{~K}^{-1}\right)$ is the overall heat transfer coefficient which is related to radiator structural properties, $\Delta t_{\mathrm{m}}(\mathrm{K})$ is the average temperature difference, which is determined by the effectiveness of radiator and the maximum temperature difference between coolant and air.

The effectiveness of radiator is defined as the real heat flow rate divided by the theoretically maximum heat flow rate.

$$
\eta=\frac{Q}{Q_{\max }}=\frac{Q}{\operatorname{MIN}\left\{\left(m_{\mathrm{lq}}\left(c_{p}\right)_{\mathrm{lq}}\right),\left(m_{\text {air }}\left(c_{p}\right)_{\text {air }}\right)\right\}\left(T_{\mathrm{lq}, \mathrm{in}}-T_{\text {air,in }}\right)}
$$

In the radiator, two types of fluids move in a cross-flow pattern and there exists no mixture process. The effectiveness is thus calculated as [81]:

$$
\begin{aligned}
& \eta=1-\exp \left\{\frac{N T U^{0.22}}{C^{*}}\left[\exp \left(-C^{*} N T U^{0.78}\right)-1\right]\right\} \\
& N T U=\frac{A K}{\operatorname{MIN}\left\{\left(m_{\mathrm{lq}}\left(c_{p}\right)_{\mathrm{lq}}\right),\left(m_{\mathrm{air}}\left(c_{p}\right)_{\text {air }}\right)\right\}} \\
& C^{*}=\frac{\operatorname{MIN}\left\{\left(m_{\mathrm{lq}}\left(c_{p}\right)_{\mathrm{lq}}\right),\left(m_{\text {air }}\left(c_{p}\right)_{\text {air }}\right)\right\}}{\operatorname{MAX}\left\{\left(m_{\mathrm{lq}}\left(c_{p}\right)_{\mathrm{lq}}\right),\left(m_{\text {air }}\left(c_{p}\right)_{\text {air }}\right)\right\}}
\end{aligned}
$$

The overall heat transfer coefficient consists of three parts, including heat convection between coolant and tube, heat conduction inside tube wall and heat convection between tube and air.

$$
\frac{1}{A K}=\frac{1}{h_{1} A_{1}}+\frac{\delta}{\lambda_{\mathrm{t}} A_{1}}+\frac{1}{h_{\mathrm{a}} A_{\mathrm{a}} \eta_{0}}
$$

where $h_{1}\left(\mathrm{~W} \mathrm{~m}^{-2} \mathrm{~K}^{-1}\right), A_{1}\left(\mathrm{~m}^{2}\right)$ are the heat transfer coefficient and effective area between coolant and tube, $\lambda_{\mathrm{t}}\left(\mathrm{W} \mathrm{m}^{-1} \mathrm{~K}^{-1}\right)$ is the heat conduction coefficient of tube wall, $h_{\mathrm{a}}\left(\mathrm{W} \mathrm{m} \mathrm{K}^{-2} \mathrm{~K}^{-1}\right), A_{\mathrm{a}}\left(\mathrm{m}^{2}\right)$ are the heat transfer coefficient and effective area between tube and air, respectively. Detailed calculation methods of the above 
coefficients are presented in Appendix D.

\subsection{Boundary and initial conditions}

In the study, the ambient temperature and pressure are $25^{\circ} \mathrm{C}, 101325 \mathrm{~Pa}$. The required air and hydrogen mass flow rate are calculated based on Faraday's law.

$m_{\text {air }}^{\text {req }}=\frac{N_{\text {stack }} I A_{\text {cell }} \xi_{\mathrm{c}} M_{\text {air }}}{4 F \times 0.21 \times 1000}, \quad m_{\mathrm{H}_{2}}^{\text {req }}=\frac{N_{\text {stack }} I A_{\text {cell }} \xi_{\mathrm{a}} M_{\mathrm{H}_{2}}}{2 F \times 1000}$

where $N_{\text {stack }}$ is the number of single fuel cells, $\xi_{\mathrm{a}}, \xi_{\mathrm{c}}$ are the anode and cathode stoichiometry, respectively.

The stack is operated under the constant current mode, indicating that each individual fuel cell is operated with the same current. In a single cell, local current density varies in the flow direction because reactant concentrations keep decreasing from upstream towards downstream. Since bipolar plate has good electrical conductivity, it is more reasonable to assume that voltage among different nodes are identical rather than assuming uniform current density distribution. The local current density is obtained by solving the system of nonlinear equations.

$$
\left\{\begin{array}{c}
V_{\text {Nernst }}+V_{\text {act }}\left(I_{1}\right)+V_{\text {ohmic }}\left(I_{1}\right)+V_{\text {conc }}\left(I_{1}\right)=V_{\text {out }} \\
V_{\text {Nernst }}+V_{\text {act }}\left(I_{2}\right)+V_{\text {ohmic }}\left(I_{2}\right)+V_{\text {conc }}\left(I_{2}\right)=V_{\text {out }} \\
\vdots \\
V_{\text {Nernst }}+V_{\text {act }}\left(I_{n}\right)+V_{\text {ohmic }}\left(I_{n}\right)+V_{\text {conc }}\left(I_{n}\right)=V_{\text {out }} \\
I_{1}+I_{2} \quad \cdots \quad I_{n-1}+I_{n}=n \cdot I
\end{array}\right.
$$

where $n$ represents the node number in the flow direction.

It should be noted that the boundary conditions of all sub-models are interrelated, including temperature, pressure, and mass flow rate. The stack cathode inlet gases are set the same as the humidifier dry channel outlet gases. The hydrogen temperature after pressure regulating valve is set identical as surrounding temperature. The stack anode inlet gas temperature is calculated as the mixing temperature between pure hydrogen from the high-pressure tank and cathode outlet gases from the 
As for membrane humidifier, the wet channel inlet gases and water saturation are set the same as that of stack cathode exhaust. The real air mass flow rate and pressure flowing into humidifier dry channel are determined by the air compressor model. The high-temperature air after compression needs to be cooled down before it enters the humidifier to avoid membrane dehydration. Thus, the air temperature after radiator is set as $30^{\circ} \mathrm{C}$. The heat loss to environment is also considered since there is no assisted equipment to maintain its operating temperature in the study.

$Q_{\mathrm{MH}, \text { loss }}=h_{\text {surr }} A_{\mathrm{MH}}\left(T_{\mathrm{MH}}-T_{\text {surr }}\right)$

As for hydrogen pump, the anode inlet gases are set identical as the stack anode exhausted gases. Convective heat loss to environment is taken into account.

$$
Q_{\mathrm{HP}, \text { loss }}=h_{\text {surr }} A_{\mathrm{HP}}\left(T_{\mathrm{HP}, \mathrm{BP}}-T_{\text {surr }}\right)
$$

For stack, membrane humidifier, and hydrogen pump, the explicit formulation calculation equations are updated with a time step of $1 \times 10^{-6} \mathrm{~s}$ to simultaneously guarantee accuracy and calculation efficiency. Increasing the time step leads to calculation divergence of gas species, and further decreasing the time step contributes negligibly.

The initial liquid water volume fraction is zero and the initial membrane water content is set as 6.0. The initial temperatures of all subsystems are set as surrounding temperature. The air filter causes 5\% atmospheric pressure drop. For air compressor model, the response interval of drive motor is set as $0.1 \mathrm{~s}$ and the time delay of PID control signal is not considered. For radiator model, the inlet air temperature and initial coolant temperature are set the same as environment. The total coolant and air 
mass flow rate are set as $1.5,2.0 \mathrm{~kg} \mathrm{~s}^{-1}$, respectively. The water tank temperature is assumed to be the same as coolant temperature because heat capacity of tank is not considered. All sub-models are developed in Matlab 2018a with user defined function files and a powerful workstation is adopted to conduct simulations.

\section{Results and discussion}

\subsection{Model validation}

To guarantee the system model accuracy, all sub-models have been rigorously validated against experimental data. However, it is impractical to validate the whole system model because such complicated and detailed PEMFC system is rarely presented in literature. As regards proton exchange membrane fuel cell (PEMFC) stack model, grid independence study is firstly conducted to show influences of the node number in the flow direction. The main simulation results such as output voltage, water volume fraction in cathode catalyst layer (CL), and cathode outlet gas velocity are compared (shown in Fig. 4(a)). It is found that three nodes are enough to guarantee the calculation accuracy (within $\pm 0.5 \%$ when compared with ten nodes). To reflect more transport details from the channel upstream to downstream, the node number is eventually set as 5 in the study. Furthermore, the stack model has been validated against experimental data under both steady-state and transient operating conditions. In Fig. 4(b), the output voltage and ohmic voltage are compared simultaneously under various cathode RH cases $(66 \%, 100 \%)$ [27], which shows good agreement. The inlet gas temperature, fuel cell temperature, and anode relative humidity (RH) are given at $80^{\circ} \mathrm{C}, 80{ }^{\circ} \mathrm{C}, 100 \%$. In Fig. 4(c), the simulation results are compared with experimental data from authors' laboratory during the startup from $-10{ }^{\circ} \mathrm{C}$ and $-5{ }^{\circ} \mathrm{C}$, which also demonstrates reasonable agreement. The effective cell area is $25 \mathrm{~cm}^{2}$, membrane thickness is $50.8 \mu \mathrm{m}$, operating current is $2.5 \mathrm{~A}$, anode and cathode operating pressure are $1.0 \mathrm{~atm}$, dry hydrogen and air are supplied at $0.5,1.5$ SLPM. The initial membrane water content is set according to high frequency resistance measurement. It should be noted that the output voltage varies from 
experimental data although the ohmic voltage matches well in the beginning, which indicates that the voltage difference comes from the activation voltage loss. It is inferred that the effective cell area may increase with the membrane becoming wetter during the cold start process. In other words, the effective area could be much smaller than the nominal cell area since the membrane is initially dry after the long-term purging, which leads to larger current density and lower output voltage in reality.

The planar membrane humidifier $(\mathrm{MH})$ model has also been compared with experimental data in literature $[63,68]$. In Fig. 4(d), the water recovery ratio under various operating temperatures and pressures are presented [63]. The inlet RH of wet channel is $100 \%$ and the corresponding flow rate is 100 SLPM. In Fig. 4(e), the water vapor transfer rate is compared under various air mass flow rates [68]. The inlet gas temperature of wet channel is given at $70{ }^{\circ} \mathrm{C}$. The inlet $\mathrm{RH}$ of wet channel and dry channel are $100 \%, 60 \%$, respectively. The validation of electrochemical hydrogen pump against experimental data [58] is shown in Fig. 4(f), where polarization curves at different $\mathrm{CO}_{2} / \mathrm{H}_{2}$ ratios are compared. The membrane surface area is $1.9 \mathrm{~cm}^{2}$. Fully humidified $\mathrm{CO}_{2} / \mathrm{H}_{2}$ gas is fed into the anode gas channel at $50{ }^{\circ} \mathrm{C}$. Fig. $4(\mathrm{~g})$ shows the steady-state performance and dynamic response of the air compressor model under the aforementioned PID control strategy, indicating that the compressor model is capable of satisfying the required air mass flow rate. In Fig. 4(h), the coolant outlet temperature with different air mass flow rates is compared with the experimental data in [78]. The coolant is supplied at 1.00,1.33, $1.67 \mathrm{~kg} \mathrm{~s}^{-1}$ with an inlet temperature of $92{ }^{\circ} \mathrm{C}$, and the inlet air temperature is given at $32{ }^{\circ} \mathrm{C}$. 


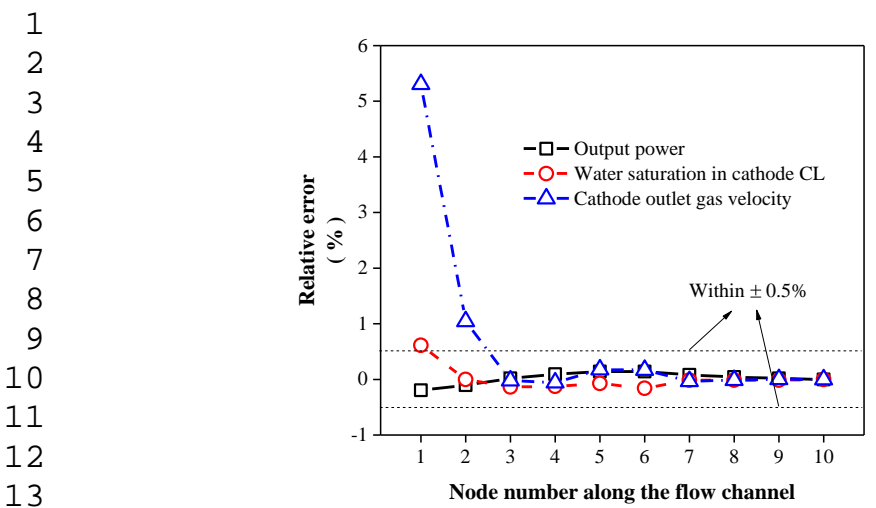

(a)

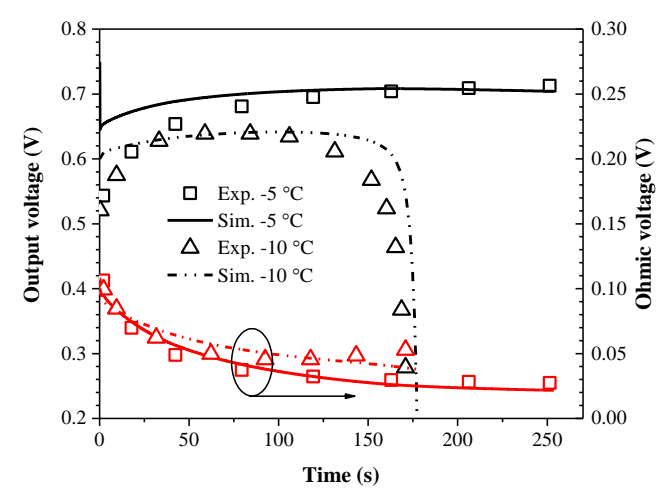

(c)

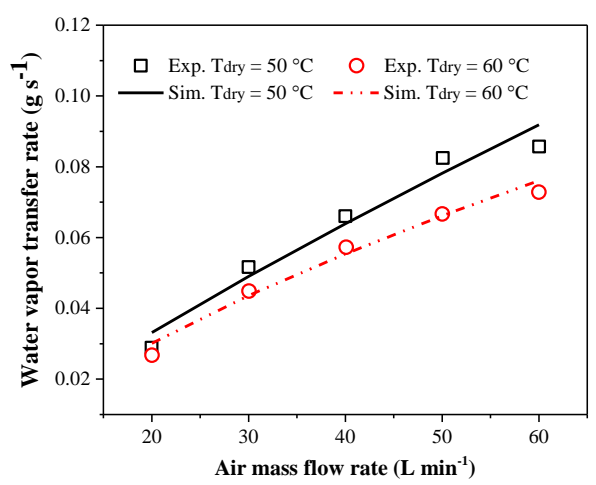

(e)

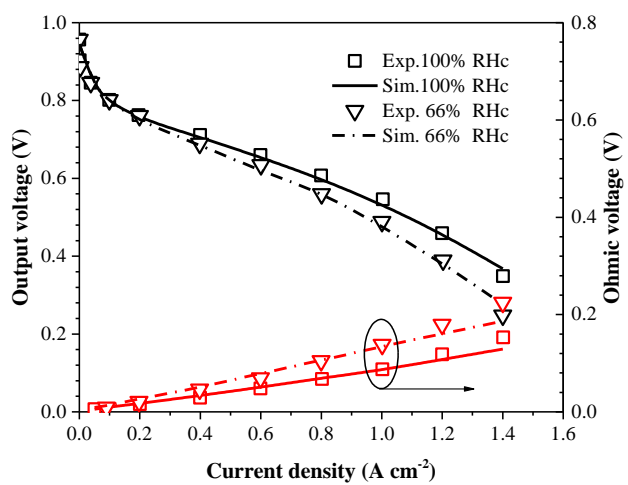

(b)

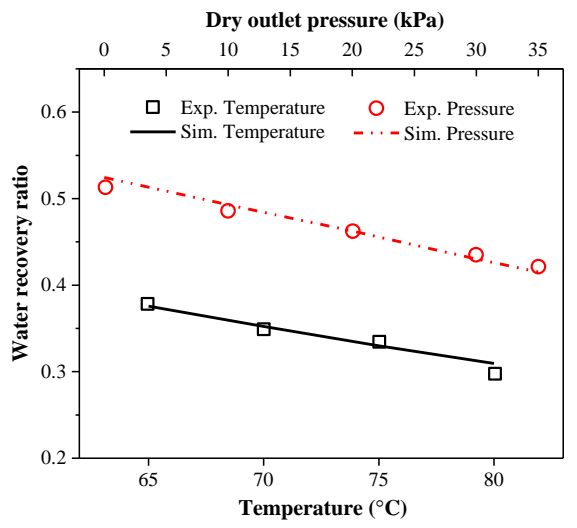

(d)

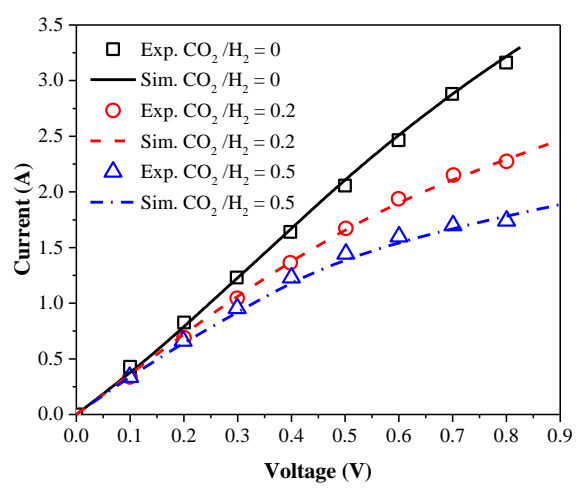

(f) 


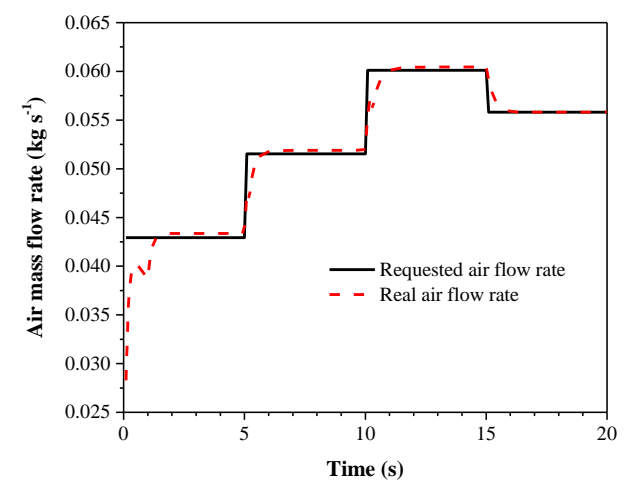

(g)

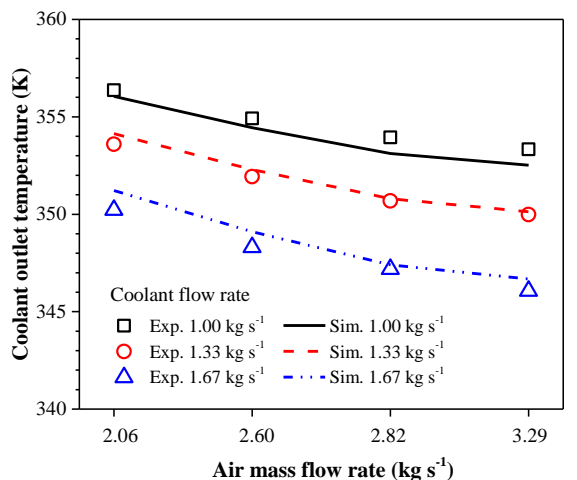

(h)

Fig. 4. Comparison between simulation results and experimental data. (a) PEMFC. Grid independence study. (b) PEMFC. Output voltage and ohmic voltage under different cathode humidification [27]. (c) PEMFC. Cold start performance under different subzero temperatures. (d) MH. Water recovery ratio with different operating conditions [63]. (e) MH. Water transfer rate with various inlet gas temperatures [68]. (f) HP. Polarization curve with different $\mathrm{CO}_{2} / \mathrm{H}_{2}$ ratios [58]. (g) Air compressor. Dynamic response and steady-state performance under the PID control strategy. (h) Radiator. Coolant outlet temperature with various air mass flow rates [78].

\subsection{Effects of stack operating temperature}

Unless otherwise noted, the current density is $1.2 \mathrm{~A} \mathrm{~cm}^{-2}$ and counter-current flow is adopted for the PEMFC stack. Since reactant gases and coolant are assumed to be uniformly distributed, there exists negligible performance differences among individual fuel cells in the simulation results. In the following results, the output performance and parameter distribution of the middle fuel cell in the stack is presented for comparison. Several typical cases are chosen to demonstrate the novelty of system model. Fig. 5 shows the cell voltage under different stack operating temperatures $\left(60^{\circ} \mathrm{C}, 70^{\circ} \mathrm{C}, 80^{\circ} \mathrm{C}\right)$. It should be noted that the required operating temperature is guaranteed by the heat management subsystem, in which a temperature trigger is set. Coolant pump works when the maximum cathode CL temperature exceeds the upper limit, and it stops when the maximum cathode CL temperature 
drops below the lower limit. To avoid large temperature fluctuation and frequent coolant pump switch, the trigger is set as $\pm 0.5{ }^{\circ} \mathrm{C}$. In Fig. 5, there is a sharp voltage drop in the first $5 \mathrm{~s}$, which is caused by the electro-osmotic drag effect. The output voltage increases gradually as the membrane electrode assembly (MEA) gets wetter owing to the electrochemically generated water. Besides, the rising cell temperature also contributes to performance improvement since the initial stack temperature is set identical as surroundings. During the temperature increment period, there exists no apparent cell voltage difference. However, the output voltage varies drastically after $40 \mathrm{~s}$. Higher voltage drop is observed when it comes to higher operating temperature, which is consistent with the previous study [82]. It can be inferred that there must be negative conditions which decreases stack performances since increasing operating temperature is beneficial to the electrochemical reactions.

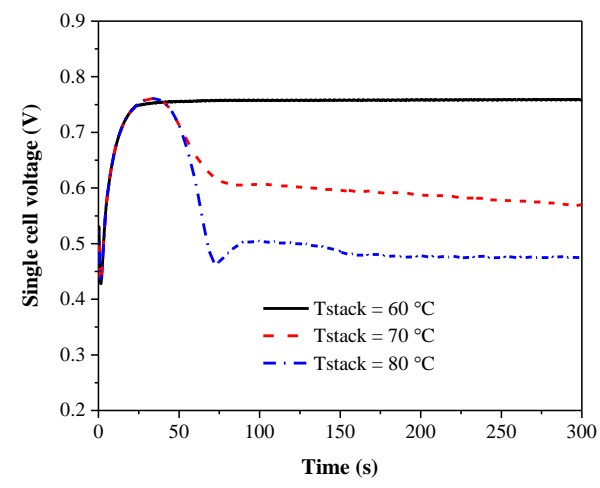

Fig. 5. Single cell output voltage under different stack operating temperatures.

Fig. 6 depicts the membrane water distribution inside fuel cell and membrane humidifier. It can be noticed that the membrane begins to dehydrate at approximately $40 \mathrm{~s}$ when the stack is operated at $70{ }^{\circ} \mathrm{C}$ and $80{ }^{\circ} \mathrm{C}$ (shown in Fig. 6(a)), indicating that the stack is likely to suffer from membrane dehydration. Poor membrane hydration reduces the ionic conductivity, resulting in more ohmic voltage loss and less output voltage. The membrane is better hydrated in the anode downstream in the case of $60{ }^{\circ} \mathrm{C}$ while it is wetter in the anode upstream in the case of $70{ }^{\circ} \mathrm{C}$, indicating that the membrane water distribution depends on operating conditions. The fuel cell cathode 


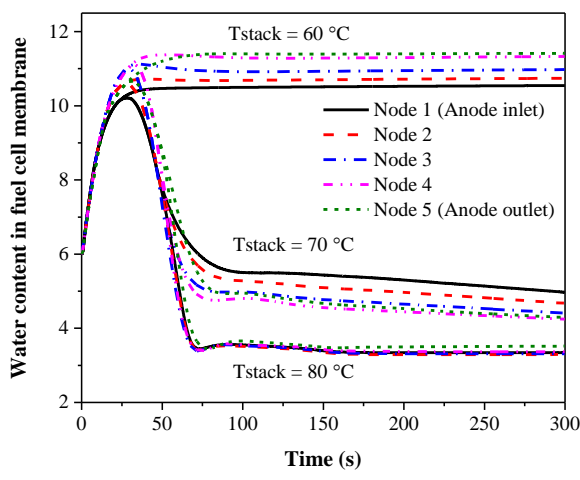

(a)

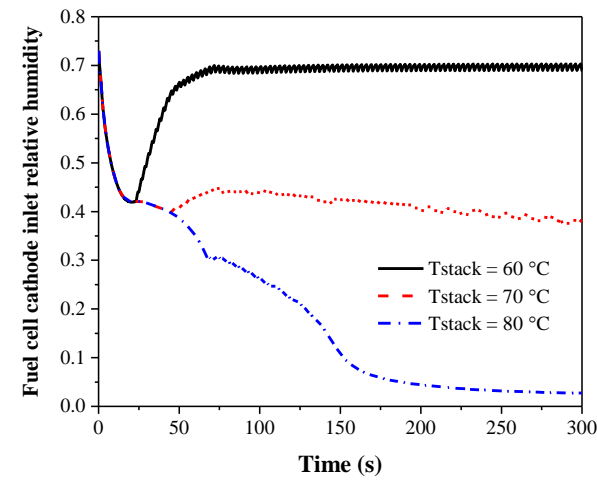

(b) 


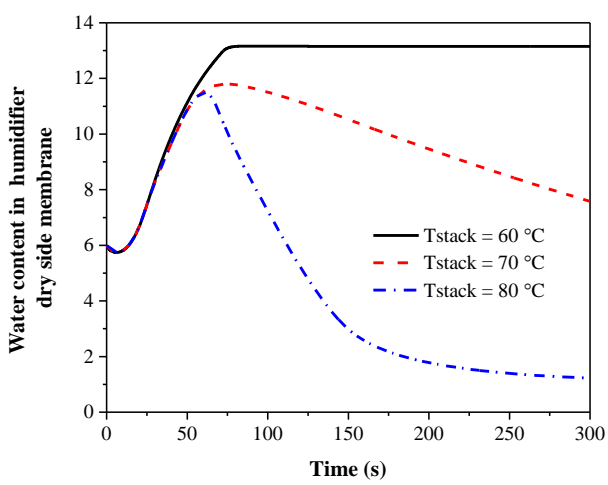

(c)

Fig. 6. Water distribution inside fuel cell and membrane humidifier under various stack operating temperatures. (a) Water content in fuel cell membrane. (b) Fuel cell cathode inlet relative humidity. (c) Water content in humidifier dry side membrane.

Fig. 7 shows the temperature distribution inside fuel cell and membrane humidifier under various stack operating temperatures. The cathode CL temperature is presented because it is usually the highest among all layers. In Fig. 7(a), it can be observed that the highest CL temperature slightly fluctuates around the required operating temperature, indicating good accuracy and reliability of the aforementioned temperature control strategy. The local CL temperature varies from the channel upstream to downstream, which is mainly caused by the uneven local current density distribution. The humidifier membrane temperature is presented in Fig. 7(b). When the stack is operated at higher temperatures, the humidifier is also stabilized at higher temperatures as a consequence of the inlet gas heating effect. The temperature increment of humidifier is much slower than the stack, indicating a longer startup period. Besides, the stabilized humidifier temperature is much lower than the stack since there exist no electrochemical reactions. It can be inferred that assisted heating method may be necessary to reduce temperature differences between the membrane humidifier and the stack. 


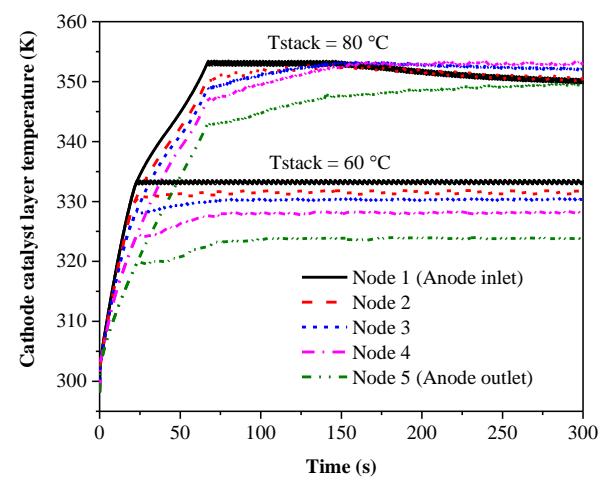

(a)

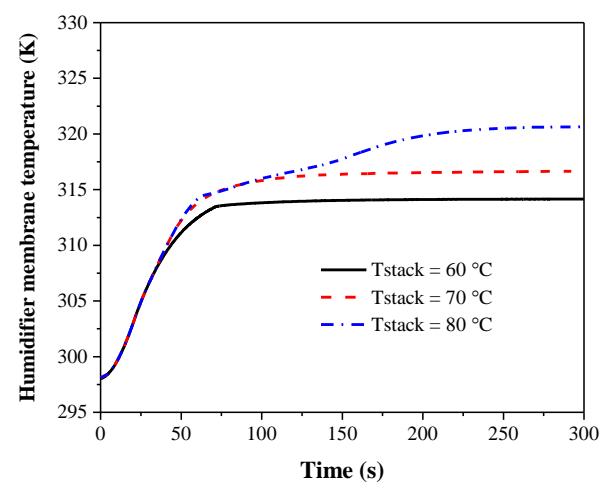

(b)

Fig. 7. Temperature distribution inside fuel cell and membrane humidifier under various stack operating temperatures. (a) Cathode catalyst layer temperature. (b) Humidifier membrane temperature.

\subsection{Effects of gas flow pattern}

Co-current flow and counter-current flow of the PEMFC stack are compared, including output performance, cathode inlet $\mathrm{RH}$, temperature, and water vapor distribution. The single fuel cell voltage is presented in Fig. 8(a). When the stack is operated at $60^{\circ} \mathrm{C}$ and $80{ }^{\circ} \mathrm{C}$, counter-current flow results in slightly better performance, however, co-current flow leads to $0.1 \mathrm{~V}$ higher output voltage at $70{ }^{\circ} \mathrm{C}$. To illustrate voltage differences, the fuel cell cathode inlet RH is demonstrated in Fig. 8(b) since it has great influences on stack performances. It can be clearly observed that co-current flow contributes to higher inlet RH under various temperatures. The increase in the inlet $\mathrm{RH}$ leads to significant voltage improvement at $70{ }^{\circ} \mathrm{C}$, however, it does not result in further performance enhancement at $60{ }^{\circ} \mathrm{C}$. It can be inferred that the stack becomes less dependent on reactant gases humidification as the operating temperature decreases. Further increasing the inlet RH contributes negligibly once it has met the requirement of keeping the membrane hydrated. Similar results about humidification level have also been observed in the previous study [82]. Meanwhile, slightly increment of gas humidification results in negligible improvement since it is woefully inadequate at $80{ }^{\circ} \mathrm{C}$. The reason why counter-current flow still behaves better with lower inlet RH is because counter-current flow may improve the heat and mass 


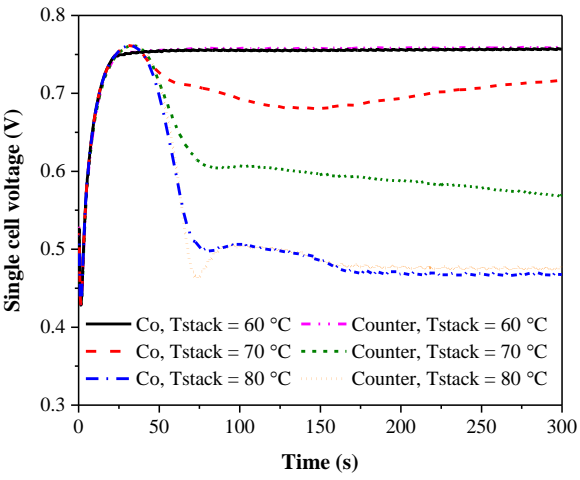

(a)

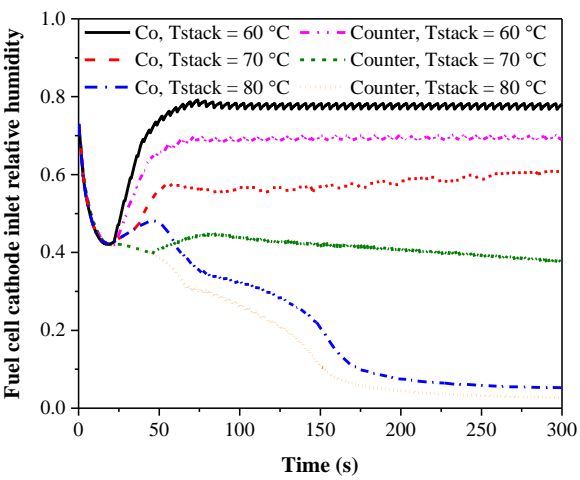

(b)

Fig. 8. Effects of gas flow pattern on system performances. (a) Output voltage. (b)

Fuel cell cathode inlet relative humidity.

Fig. 9 shows the cathode water vapor concentration and temperature distribution at $80{ }^{\circ} \mathrm{C}$, and the contour maps are plotted at $300 \mathrm{~s}$. It should be noticed that component layer thicknesses in the figure are not to scale as reality. As shown in Fig. 9(a), the largest temperature difference reaches appropriately $20^{\circ} \mathrm{C}$ in the co-current flow mode while it is about $10{ }^{\circ} \mathrm{C}$ in the counter-current mode. As stated previously, the inlet reactant temperatures are decided by the corresponding auxiliary sub-models. The temperature of membrane humidifier is much lower than the stack as shown in Fig. 7(b), indicating that the humidified air has cooling effects on the stack temperature. Therefore, the cell temperature at the inlet region of gas channel in the co-current flow mode is obviously lower. Counter-current flow is more beneficial since it significantly contributes to temperature uniformity from the channel upstream to downstream, which is of great importance for fuel cell durability. The cathode water vapor distribution in porous layers and flow channel is presented in Fig. 9(b). Not only does it illustrate the effects of gas flow pattern on the water vapor transport inside fuel cell, it also reveals the effects on water utilization in the whole system. In 
co-current flow mode, the water vapor accumulation phenomenon is obvious since hydrogen and air move in the same direction, which results in higher outlet water vapor concentration. The water vapor concentration in the counter-current flow is smaller than that in the co-current flow mode, however, it is more evenly distributed, which reflects better membrane hydration uniformity. In the system, the water transport and utilization are fully coupled. Lower cathode outlet vapor concentration results in lower inlet $\mathrm{RH}$ of the humidifier wet channel, thus decreasing the humidifier dry channel outlet water vapor concentration. Consequently, the cathode inlet RH of the stack is reduced, which results in more severe membrane dehydration. In general, counter-current flow has positive effects on the distribution uniformity inside fuel cell while co-current flow contributes to better water utilization at a system level. Note that only a few cases are presented in the study. Once the insufficient reactant gases humidification problem is solved, counter-current flow of the PEMFC stack may generate better output voltage than co-current flow mode.

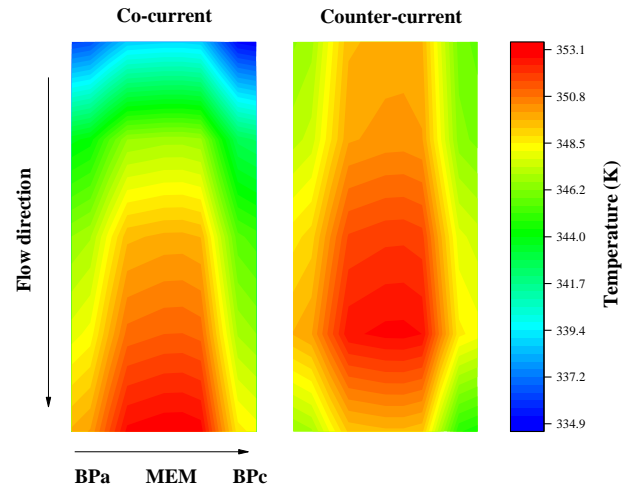

(a)

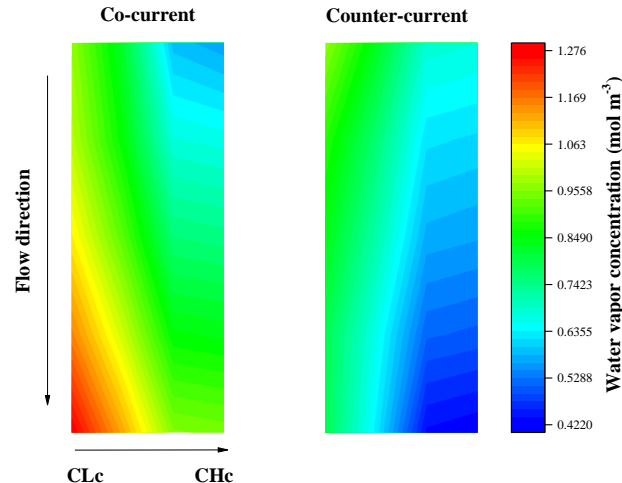

(b)

Fig. 9. Effects of gas flow pattern on temperature and water vapor distribution, $T_{\text {stack }}=$ $80{ }^{\circ} \mathrm{C}, t=300 \mathrm{~s}$. (a) Temperature. (b) Cathode water vapor concentration.

\subsection{Effects of membrane humidifier design}

The effects of membrane humidifier design are investigated since the stack is likely to suffer from membrane dehydration at high operating temperatures. Improving the humidifier performance may help alleviate the fuel cell dehydration phenomenon. Fig. 
10(a) shows the single cell voltage under various membrane humidifier areas. It is observed that doubling or halving humidifier area has negligible influences on stack performances at $60{ }^{\circ} \mathrm{C}$ while it results in significant performance variations at $70{ }^{\circ} \mathrm{C}$ When the stack operating temperature is further increased to $80^{\circ} \mathrm{C}$, the influences of humidifier area become less conspicuous. The water vapor transfer rate is demonstrated in Fig. 10(b) with the operating temperature equal to $60{ }^{\circ} \mathrm{C}$. In a system model, the water transfer in membrane humidifier is coupled with cathode outlet vapor concentration of the stack. It is necessary to keep the inlet gases unchanged to investigate the humidifier design on its humidification performance and that is the reason why $60{ }^{\circ} \mathrm{C}$ is selected. Extended gas resident time in flow channels is the reason that larger humidifier area enhances the water vapor transfer rate after long-term operation, which is consistent with the previous study [68]. However, the transfer rate rises more rapidly with smaller humidifier area as indicated by larger curve slopes in Fig. 10(b). To reflect the water absorption and desorption process inside humidifier, phase changes between vapor and membrane water are considered by assuming reasonable phase change rates. It is the reason why longer time is taken to reach the same water vapor transfer rate with a larger humidifier area. It is found that optimizing membrane humidifier area does not fundamentally solve the membrane dehydration problem under high operating temperatures, indicating that further investigation should be conducted for better understanding.

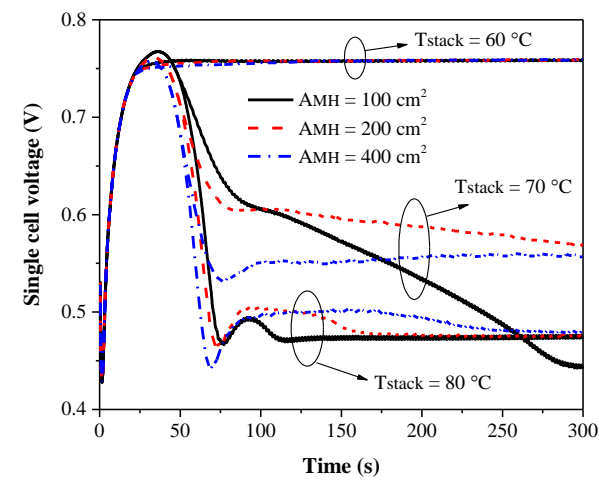

(a)

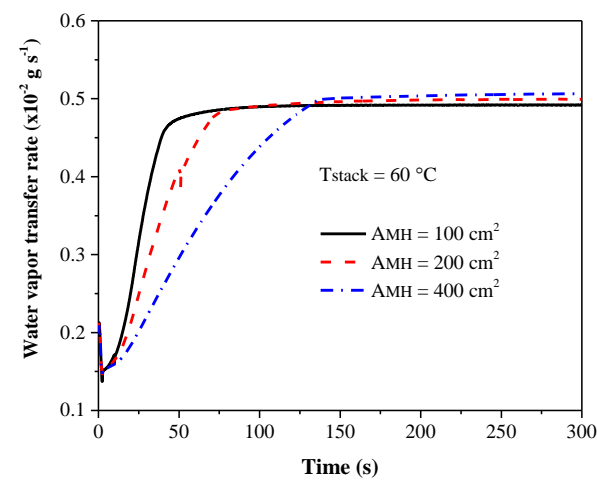

(b)

Fig. 10. Effects of membrane humidifier design on system performance. (a) Single cell voltage under various humidifier area. (b) Water vapor transfer rate, $T_{\text {stack }}=60^{\circ} \mathrm{C}$. 


\section{Conclusion}

A comprehensive proton exchange membrane fuel cell (PEMFC) system model, consisting of stack, membrane humidifier, electrochemical hydrogen pump, air compressor and radiator, is developed under both steady-state and transient operating conditions. Nitrogen crossover, water saturation in flow channels, and phase changes among water/ice/vapor are integrated in the stack model. The governing equations about auxiliary subsystems are also explained in detail. All sub-models have been rigorously validated against experimental data to guarantee the system model accuracy. The effects of stack operating temperature, gas flow pattern, and humidifier structural design are investigated at a system level to study the interaction among the stack and auxiliary subsystems. The results indicate that the stack is successfully maintained at required operating temperatures $\left(60{ }^{\circ} \mathrm{C}, 70^{\circ} \mathrm{C}, 80^{\circ} \mathrm{C}\right)$ with help of the radiator when the whole system starts from ambient temperature $\left(25^{\circ} \mathrm{C}\right)$. However, over $20{ }^{\circ} \mathrm{C}$ temperature difference is observed between the membrane humidifier and the stack, indicating that assisted heating methods may be necessary for humidifier during long-term operation. The PEMFC stack is likely to suffer from membrane dehydration when the operating temperature is $70{ }^{\circ} \mathrm{C}$, and the problem becomes more severe at $80{ }^{\circ} \mathrm{C}$. The water content in stack is strongly affected by the inlet gases humidification. Meanwhile, the membrane humidifier relies on stack cathode exhaust gases to humidify dry inlet gases, leading to the coupled water management issue at a system level. In comparison, the counter-current flow pattern has positive effects on reducing temperature gradient inside the fuel cell while the co-current flow pattern contributes to better water utilization of the whole system, which may lead to higher output performances. As regards the membrane dehydration under high operating temperatures, it is found that optimizing membrane humidifier area does not fundamentally solve the problem. Increasing humidifier area contributes to higher water vapor transfer rate, however, it results in much slower humidification responses.

\section{Acknowledgements}


This work is supported by the National Key Research and Development Program of China (2018YFB0105500), the National Natural Science Foundation of China (grant No. 51976138), and the China-UK International Cooperation and Exchange Project (Newton Advanced Fellowship) jointly supported by the National Natural Science Foundation of China (grant No. 51861130359) and the UK Royal Society (grant No. NAF\R1\180146).

\section{References}

[1] Ellis M W, Von Spakovsky M R, Nelson D J. Fuel cell systems: efficient, flexible energy conversion for the 21st century. Proc IEEE, 2001, 89(12): 1808-1818. doi:10.1109/5.975914.

[2] Wu H W. A review of recent development: Transport and performance modeling of PEM fuel cells. Appl Energy, 2016, 165: 81-106. https://doi.org/10.1016/j.apenergy.2015.12.075

[3] Ji M, Wei Z. A review of water management in polymer electrolyte membrane fuel cells. Energies, 2009, 2(4): 1057-1106. https://doi.org/10.3390/en20401057

[4] Jiao K, Li X. Water transport in polymer electrolyte membrane fuel cells. Prog Energy Combust Sci, 2011, 37(3): 221-291. https://doi.org/10.1016/j.pecs.2010.06.002

[5] Spiegel C. PEM fuel cell modeling and simulation using MATLAB. Elsevier, 2011.

[6] Dicks A, Rand D A J. Fuel cell systems explained. Wiley, 2018.

[7] Yang Z, Du Q, Jia Z, et al. Effects of operating conditions on water and heat management by a transient multi-dimensional PEMFC system model. Energy, 2019. https://doi.org/10.1016/j.energy.2019.06.148

[8] Kim M, Sohn Y J, Cho C W, et al. Customized design for the ejector to recirculate a humidified hydrogen fuel in a submarine PEMFC. J Power Sources, 2008, 176(2): 529-533. https://doi.org/10.1016/j.jpowsour.2007.08.069

[9] Yin Y, Fan M, Jiao K, et al. Numerical investigation of an ejector for anode recirculation in proton exchange membrane fuel cell system. Energy Convers 
Manag, 2016, 126: 1106-1117. https://doi.org/10.1016/j.enconman.2016.09.024

[10]Barbir F, Görgün H. Electrochemical hydrogen pump for recirculation of hydrogen in a fuel cell stack. J appl electrochem, 2007, 37(3): 359-365. doi:10.1007/s10800-006-9266-0.

[11] Onda K, Araki T, Ichihara K, et al. Treatment of low concentration hydrogen by electrochemical pump or proton exchange membrane fuel cell. J Power Sources, 2009, 188(1): 1-7. https://doi.org/10.1016/j.jpowsour.2008.11.135

[12]Cheng X, Shi Z, Glass N, et al. A review of PEM hydrogen fuel cell contamination: Impacts, mechanisms, and mitigation. J Power Sources, 2007, 165(2): 739-756. https://doi.org/10.1016/j.jpowsour.2006.12.012

[13]Nagahara Y, Sugawara S, Shinohara K. The impact of air contaminants on PEMFC performance and durability. J Power Sources, 2008, 182(2): 422-428. https://doi.org/10.1016/j.jpowsour.2007.12.091

[14]Zamel N, Li X. Effect of contaminants on polymer electrolyte membrane fuel cells. Prog Energy Combust Sci, 2011, 37(3): 292-329. https://doi.org/10.1016/j.pecs.2010.06.003

[15]Zhang J, Tang Y, Song C, et al. PEM fuel cell relative humidity (RH) and its effect on performance at high temperatures. Electrochim Acta, 2008, 53(16): 5315-5321. https://doi.org/10.1016/j.electacta.2008.02.074

[16]Jian Q, Ma G, Qiu X. Influences of gas relative humidity on the temperature of membrane in PEMFC with interdigitated flow field. Renew Energy, 2014, 62: 129-136. https://doi.org/10.1016/j.renene.2013.06.046

[17] Yan Q, Toghiani H, Causey H. Steady state and dynamic performance of proton exchange membrane fuel cells (PEMFCs) under various operating conditions and load changes. J Power Sources, 2006, 161(1): 492-502. https://doi.org/10.1016/j.jpowsour.2006.03.077

[18]Chang Y, Qin Y, Yin Y, et al. Humidification strategy for polymer electrolyte membrane fuel cells-A review. Appl energy, 2018, 230: 643-662. https://doi.org/10.1016/j.apenergy.2018.08.125

[19]Li Y, Pei P, Wu Z, et al. Approaches to avoid flooding in association with pressure 
drop in proton exchange membrane fuel cells. Appl Energy, 2018, 224: 42-51. https://doi.org/10.1016/j.apenergy.2018.04.071

[20] Wu J, Yuan X Z, Martin J J, et al. A review of PEM fuel cell durability: Degradation mechanisms and mitigation strategies. J Power Sources, 2008, 184(1): 104-119. https://doi.org/10.1016/j.jpowsour.2008.06.006

[21]Pei P, Chen H. Main factors affecting the lifetime of Proton Exchange Membrane fuel cells in vehicle applications: A review. Appl Energy, 2014, 125: 60-75.

\section{https://doi.org/10.1016/j.apenergy.2014.03.048}

[22] Islam M R, Shabani B, Rosengarten G, et al. The potential of using nanofluids in PEM fuel cell cooling systems: A review. Renew Sustain Energy Rev, 2015, 48: 523-539. https://doi.org/10.1016/j.rser.2015.04.018

[23]Ehsani M, Gao Y, Longo S, et al. Modern electric, hybrid electric, and fuel cell vehicles. CRC press, 2018.

[24] Kim S, Hong I. Effects of humidity and temperature on a proton exchange membrane fuel cell (PEMFC) stack. J Ind Eng Chem, 2008, 14(3): 357-364. https://doi.org/10.1016/j.jiec.2008.01.007

[25] Iranzo A, Boillat P, Biesdorf J, et al. Investigation of the liquid water distributions in a $50 \mathrm{~cm}^{2}$ PEM fuel cell: Effects of reactants relative humidity, current density, and cathode stoichiometry. Energy, 2015, 82: 914-921. https://doi.org/10.1016/j.energy.2015.01.101

[26]Devrim Y, Albostan A. Enhancement of PEM fuel cell performance at higher temperatures and lower humidities by high performance membrane electrode assembly based on Nafion/zeolite membrane. Int J Hydrogen Energy, 2015, 40(44): 15328-15335. https://doi.org/10.1016/j.ijhydene.2015.02.078

[27]Ozen D N, Timurkutluk B, Altinisik K. Effects of operation temperature and reactant gas humidity levels on performance of PEM fuel cells. Renew Sustain Energy Rev, 2016, 59: 1298-1306. https://doi.org/10.1016/j.rser.2016.01.040

[28] Wang Y J, Long W, Wang L, et al. Unlocking the door to highly active ORR catalysts for PEMFC applications: polyhedron-engineered Pt-based nanocrystals. Energy Environ Sci, 2018, 11(2): 258-275. DOI: 10.1039/C7EE02444D 
[29]Ratso S, Sahraie N R, Sougrati M T, et al. Synthesis of highly-active Fe-N-C catalysts for PEMFC with carbide-derived carbons. J Mater Chem A, 2018, 6(30): 14663-14674. DOI: 10.1039/C8TA02325E

[30]Liu M, Zhao Z, Duan X, et al. Nanoscale Structure Design for High Performance Pt - Based ORR Catalysts. Adv Mater, 2019, 31(6): 1802234. https://doi.org/10.1002/adma.201802234

[31]Zhao J, Shahgaldi S, Alaefour I, et al. Pore structure and effective diffusion coefficient of catalyzed electrodes in polymer electrolyte membrane fuel cells. Int J Hydrogen Energy, 2018, 43(7): 3776-3785. https://doi.org/10.1016/j.ijhydene.2018.01.019

[32]Zhao J, Shahgaldi S, Ozden A, et al. Geometric pore surface area and fractal dimension of catalyzed electrodes in polymer electrolyte membrane fuel cells. Int J Energy Research, 2019, 43(7): 3011-3019. https://doi.org/10.1002/er.4260

[33] Ashrafi M, Kanani H, Shams M. Numerical and experimental study of two-phase flow uniformity in channels of parallel PEM fuel cells with modified Z-type flow-fields. Energy, 2018, 147: 317-328. https://doi.org/10.1016/j.energy.2018.01.064

[34]Pekula N, Heller K, Chuang P A, et al. Study of water distribution and transport in a polymer electrolyte fuel cell using neutron imaging. Nucl. Instruments Methods Phys. Res. Sect. A Accel. Spectrometers, Detect. Assoc. Equip., 2005, 542(1-3): 134-141. https://doi.org/10.1016/j.nima.2005.01.090

[35] Tsushima S, Hirai S. In situ diagnostics for water transport in proton exchange membrane fuel cells. Prog Energy Combust Sci, 2011, 37(2): 204-220. https://doi.org/10.1016/j.pecs.2010.06.001

[36]Xie X, Zhang G, Zhou J, et al. Experimental and theoretical analysis of ionomer/carbon ratio effect on PEM fuel cell cold start operation. Int J Hydrogen Energy, 2017, 42(17): 12521-12530. https://doi.org/10.1016/j.ijhydene.2017.02.183

[37] Ishikawa Y, Shiozawa M, Kondo M, et al. Theoretical analysis of supercooled states of water generated below the freezing point in a PEFC. Int J Heat Mass 
Trans, 2014, 74: 215-227.

https://doi.org/10.1016/j.ijheatmasstransfer.2014.03.038

[38]Plazanet M, Sacchetti F, Petrillo C, et al. Water in a polymeric electrolyte membrane: Sorption/desorption and freezing phenomena. J Mem Sci, 2014, 453: 419-424. https://doi.org/10.1016/j.memsci.2013.11.026

[39]Jiao K, Li X. Effects of various operating and initial conditions on cold start performance of polymer electrolyte membrane fuel cells. Int J Hydrogen Energy, 2009, 34(19): 8171-8184. https://doi.org/10.1016/j.ijhydene.2009.07.102

[40]Jeon D H, Kim K N, Baek S M, et al. The effect of relative humidity of the cathode on the performance and the uniformity of PEM fuel cells. Int J Hydrogen Energy, 2011, 36(19): 12499-12511. https://doi.org/10.1016/j.ijhydene.2011.06.136

[41] Yang Z, Du Q, Huo S, et al. Effect of membrane electrode assembly design on the cold start process of proton exchange membrane fuel cells. Int J Hydrogen Energy, 2017, 42(40): 25372-25387. https://doi.org/10.1016/j.ijhydene.2017.08.106

[42]Fan L, Zhang G, Jiao K. Characteristics of PEMFC operating at high current density with low external humidification. Energy Convers Manag, 2017, 150: 763-774. https://doi.org/10.1016/j.enconman.2017.08.034

[43]Zhang G, Fan L, Sun J, et al. A 3D model of PEMFC considering detailed multiphase flow and anisotropic transport properties. Int J Heat Mass Trans, 2017, 115: 714-724. https://doi.org/10.1016/j.ijheatmasstransfer.2017.07.102

[44]Zhang G, Xie X, Xie B, et al. Large-scale multi-phase simulation of proton exchange membrane fuel cell. Int J Heat Mass Trans, 2019, 130: 555-563. https://doi.org/10.1016/j.ijheatmasstransfer.2018.10.122

[45] Tolj I, Bezmalinovic D, Barbir F. Maintaining desired level of relative humidity throughout a fuel cell with spatially variable heat removal rates. Int J Hydrogen Energy, 2011, 36(20): 13105-13113.

\section{https://doi.org/10.1016/j.ijhydene.2011.07.078}

[46]Jiang Y, Yang Z, Jiao K, et al. Sensitivity analysis of uncertain parameters based on an improved proton exchange membrane fuel cell analytical model. Energy 
Convers Manag, 2018, 164: 639-654.

https://doi.org/10.1016/j.enconman.2018.03.002

[47]Pei P, Wu Z, Li Y, et al. Improved methods to measure hydrogen crossover current in proton exchange membrane fuel cell. Appl Energy, 2018, 215: 338-347. https://doi.org/10.1016/j.apenergy.2018.02.002

[48]He J, Ahn J, Choe S Y. Analysis and control of a fuel delivery system considering a two-phase anode model of the polymer electrolyte membrane fuel cell stack. $\mathbf{J}$ Power Sources, 2011, 196(10): 4655-4670. https://doi.org/10.1016/j.jpowsour.2011.01.019

[49]Promislow K, St-Pierre J, Wetton B. A simple, analytic model of polymer electrolyte membrane fuel cell anode recirculation at operating power including nitrogen crossover. J Power Sources, 2011, 196(23): 10050-10056. https://doi.org/10.1016/j.jpowsour.2011.08.070

[50]Rabbani A, Rokni M. Effect of nitrogen crossover on purging strategy in PEM fuel cell systems. Appl energy, 2013, 111: 1061-1070. https://doi.org/10.1016/j.apenergy.2013.06.057

[51]Chen Y S, Yang C W, Lee J Y. Implementation and evaluation for anode purging of a fuel cell based on nitrogen concentration. Appl Energy, 2014, 113: 1519-1524. https://doi.org/10.1016/j.apenergy.2013.09.028

[52]Hwang J J. Effect of hydrogen delivery schemes on fuel cell efficiency. J Power Sources, 2013, 239: 54-63. https://doi.org/10.1016/j.jpowsour.2013.03.090

[53]Rabbani A, Rokni M. Effect of nitrogen crossover on purging strategy in PEM fuel cell systems. Appl energy, 2013, 111: 1061-1070. https://doi.org/10.1016/j.apenergy.2013.06.057

[54]Chen Y S, Yang C W, Lee J Y. Implementation and evaluation for anode purging of a fuel cell based on nitrogen concentration. Appl Energy, 2014, 113: 1519-1524. https://doi.org/10.1016/j.apenergy.2013.09.028

[55]Ryan O. Fuel Cell Fundamentals. Publishing house of electronics industry, 2007.

[56]Dadvar M, Afshari E. Analysis of design parameters in anodic recirculation system based on ejector technology for PEM fuel cells: A new approach in 
designing. Int J Hydrogen Energy, 2014, 39(23): 12061-12073.

https://doi.org/10.1016/j.ijhydene.2014.06.046

[57] Onda K, Araki T, Ichihara K, et al. Treatment of low concentration hydrogen by electrochemical pump or proton exchange membrane fuel cell. J Power Sources, 2009, 188(1): 1-7. https://doi.org/10.1016/j.jpowsour.2008.11.135

[58] Abdulla A, Laney K, Padilla M, et al. Efficiency of hydrogen recovery from reformate with a polymer electrolyte hydrogen pump. AIChE J, 2011, 57(7): 1767-1779. https://doi.org/10.1002/aic.12406

[59]Becherif M, Hissel D. MPPT of a PEMFC based on air supply control of the motocompressor group. Int J Hydrogen Energy, 2010, 35(22): 12521-12530. https://doi.org/10.1016/j.ijhydene.2010.06.094

[60] Matraji I, Laghrouche S, Jemei S, et al. Robust control of the PEM fuel cell air-feed system via sub-optimal second order sliding mode. Appl Energy, 2013, 104: 945-957. https://doi.org/10.1016/j.apenergy.2012.12.012

[61] Wang Y X, Xuan D J, Kim Y B. Design and experimental implementation of time delay control for air supply in a polymer electrolyte membrane fuel cell system. Int J Hydrogen Energy, 2013, 38(30): 13381-13392. https://doi.org/10.1016/j.ijhydene.2013.06.040

[62] Liu Z, Li L, Ding Y, et al. Modeling and control of an air supply system for a heavy duty PEMFC engine. Int J Hydrogen Energy, 2016, 41(36): 16230-16239. https://doi.org/10.1016/j.ijhydene.2016.04.213

[63] Kadylak D, Mérida W. Experimental verification of a membrane humidifier model based on the effectiveness method. J Power Sources, 2010, 195(10): 3166-3175. https://doi.org/10.1016/j.jpowsour.2009.12.005

[64] Yu S, Im S, Kim S, et al. A parametric study of the performance of a planar membrane humidifier with a heat and mass exchanger model for design optimization. Int J Heat Mass Trans, 2011, 54(7-8): 1344-1351. https://doi.org/10.1016/j.ijheatmasstransfer.2010.11.054

[65]Bhatia D, Sabharwal M, Duelk C. Analytical model of a membrane humidifier for polymer electrolyte membrane fuel cell systems. Int J Heat Mass Trans, 2013, 
58(1-2): 702-717. https://doi.org/10.1016/j.ijheatmasstransfer.2012.11.033

[66]Park S, Jung D. Effect of operating parameters on dynamic response of water-to-gas membrane humidifier for proton exchange membrane fuel cell vehicle. Int J Hydrogen Energy, 2013, 38(17): 7114-7125.

https://doi.org/10.1016/j.ijhydene.2013.03.170

[67]Afshari E, Houreh N B. Performance analysis of a membrane humidifier containing porous metal foam as flow distributor in a PEM fuel cell system. Energy Convers Manag, 2014, 88: 612-621. https://doi.org/10.1016/j.enconman.2014.08.067

[68]Chen C Y, Yan W M, Lai C N, et al. Heat and mass transfer of a planar membrane humidifier for proton exchange membrane fuel cell. Int J Heat Mass Trans, 2017, 109: 601-608. https://doi.org/10.1016/j.ijheatmasstransfer.2017.02.045

[69] Kandlikar S G, Lu Z. Thermal management issues in a PEMFC stack-A brief review of current status. Appl Therm Eng, 2009, 29(7): 1276-1280. https://doi.org/10.1016/j.applthermaleng.2008.05.009

[70]Zhang G, Kandlikar S G. A critical review of cooling techniques in proton exchange membrane fuel cell stacks. Int J Hydrogen Energy, 2012, 37(3): 2412-2429. https://doi.org/10.1016/j.ijhydene.2011.11.010

[71] Gwak G, Ju H. A rapid start-up strategy for polymer electrolyte fuel cells at subzero temperatures based on control of the operating current density. Int J Hydrogen Energy, 2015, 40(35): 11989-11997. https://doi.org/10.1016/j.ijhydene.2015.05.179

[72] Guo Q, Luo Y, Jiao K. Modeling of assisted cold start processes with anode catalytic hydrogen-oxygen reaction in proton exchange membrane fuel cell. Int J Hydrogen Energy, 2013, 38(2): 1004-1015. https://doi.org/10.1016/j.ijhydene.2012.10.067

[73]Luo Y, Jiao K. Cold start of proton exchange membrane fuel cell. Prog Energy Combust Sci, 2017. https://doi.org/10.1016/j.pecs.2017.10.003

[74] Yang S, Chellali R, Lu X, et al. Modeling and optimization for proton exchange membrane fuel cell stack using aging and challenging $\mathrm{P}$ systems based 
Table A.1. Planar membrane humidifier properties.

\begin{tabular}{ll}
\hline Parameter & Value \\
\hline Number of membranes & 300 \\
Membrane area & $200 \mathrm{~cm}^{2}$ \\
Channel length; width; depth; rib width & $200 ; 1.0 ; 1.0 ; 1.0 \mathrm{~mm}$ \\
Membrane thickness & $0.050 \mathrm{~mm}$ \\
Heat transfer coefficient $\quad$ between & $h_{\text {surr }}=20 \mathrm{~W} \mathrm{~m}^{-2} \mathrm{~K}^{-1}$ \\
humidifier and surrounding & \\
\hline
\end{tabular}

Table A.2. Source terms.

\begin{tabular}{|c|c|}
\hline Source terms & Unit \\
\hline$S_{\mathrm{MH}, \mathrm{mw}}= \begin{cases}-S_{\mathrm{m}-\mathrm{v}} & \text { (in wet side }) \\
-S_{\mathrm{m}-\mathrm{v}} & \text { (in dry side) }\end{cases}$ & $\mathrm{kmol} \mathrm{m}^{-3} \mathrm{~s}^{-1}$ \\
\hline$S_{\mathrm{MH}, \mathrm{vp}}= \begin{cases}1000 S_{\mathrm{m}-\mathrm{v}}-S_{\mathrm{v}-1}+S_{\mathrm{vp}, \text { flow }} & \text { (in wet channel) } \\
1000 S_{\mathrm{m}-\mathrm{v}}+S_{\mathrm{vp}, \text { flow }} & \text { (in dry channel) }\end{cases}$ & $\mathrm{mol} \mathrm{m}{ }^{-3} \mathrm{~s}^{-1}$ \\
\hline$S_{\mathrm{vp}, \mathrm{flow}}=\frac{\left(c_{\mathrm{vp}, \mathrm{in}} u_{\mathrm{in}}-c_{\mathrm{vp}, \mathrm{out}} u_{\mathrm{out}}\right) A_{\mathrm{MH}, \mathrm{in}}}{r_{\mathrm{MH}, \mathrm{CH}} A_{\mathrm{MH}} \delta_{\mathrm{CH}}}$ & $\mathrm{mol} \mathrm{m}{ }^{-3} \mathrm{~s}^{-1}$ \\
\hline$S_{\mathrm{MH}, \mathrm{lq}}=\frac{S_{\mathrm{v}-1} M_{\mathrm{H} 2 \mathrm{O}}}{1000}+\frac{\left(s_{\mathrm{lq}, \mathrm{in}} u_{\mathrm{in}}-s_{\mathrm{lq}, \mathrm{out}} u_{\mathrm{out}}\right) \zeta_{\mathrm{rati}} \rho_{\mathrm{lq}} A_{\mathrm{MH}, \text { in }}}{r_{\mathrm{MH}, \mathrm{CH}} A_{\mathrm{MH}} \delta_{\mathrm{CH}}}$ & $\mathrm{kg} \mathrm{m}^{-3} \mathrm{~s}^{-1}$ \\
\hline$S_{\mathrm{T}}=\left\{\begin{array}{lr}Q_{\text {gas }} & \text { (in dry channel) } \\
h_{\text {cond }}\left(-S_{\mathrm{m}-\mathrm{v}} M_{\mathrm{H}_{2} \mathrm{O}}\right) & \text { (in membrane) } \\
Q_{\mathrm{gas}}+h_{\text {cond }} S_{\mathrm{v}-1} & \text { (in wet channel) }\end{array}\right.$ & $\mathrm{W} \mathrm{m} \mathrm{m}^{-3}$ \\
\hline
\end{tabular}

\section{Appendix B}

This appendix presents the calculation equations for the electrochemical hydrogen 
pump model, including membrane water, hydrogen, water vapor, and temperature.

Membrane water content is calculated at the center of catalyst layer (CL) and membrane.

$$
\begin{aligned}
& \lambda_{\mathrm{HP}, \mathrm{CLa}}^{t}=\lambda_{\mathrm{HP}, \mathrm{CLa}}^{t-\Delta t}+\left[\frac{\left(\lambda_{\mathrm{HP}, \mathrm{MEM}}^{t-\Delta t}-\lambda_{\mathrm{HP}, \mathrm{CLa}}^{t-\Delta t}\right) D_{\mathrm{HP}, \mathrm{MEM} \_\mathrm{CLa}}^{\lambda, \mathrm{ef}}}{\left(\frac{\delta_{\mathrm{HP}, \mathrm{CLa}}}{2}+\frac{\delta_{\mathrm{HP}, \mathrm{MEM}}}{2}\right) \delta_{\mathrm{HP}, \mathrm{CLa}}}+S_{\mathrm{HP}, \mathrm{mw}} \frac{E W_{\mathrm{HP}}}{\rho_{\mathrm{HP}, \mathrm{MEM}}}\right] \frac{\Delta t}{\omega_{\mathrm{HP}, \mathrm{CLa}}} \\
& \lambda_{\mathrm{HP}, \mathrm{MEM}}^{t}=\lambda_{\mathrm{HP}, \mathrm{MEM}}^{t-\Delta t}+\left[\frac{\left(\lambda_{\mathrm{HP}, \mathrm{CLc}}^{t-\Delta t}-\lambda_{\mathrm{HP}, \mathrm{MEM}}^{t-\Delta t}\right) D_{\mathrm{HP}, \mathrm{MEM} \_\mathrm{CLc}}^{\lambda, \text { ef }}}{\left(\frac{\delta_{\mathrm{HP}, \mathrm{CLc}}}{2}+\frac{\delta_{\mathrm{HP}, \mathrm{MEM}}}{2}\right) \delta_{\mathrm{HP}, \mathrm{MEM}}}-\frac{\left(\lambda_{\mathrm{HP}, \mathrm{MEM}}^{t-\Delta t}-\lambda_{\mathrm{HP}, \mathrm{CLa}}^{t-\Delta t}\right) D_{\mathrm{HP}, \mathrm{MEM} \_\mathrm{CLa}}^{\lambda, \text { eff }}}{\left(\frac{\delta_{\mathrm{HP}, \mathrm{CLa}}}{2}+\frac{\delta_{\mathrm{HP}, \mathrm{MEM}}}{2}\right) \delta_{\mathrm{HP}, \mathrm{MEM}}}\right] \Delta t \\
& \lambda_{\mathrm{HP}, \mathrm{CLc}}^{t}=\lambda_{\mathrm{HP}, \mathrm{CLc}}^{t-\Delta t}+\left[-\frac{\left(\lambda_{\mathrm{HP}, \mathrm{CLc}}^{t-\Delta t}-\lambda_{\mathrm{HP}, \mathrm{MEM}}^{t-\Delta t}\right) D_{\mathrm{HP}, \mathrm{MEM} \_\mathrm{CLc}}^{\lambda}}{\left(\frac{\delta_{\mathrm{HP}, \mathrm{CLc}}}{2}+\frac{\delta_{\mathrm{HP}, \mathrm{MEM}}}{2}\right) \delta_{\mathrm{HP}, \mathrm{CLc}}}+S_{\mathrm{HP}, \mathrm{mw}} \frac{E W_{\mathrm{HP}}}{\rho_{\mathrm{HP}, \mathrm{MEM}}}\right] \frac{\Delta t}{\omega_{\mathrm{HP}, \mathrm{CLc}}}
\end{aligned}
$$

where $\lambda_{\mathrm{HP}, \mathrm{CLa}}^{t-\Delta t}, \lambda_{\mathrm{HP}, \mathrm{MEM}}^{t-\Delta t}, \lambda_{\mathrm{HP}, \mathrm{CLc}}^{t-\Delta t}$ are the membrane water content of CLa, membrane, CLc at last time step, $\lambda_{\mathrm{HP}, \mathrm{CLa}}^{t}, \lambda_{\mathrm{HP}, \mathrm{MEM}}^{t}, \lambda_{\mathrm{HP}, \mathrm{CL}}^{t}$ are that of CLa, membrane, CLc at next time step, $S_{\mathrm{HP}, \mathrm{mw}}\left(\mathrm{kmol} \mathrm{m} \mathrm{m}^{-3}\right)$ is the membrane water source term, which includes the electro-osmotic drag effect and phase changes.

Gas concentration at the center of CL, GDL, and gas channel $(\mathrm{CH})$ are calculated as:

$$
\begin{aligned}
& c_{\mathrm{HP}, \mathrm{i} \_\mathrm{CLc}}^{t}=c_{\mathrm{HP}, \mathrm{i} \_\mathrm{CLc}}^{t-t}+\left[S_{\mathrm{HP}, \mathrm{i}}-\frac{\left(c_{\mathrm{HP}, \mathrm{i} \_\mathrm{CLc}}^{t-t}-c_{\mathrm{HP}, \mathrm{i} \_\mathrm{GDLc}}^{t-\Delta t}\right) D_{\mathrm{HP}, \mathrm{CLc} \_\mathrm{GDLc}}^{\mathrm{i}, \text { eff }}}{\left(\frac{\delta_{\mathrm{HP}, \mathrm{CLc}}}{2}+\frac{\delta_{\mathrm{HP}, \mathrm{GDLc}}}{2}\right) \delta_{\mathrm{HP}, \mathrm{CLc}}}\right] \frac{\Delta t}{\varepsilon_{\mathrm{HP}, \mathrm{CLc}}} \\
& c_{\mathrm{HP}, \mathrm{i}_{-} \mathrm{GDLc}}^{t}=c_{\mathrm{HP}, \mathrm{i} \_\mathrm{GDLc}}^{t-\Delta t}+ \\
& {\left[\frac{\left(c_{\mathrm{HP}, \mathrm{i}, \mathrm{CLc}}^{t-t}-c_{\mathrm{HP}, \mathrm{i} \_\mathrm{GDLc}}^{t-\Delta t}\right) D_{\mathrm{HP}, \mathrm{CLc} \_\mathrm{GDLc}}^{\mathrm{i} \text { eff }}}{\left(\frac{\delta_{\mathrm{HP}, \mathrm{CLc}}}{2}+\frac{\delta_{\mathrm{HP}, \mathrm{GDLc}}}{2}\right) \delta_{\mathrm{HP}, \mathrm{GDLc}}}-\frac{r_{\mathrm{HP}, \mathrm{CH}}\left(c_{\mathrm{HP}, \mathrm{i}, \mathrm{GDLc}}^{t-\Delta t}-c_{\mathrm{HP}, \mathrm{i} \_\mathrm{CHc}}^{t-\Delta t}\right) D_{\mathrm{HP}, \mathrm{GDLc}}^{\mathrm{i}, \text { eff }}}{\left(\frac{\delta_{\mathrm{HP}, \mathrm{GDLc}}}{2}\right) \delta_{\mathrm{HP}, \mathrm{GDLc}}}\right] \frac{\Delta t}{\varepsilon_{\mathrm{HP}, \mathrm{GDLc}}}}
\end{aligned}
$$


where $c_{\mathrm{HP}, \mathrm{i}_{-} \mathrm{CL}}^{t-\Delta t}, c_{\mathrm{HP}, \mathrm{i} \_\mathrm{GDLc}}^{t-\Delta t}, c_{\mathrm{HP}, \mathrm{i}_{-} \mathrm{CHc}}^{t-\Delta t}\left(\mathrm{~mol} \mathrm{~m}^{-3}\right)$ represent the gas concentration of CL, GDL, $\mathrm{CH}$ at last time step, $c_{\mathrm{HP}, \mathrm{i}, \mathrm{CL}}^{t}, c_{\mathrm{HP}, \mathrm{i} \text { GGDLc }}^{t}, c_{\mathrm{HP}, \mathrm{i} \_\mathrm{CHc}}^{t}\left(\mathrm{~mol} \mathrm{~m}{ }^{-3}\right)$ represent the gas concentration of CL, GDL, $\mathrm{CH}$ at next time step $\left(\mathrm{i}=\mathrm{H}_{2}, \mathrm{vp}\right), S_{\mathrm{HP}, \mathrm{i} \text { fllow }}\left(\mathrm{kmol} \mathrm{m}^{-3} \mathrm{~s}^{-1}\right)$ is the source term of gas species.

Temperature at the center of each layer is calculated in the same way.

$$
\begin{aligned}
& T_{\mathrm{HP}, \mathrm{BP}}^{t}=T_{\mathrm{HP}, \mathrm{BP}}^{t-\Delta t}+\left[\frac{\left(T_{\mathrm{HP}, \mathrm{CH}}^{t-\Delta t}-T_{\mathrm{HP}, \mathrm{BP}}^{t-\Delta t}\right) k_{\mathrm{HP}, \mathrm{BP} \_\mathrm{CH}}^{\mathrm{eff}}}{\left(\frac{\delta_{\mathrm{HP}, \mathrm{BP}}}{2}+\frac{\delta_{\mathrm{HP}, \mathrm{CH}}}{2}\right) \delta_{\mathrm{HP}, \mathrm{BP}}}-\frac{h_{\text {surr }}\left(T_{\mathrm{HP}, \mathrm{BP}}^{t-\Delta t}-T_{\text {surr }}\right)}{\delta_{\mathrm{HP}, \mathrm{BP}}}+S_{\mathrm{HP}, \mathrm{T}}\right] \frac{\Delta t}{\rho c_{\mathrm{p}}} \\
& T_{\mathrm{HP}, \mathrm{CH}}^{t}=T_{\mathrm{HP}, \mathrm{CH}}^{t-\Delta t}+\left[\frac{\left(T_{\mathrm{HP}, \mathrm{GDL}}^{t-\Delta t}-T_{\mathrm{HP}, \mathrm{CH}}^{t-\Delta t}\right) k_{\mathrm{HP}, \mathrm{GDL} \_\mathrm{CH}}^{\mathrm{eff}}}{\left(\frac{\delta_{\mathrm{HP}, \mathrm{CH}}}{2}+\frac{\delta_{\mathrm{HP}, \mathrm{GDL}}}{2}\right) \delta_{\mathrm{HP}, \mathrm{CH}}}-\frac{\left(T_{\mathrm{HP}, \mathrm{CH}}^{t-\Delta t}-T_{\mathrm{HP}, \mathrm{BP}}^{t-\Delta t}\right) k_{\mathrm{HP}, \mathrm{BP} \_\mathrm{CH}}^{\mathrm{eff}}}{\left(\frac{\delta_{\mathrm{HP}, \mathrm{BP}}}{2}+\frac{\delta_{\mathrm{HP}, \mathrm{CH}}}{2}\right) \delta_{\mathrm{HP}, \mathrm{CH}}}+S_{\mathrm{HP}, \mathrm{T}}\right] \frac{\Delta t}{\rho c_{\mathrm{p}}} \\
& T_{\mathrm{HP}, \mathrm{MEM}}^{t}=T_{\mathrm{HP}, \mathrm{MEM}}^{t-\Delta t}+ \\
& {\left[\frac{\left(T_{\mathrm{HP}, \mathrm{CLc}}^{t-\Delta t}-T_{\mathrm{HP}, \mathrm{MEM}}^{t-\Delta t}\right) k_{\mathrm{HP}, \mathrm{CL} \_\mathrm{MEM}}^{\mathrm{eff}}}{\left(\frac{\delta_{\mathrm{HP}, \mathrm{CLc}}}{2}+\frac{\delta_{\mathrm{HP}, \mathrm{MEM}}}{2}\right) \delta_{\mathrm{HP}, \mathrm{MEM}}}-\frac{\left(T_{\mathrm{HP}, \mathrm{MEM}}^{t-\Delta t}-T_{\mathrm{HP}, \mathrm{CLa}}^{t-\Delta t}\right) k_{\mathrm{HP}, \mathrm{MEM} \_\mathrm{CLa}}^{\mathrm{eff}}}{\left(\frac{\delta_{\mathrm{HP}, \mathrm{MEM}}}{2}+\frac{\delta_{\mathrm{HP}, \mathrm{CLa}}}{2}\right) \delta_{\mathrm{HP}, \mathrm{MEM}}}+S_{\mathrm{HP}, \mathrm{T}}\right] \frac{\Delta t}{\rho c_{\mathrm{p}}}}
\end{aligned}
$$

where $T_{\mathrm{HP}, \mathrm{BP}}^{t-\Delta t}, T_{\mathrm{HP}, \mathrm{CH}}^{t-\Delta t}, T_{\mathrm{HP}, \mathrm{MEM}}^{t-\Delta t}(\mathrm{~K})$ are the temperature of BP, $\mathrm{CH}, \mathrm{MEM}$ at last time step, $T_{\mathrm{HP}, \mathrm{BP}}^{t}, T_{\mathrm{HP}, \mathrm{CH}}^{t}, T_{\mathrm{HP}, \mathrm{MEM}}^{t}(\mathrm{~K})$ are the temperature at next time step. $S_{\mathrm{HP}, \mathrm{T}}(\mathrm{W}$ $\mathrm{m}^{-3}$ ) is the heat source term.

\section{Appendix C}


This appendix lists the calibration process of the compressor characteristics. The multinomial coefficients of curving fitting results, the proportion-integral-derivative control strategy, and the corresponding calculation procedure are also presented.

The air mass flow rate and rotating speed are calibrated as:

$$
\begin{aligned}
& m_{\text {air, }, \mathrm{rr}}=\frac{m_{\mathrm{cp}} \sqrt{\theta_{\mathrm{f}}}}{\delta_{\mathrm{f}}}, N_{\mathrm{cr}}=\frac{N_{\mathrm{cp}}}{\sqrt{\theta_{\mathrm{f}}}} \\
& \theta_{\mathrm{f}}=\frac{T_{\mathrm{cp}, \mathrm{in}}}{288}, \delta_{\mathrm{f}}=\frac{p_{\mathrm{cp}, \mathrm{in}}}{101325}
\end{aligned}
$$
where $m_{\mathrm{cp}}\left(\mathrm{kg} \mathrm{s}^{-1}\right)$ is the mass flow rate, $N_{\mathrm{cp}}(\mathrm{RPM})$ is the rotating speed, $m_{\text {air,cr }}$ $\left(\mathrm{kg} \mathrm{s}^{-1}\right)$ is the corrected mass flow rate, $N_{\text {cr }}$ (RPM) is the corrected rotating speed, $T_{\text {cp,in }}(\mathrm{K})$ is the air inlet temperature, $p_{\mathrm{cp}, \text { in }}(\mathrm{Pa})$ is the air inlet pressure, $\theta_{\mathrm{f}}, \delta_{\mathrm{f}}$ are the temperature and pressure calibration factor, respectively.

Table C.1. Multinomial coefficients of curving fitting results.

\begin{tabular}{llllllll}
\hline Parameter & Value & Parameter & Value & Parameter & Value & Parameter & Value \\
\hline $\mathrm{p}_{00}$ & 0.0483 & $\mathrm{p}_{30}$ & 0.806 & $\mathrm{p}_{40}$ & -0.603 & $\mathrm{p}_{50}$ & 0.214 \\
$\mathrm{p}_{10}$ & 0.361 & $\mathrm{p}_{21}$ & -2.70 & $\mathrm{p}_{31}$ & 3.017 & $\mathrm{p}_{41}$ & -1.448 \\
$\mathrm{p}_{01}$ & -0.297 & $\mathrm{p}_{12}$ & 2.696 & $\mathrm{p}_{22}$ & -5.12 & $\mathrm{p}_{32}$ & 3.663 \\
$\mathrm{p}_{20}$ & -0.682 & $\mathrm{p}_{03}$ & -0.819 & $\mathrm{p}_{13}$ & 3.578 & $\mathrm{p}_{23}$ & -4.324 \\
$\mathrm{p}_{11}$ & 1.352 & & & $\mathrm{p}_{04}$ & -0.883 & $\mathrm{p}_{14}$ & 2.435 \\
$\mathrm{p}_{02}$ & -0.617 & & & & & $\mathrm{p}_{05}$ & -0.536 \\
\hline
\end{tabular}

Note: The sum of squares due to error (SSE) is 0.008865 , and the coefficient of determination (R-square) is 0.9805 , indicating good curve fitting results.

As stated in Subsection 2.4, the terminal voltage determines the rotating speed of drive motor, thus determining the mass flow rate of compressor. The variance of real/required mass flow rate is set as the control deviation, and the controlled terminal 
voltage is calculated.

$$
\begin{aligned}
& e(t)=m_{\mathrm{air}}^{\mathrm{req}}-m_{\mathrm{air}}^{\text {real }} \\
& u(t)=K_{\mathrm{p}} e(t)+K_{\mathrm{I}} \int e(t) d t+K_{\mathrm{D}} \frac{d e(t)}{d t} \\
& v_{\mathrm{cm}}^{\mathrm{PID}}=v_{\mathrm{cm}}+u(t)
\end{aligned}
$$

The calculation procedure of the air compressor model is explained as follows. Firstly, the required air mass flow rate and pressure ratio are calculated according to stack operating conditions. After the temperature and pressure calibration, the specific working point in characteristics of air compressor is determined. If the point locates in surging region or exceeds maximum flow rate, it is adjusted to ensure normal operation of compressor. Given temporary compressor rotating speed, the real mass flow rate is obtained based on aforementioned polynomial fitting results. Then, the control variance is calculated and the corresponding motor terminal voltage is acquired. The new rotating speed is subsequently calculated based on the inertance of drive motor. Finally, the new air mass flow rate is obtained. The above procedure continues until the required air mass flow rate and pressure ratio are simultaneously reached.

\section{Appendix D}

This appendix gives the schematic diagram of a ribbon-tubular fin radiator and the corresponding structural properties. The calculation equations for heat transfer coefficients are also presented. 

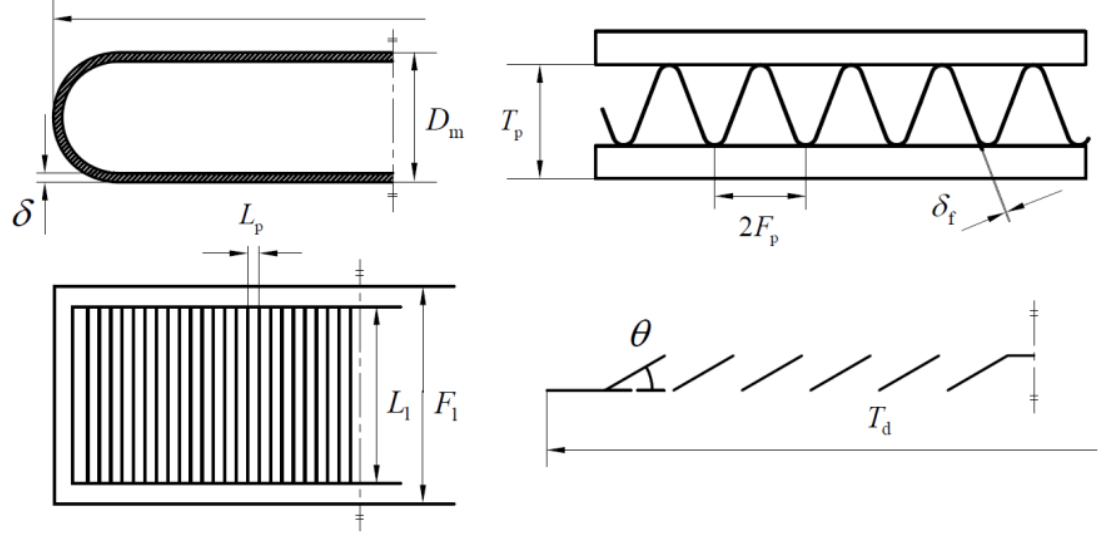

Fig. D.1. Schematic diagram of a ribbon-tubular fin radiator [78].

Table D.1. Radiator structural properties [78].

\begin{tabular}{llll}
\hline Parameter & Value & Parameter & Value $(\mathrm{mm})$ \\
\hline Tube length $L$ & 600 & Fin thickness $\delta_{\mathrm{f}}$ & $0.06 \mathrm{~mm}$ \\
Tube width $D_{\mathrm{m}}$ & $1.5 \mathrm{~mm}$ & Fin pitch $F_{\mathrm{p}}$ & $1.115 \mathrm{~mm}$ \\
Tube length $T_{\mathrm{d}}$ & $16 \mathrm{~mm}$ & Fin number $n_{\mathrm{f}}$ & 266 \\
Tube thickness $\delta$ & $0.25 \mathrm{~mm}$ & Louver pitch $L_{\mathrm{p}}$ & $0.805 \mathrm{~mm}$ \\
Tube pitch $T_{\mathrm{p}}$ & $6.5 \mathrm{~mm}$ & Louver length $L_{1}$ & $4.56 \mathrm{~mm}$ \\
Tube number $n_{\mathrm{t}}$ & 58 & Louver angle $\theta$ & $30^{\circ}$ \\
Fin length $F_{1}$ & $5 \mathrm{~mm}$ & & \\
\hline
\end{tabular}

As previously stated, the overall heat transfer coefficient consists of three parts, including heat convection between coolant and tube, heat conduction inside tube wall and heat convection between tube and air. The heat transfer coefficient between coolant and tube is calculated as:

$h_{l}=\frac{N u \lambda_{1}}{l_{1}}$

where $N u$ is the Nusselt number, $\lambda_{1}\left(\mathrm{~W} \mathrm{~m}^{-1} \mathrm{~K}^{-1}\right)$ is the conductive heat transfer 
coefficient of coolant, $l_{1}(\mathrm{~m})$ is the characteristic length. Based on tube structures shown in Fig. D.1, the sectional area and perimeter are calculated as:

$l_{1}=\frac{4 A_{\mathrm{t}}}{P_{\mathrm{t}}}$

$A_{\mathrm{t}}=\left(T_{\mathrm{d}}-D_{\mathrm{m}}\right)\left(D_{\mathrm{m}}-2 \delta\right)+\pi\left(\frac{D_{\mathrm{m}}-2 \delta}{2}\right)^{2}$

$P_{\mathrm{t}}=2\left[\left(T_{\mathrm{d}}-D_{\mathrm{m}}\right)-\pi\left(D_{\mathrm{m}}-2 \delta\right) / 2\right]$

The Nusselt number is determined by coolant flow condition inside tube and it is calculated based on empirical equations [81].

$N u=\left\{\begin{array}{lr}6.49 & \left(R e_{1}<2300\right) \\ \frac{\left(R e_{1}-1000\right) P r_{1}\left(f_{1} / 2\right)}{1.07+12.7 \sqrt{f_{1} / 2}\left(P r_{1}^{2 / 3}-1\right)} & \left(3000 \leq R e_{1}<5 \times 10^{6}\right)\end{array}\right.$

$f_{1}=\left(1.58 \ln R e_{1}-3.28\right)^{-2}$

where $P r_{1}$ is the Prandtl number, $f_{1}$ is the friction factor.

Heat is absorbed from coolant, then it is released to air through louver. The heat transfer coefficient between tube and air is calculated as [78]:

$$
\begin{aligned}
& j=R e_{\text {air }}^{-0.49}\left(\frac{\theta}{90}\right)^{0.27}\left(\frac{F_{\mathrm{p}}}{L_{\mathrm{p}}}\right)^{-0.14}\left(\frac{F_{1}}{L_{\mathrm{p}}}\right)^{-0.29}\left(\frac{T_{\mathrm{d}}}{L_{\mathrm{p}}}\right)^{-0.23}\left(\frac{L_{1}}{L_{\mathrm{p}}}\right)^{0.68}\left(\frac{T_{\mathrm{p}}}{L_{\mathrm{p}}}\right)^{-0.28}\left(\frac{\delta_{\mathrm{f}}}{L_{\mathrm{p}}}\right)^{-0.05} \\
& h_{\mathrm{a}}=\frac{j\left(c_{p}\right)_{\text {air }} G_{\text {air }}}{\operatorname{Pr}_{\text {air }}^{/ 23}} \\
& G_{\text {air }}=\frac{m_{\text {air }}}{2 n_{\mathrm{t}} n_{\mathrm{f}} A_{\mathrm{a} \text {, min }}}
\end{aligned}
$$

where $j$ is the heat transfer factor and it is related to the louver structure. $G_{\text {air }}(\mathrm{kg}$ $\left.\mathrm{m}^{-2} \mathrm{~s}^{-1}\right)$ is the air mass flow rate per effective flow area. $A_{\mathrm{a}, \min }\left(\mathrm{m}^{2}\right)$ is the sectional area encircled by adjacent tubes and fins. Since there are fins on the surface of each tube to enhance heat transfer, it is necessary to take fin efficiency into consideration. 


$$
\begin{aligned}
& \eta_{0}=\frac{A_{\mathrm{f}, 1}+\eta_{\mathrm{f}} A_{\mathrm{f}, 2}}{A_{\mathrm{f}, 1}+A_{\mathrm{f}, 2}}, \quad \eta_{\mathrm{f}}=\frac{\operatorname{th}(m l)}{m l} \\
& m=\sqrt{\frac{2 h_{\mathrm{a}}\left(F_{\mathrm{d}}+\delta_{\mathrm{f}}\right)}{\lambda F_{\mathrm{d}} \delta_{\mathrm{f}}}}, \quad l=\sqrt{F_{\mathrm{p}}^{2}+F_{1}^{2}}
\end{aligned}
$$

where $\eta_{0}$ is the overall heat transfer efficiency, $\eta_{\mathrm{f}}$ is the fin efficiency, $A_{\mathrm{f}, 1}, A_{\mathrm{f}, 2}$ $\left(\mathrm{m}^{2}\right)$ are the fin base area and fin surface area, respectively. 
Highlights

1. A comprehensive PEMFC system model integrating all subsystems is developed.

2. All sub-models are rigorously validated to guarantee the system model accuracy.

3. Membrane dehydration is observed when the stack is operated at $70{ }^{\circ} \mathrm{C}$ and $80{ }^{\circ} \mathrm{C}$.

4. Co-current flow pattern contributes to higher water utilization of whole system.

5. Increasing humidifier area results in much slower humidification responses. 
A comprehensive proton exchange membrane fuel cell

\title{
system model integrating various auxiliary subsystems
}

\author{
Zirong Yang ${ }^{\mathrm{a}}$, Qing Du ${ }^{\mathrm{a}, *}$, Zhiwei Jia ${ }^{\mathrm{b}}$, Chunguang Yang ${ }^{\mathrm{b}}$, Jin Xuan ${ }^{\mathrm{c}}$, Kui Jiao ${ }^{\mathrm{a}, *}$ \\ a. State Key Laboratory of Engines, Tianjin University, 135 Yaguan Road, Tianjin, 300350, China \\ b. Zhengzhou Yutong Bus CO., LTD, Yutong Industry Park, Zhengzhou, 450016, China \\ c. Department of Chemical Engineering, Loughborough University, Loughborough, LE11 3TU, \\ United Kingdom \\ *Corresponding authors: duqing@tju.edu.cn (Q. Du); kjiao@tju.edu.cn (K. Jiao)
}

\begin{abstract}
A comprehensive proton exchange membrane fuel cell (PEMFC) system model is developed, including a pseudo two-dimensional transient multiphase stack model, a one-dimensional transient multiphase membrane humidifier model, a one-dimensional electrochemical hydrogen pump model, an air compressor model with proportion-integral-derivative control and a ribbon-tubular fin radiator model. All sub-models have been rigorously validated against experimental data to guarantee the system model accuracy. The effects of stack operating temperature, gas flow pattern and humidifier structural design are investigated to cast insights into the interaction among stack and auxiliary subsystems. The results indicate that the stack is successfully maintained at required operating temperatures $\left(60^{\circ} \mathrm{C}, 70{ }^{\circ} \mathrm{C}, 80{ }^{\circ} \mathrm{C}\right)$ with help of the radiator when the whole system starts from ambient temperature $\left(25^{\circ} \mathrm{C}\right)$. However, the stack is likely to suffer from membrane dehydration when operated at $70{ }^{\circ} \mathrm{C}$, and the problem becomes more severe at $80{ }^{\circ} \mathrm{C}$, causing significant performance deterioration. The water and temperature distribution inside the system are further demonstrated. The co-current flow pattern contributes to better water utilization of the whole system which may lead to higher output performances. But the counter-current flow pattern has positive effects on parameter distribution uniformity inside fuel cell, which is beneficial for the stack durability. As regards the membrane dehydration, it is found that optimizing membrane humidifier area does not fundamentally solve the problem. Increasing humidifier area contributes to higher water vapor transfer rate, however, it results in much slower humidification responses.
\end{abstract}




\section{Nomenclature}

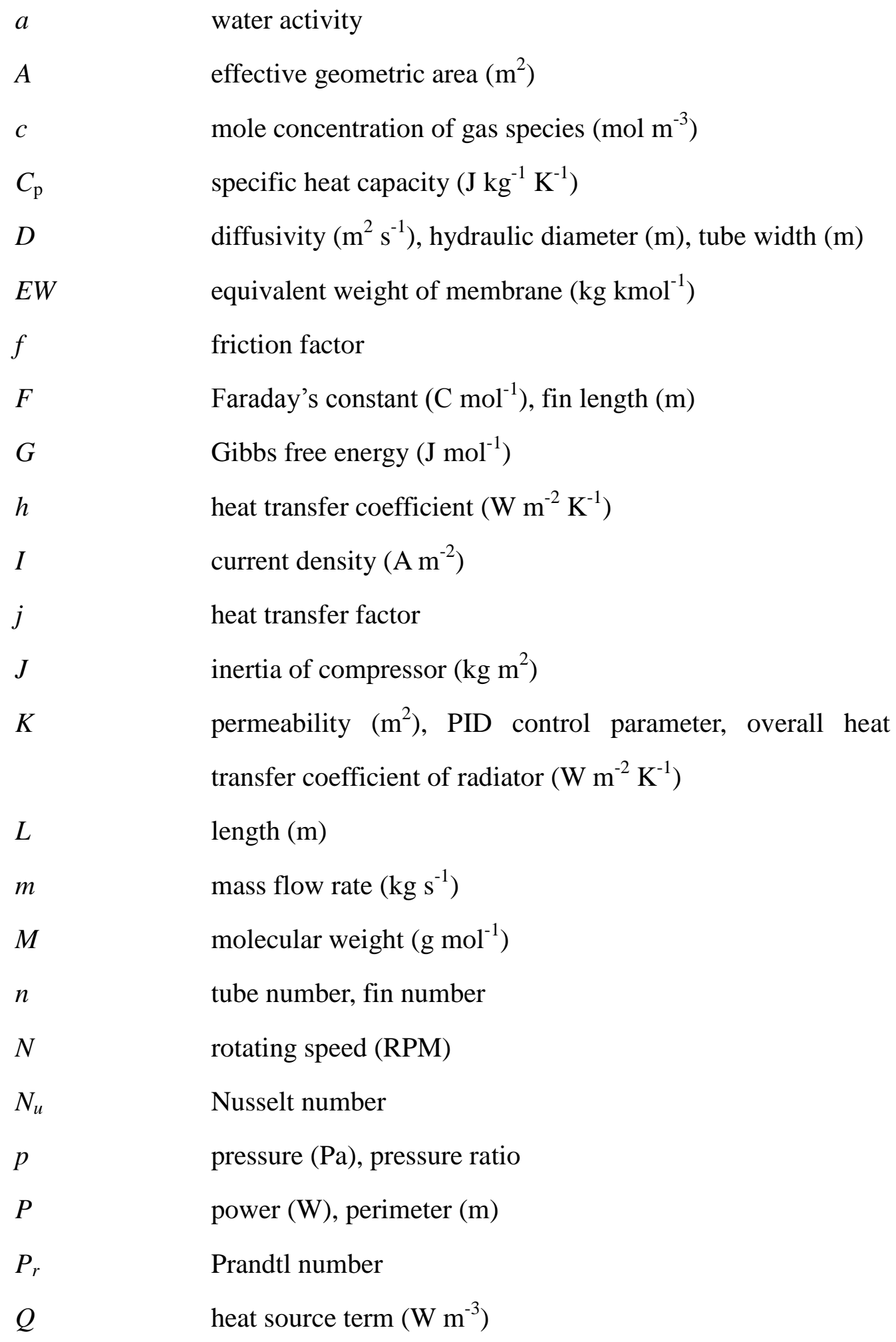


area ratio

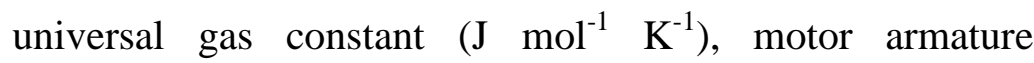
resistance $(\Omega)$

$R e$

S

$S$

Sher

$t$

$\Delta t$

$\Delta t_{\mathrm{m}}$

T

$u$

V

Greek letters

$\varepsilon$

$\zeta$

$\lambda$

$\xi$

$\mu$

$\rho$

$\omega$

$\sigma$

$\delta$

$\psi$

$\eta$

$\gamma$

Reynolds number

volume fraction in pore structures

source terms $\left(\mathrm{kmol} \mathrm{m}^{-3} \mathrm{~s}^{-1}, \mathrm{~kg} \mathrm{~m}^{-3} \mathrm{~s}^{-1}, \mathrm{~W} \mathrm{~m}^{-3}\right)$, entropy ( $\mathrm{mol}^{-1} \mathrm{~K}^{-1}$ )

Sherwood number

time (s)

time step size (s)

average temperature difference $(\mathrm{K})$

temperature $(\mathrm{K})$, tube length $(\mathrm{m})$

velocity $\left(\mathrm{m} \mathrm{s}^{-1}\right)$, velocity ratio

voltage $(\mathrm{V})$

porosity

water transfer rate $\left(\mathrm{s}^{-1}\right)$

membrane water content

stoichiometry ratio

dynamic viscosity $\left(\mathrm{kg} \mathrm{m}^{-1} \mathrm{~s}^{-1}\right)$

density $\left(\mathrm{kg} \mathrm{m}^{-3}\right)$

volume fraction of ionomer, rotation angular frequency (rad $\left.\mathrm{s}^{-1}\right)$

surface tension $\left(\mathrm{N} \mathrm{m}^{-1}\right)$

thickness (m), pressure calibration factor

water volume fraction in hydrated membrane

efficiency

compressibility coefficient 
contact angle $\left({ }^{\circ}\right)$, temperature calibration factor, louver angle

$\left({ }^{\circ}\right)$

torque $(\mathrm{N} \mathrm{m})$

conductivity $\left(\mathrm{S} \mathrm{m}^{-1}\right)$, motor torque constant

motor terminal voltage $(\mathrm{V})$

Subscripts and superscripts

a

act

atm

BP

c

$\mathrm{CH}$

CL

$\mathrm{cm}$

conc

cond

cool

$\mathrm{cp}$

cr

D

dry

eff

EOD

eq

f

FPD

fusn

g anode

activation

atmosphere

bipolar plate

cathode, capillary

flow channel

catalyst layer

compressor motor

concentration

condensation

coolant

compressor

corrected

derivative

dry channel

effective

electro-osmotic drag

equilibrium

fin

freezing point depression

fusion

gas phase 


$\begin{array}{ll}\text { GDL } & \text { gas diffusion layer } \\ \mathrm{H}_{2} & \text { hydrogen } \\ \mathrm{HP} & \text { hydrogen pump } \\ \mathrm{I} & \text { integral } \\ \text { ice } & \text { ice } \\ \text { in } & \text { inlet } \\ \text { 1 } & \text { liquid phase } \\ \text { lq } & \text { liquid water } \\ \mathrm{MEM} & \text { membrane } \\ \mathrm{MH} & \text { membrane humidifier } \\ \mathrm{mw} & \text { membrane water } \\ \mathrm{MPL} & \text { micro-porous layer } \\ \mathrm{N} & \text { standard condition } \\ \mathrm{N}_{2} & \text { nitrogen } \\ \mathrm{Nernst} & \text { Nernst } \\ \mathrm{O}_{2} & \text { oxygen } \\ \text { ohmic } & \text { ohmic } \\ \text { out } & \text { output, outlet } \\ \mathrm{P} & \text { proportion } \\ \text { pc } & \text { phase change } \\ \text { per } & \text { permeation } \\ \text { react } & \text { reaction } \\ \text { ref } & \text { reference state } \\ \text { req } & \text { requested } \\ \text { sat } & \text { saturation } \\ \text { suplq } & \text { super-cooled water } \\ \text { surr } & \text { surroundings } \\ \text { wet } & \text { water vapor } \\ \text { wet channel }\end{array}$


m-1 membrane water to super-cooled liquid water

$\mathrm{m}-\mathrm{v} \quad$ membrane water to water vapor

1-i super-cooled water to ice

v-1 water vapor to super-cooledVliquid water 


\section{Introduction}

Proton exchange membrane fuel cell (PEMFC) is widely acknowledged as one of the most promising alternative power sources for the automobile industry owing to its high power density, high energy conversion efficiency, and low/zero emission [1,2]. However, PEMFC is still far away from the global commercialization due to numerous technical challenges such as water and heat management inside single fuel cells, and this issue becomes even more complicated at a system level $[3,4]$. The system performance is determined not only by the stack but also by various auxiliary subsystems, making system design and optimization much more sophisticated. Therefore, a comprehensive understanding of the interaction between stack and auxiliary subsystems is necessary for the development of a high-efficiency PEMFC system [5-7].

The schematic diagram of a comprehensive PEMFC system is shown in Fig.1, including stack, reactant gases supply subsystem, humidification subsystem, and heat management subsystem. After exiting the high-pressure hydrogen tank, hydrogen is regulated at the requested pressure and mass flow rate through solenoid valves, which is subsequently supplied to the stack to generate electricity. To improve fuel utilization, there usually exists a recirculation loop in fuel cell vehicles (FCVs). There are different types of hydrogen recirculation pump such as motor-driven pump, ejector, and electrochemical hydrogen pump [8-11]. For the air intake, an air filter is engaged to eliminate impurities, which is of great importance for component lifetime in PEMFC systems [12-14]. A compressor or blower is indispensable to increase the stack operating pressure. To avoid carbon corrosion in cathode catalyst layer, solenoid valves are placed before and after the stack to prevent the residual air in manifolds from entering after shutdown. Humidification subsystem is responsible for humidifying reactant gases since fuel cell is likely to suffer from the membrane dehydration without sufficient gas humidification $[15,16]$. However, excessive humidification may lead to liquid water flooding, which also deteriorates fuel cell performances [17-19]. Spray humidifier, membrane humidifier and enthalpy wheel 


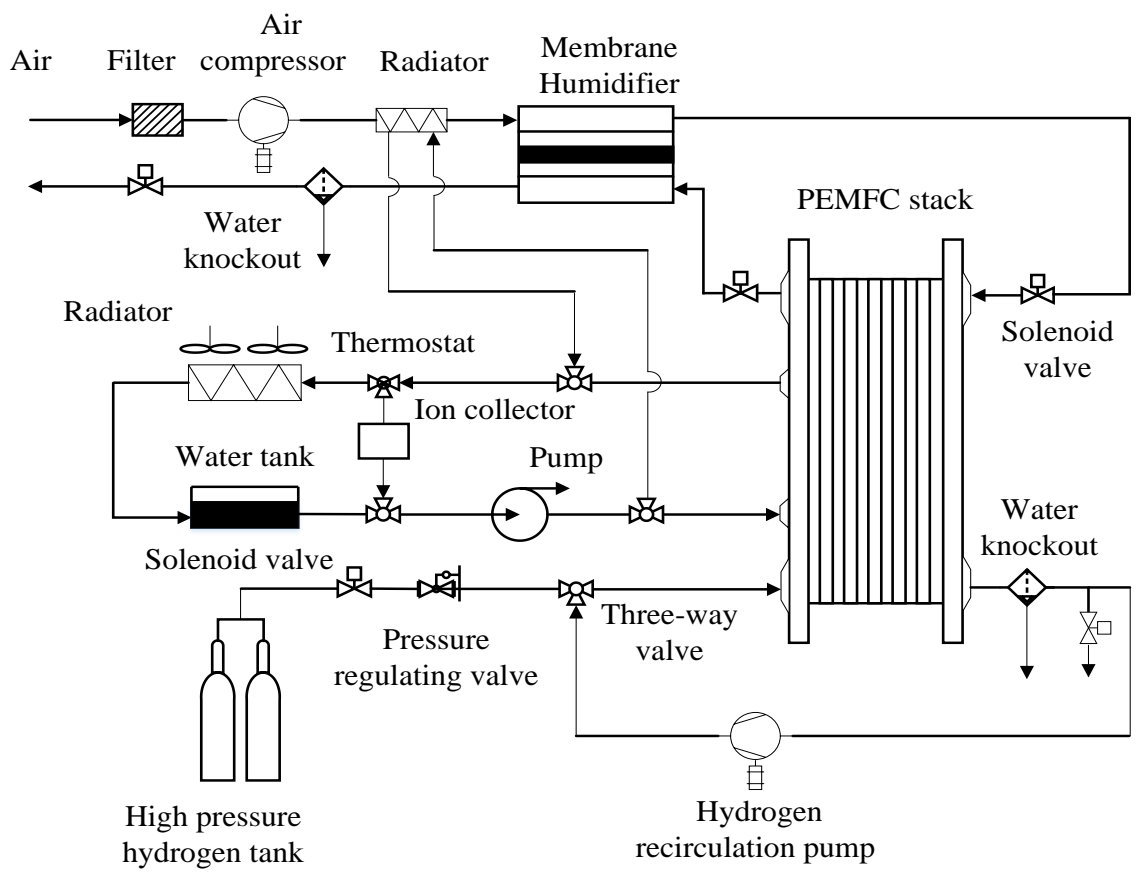

Fig. 1. Schematic diagram of a comprehensive proton exchange membrane fuel cell system.

In the past decades, a large number of experimental and numerical studies have been 
conducted towards fuel cells and stacks. Effects of operating conditions such as relative humidity, temperature, and pressure have been investigated [15-18,24-27] to optimize fuel cell performances. Much attention has also been paid to the structural design and optimization, such as the catalyst [28-30], porous electrode [31,32] and flow channel [33]. Through steady-state polarization curves, transient response and electrochemical impedance spectroscopy (EIS) techniques, Yan et al. [17] found that the cathode inlet gas humidification had significant influences on output performances. Besides, $75{ }^{\circ} \mathrm{C}$ was found to be the best operating temperature among five temperatures ranging from $65^{\circ} \mathrm{C}$ to $85^{\circ} \mathrm{C}$ under full humidification conditions. Similar investigations were conducted by Kim [24], Iranzo [25] and Ozen [27]. It was further observed that single fuel cell or stack performances were more affected by the cathode humidification than the anode humidification. To cast more insights, visualization studies such as neutron imaging [34,35], scanning electron microscopy (SEM) [36], infrared radiation imaging [37] and other high-tech methods [38] have been adopted. In addition to experiments, many theoretical or numerical models have been developed with focuses on operating conditions and structural designs [39-46]. Jiao et al. [39] developed a three-dimensional multiphase transient model to investigate gas humidification influences during cold start process. It was found that the relative humidity had negligible effects since the saturated water vapor pressure was small at subzero temperatures. Tolj et al. [45] developed a pseudo 2D model to investigate the possibility of using product water to internally humidify reactant gases. However, auxiliary equipment such as air compressor, humidifier, and hydrogen pump was hardly taken into consideration in the aforementioned studies. The operation conditions were realized by simply assuming the boundary conditions, which was not coupled with real performances of auxiliary subsystems. The interaction among PEMFC stack and various subsystems needs further investigation because it provides practical suggestions about heat and water management at a system level.

Although comprehensive system studies are rarely presented in literature, numerous researches have been conducted on individual auxiliary subsystems. As regards the 
hydrogen supply subsystem, studies were mainly aimed at eliminating anode nitrogen accumulation and improving fuel utilization [47-54]. He et al. [48] developed a control-oriented model of the fuel delivery system to investigate effective control strategies. Peomislow et al. [49] presented an analytic model to investigate the anode nitrogen accumulation phenomenon. The nitrogen crossover and purging strategies were also studied by Rabbani [50] and Chen [51]. Hwang [52] compared three different hydrogen supply schemes to investigate the PEMFC system efficiency, including flow-through mode, dead-end mode, and recirculation mode. However, much less attention has been paid to hydrogen pump such as ejector and electrochemical hydrogen pump [56-58]. When it comes to the air supply subsystem, improving compressor dynamic responses and decreasing its parasitic power consumption were the main concerns [59-62]. Wang et al. [61] studied the air flow control for preventing cathode starvation when operating conditions were changed. Liu et al. [62] established a semi-mechanical semi-imperial air supply model to investigate the dynamic control of a centrifugal compressor. The control method was further validated in a $150 \mathrm{~kW}$ PEMFC engine system. The researches on humidification subsystem have concentrated on effects of operating conditions and structural designs [63-68]. Yu et al. [64] developed a static model based on planar heat exchanger to investigate effects of geometric parameters and operating parameters. Divesh et al. [65] developed a steady-state analytical model in counter-current flow mode, which could be applied for both plate-and-frame humidifier and shell-and-tube humidifier. However, the aforementioned humidifier models were developed based on either water-to-gas humidification or gas-to-gas humidification while both may happen in real PEMFC subsystems, making it necessary to consider different humidification methods simultaneously. There also existed some researches about the heat management subsystem, which mainly focused on cold startup techniques and cooling strategies [69-73]. Guo et al. [72] studied the hydrogen-oxygen catalytic reaction with a three-dimensional multiphase cold start model. Detailed unassisted and assisted cold start strategies have been summarized by Luo and Jiao [73]. Despite aforementioned studies, modeling of the whole PEMFC system with detailed 
information about auxiliary subsystems is rarely presented in literature. The system model not only reveals heat and mass transport processes inside each individual subsystem but also exhibits the coupled water and heat management at a system level. Water management and optimization of the whole system is supposed to give valuable advice for PEMFC applications.

In the present study, a comprehensive PEMFC system model is developed, including stack, membrane humidifier, hydrogen pump, air compressor and radiator. Detailed methodologies about the five subsystems are presented. After rigorous model validation, the effects of stack operating temperature, gas flow pattern, and humidifier structural design on system performances are investigated. The output voltage, membrane water content, water vapor and temperature distribution are compared to cast insights into the interaction among stack and auxiliary subsystems.

\section{Model development}

A typical proton exchange membrane fuel cell (PEMFC) system consists of stack, gas supply subsystems, humidification subsystem, and heat management subsystem as shown in Fig. 1. The governing equations of stack, membrane humidifier, electrochemical hydrogen pump, air compressor, and radiator are explained in the following subsections.

\subsection{PEMFC stack model}

The schematic diagram of a pseudo two-dimensional PEMFC stack model is illustrated in Fig.2, including bipolar plate (BP), gas channel $(\mathrm{CH})$, gas diffusion layer (GDL), micro-porous layer (MPL), catalyst layer (CL) and proton exchange membrane (MEM). The stack properties and operating conditions are given in Table 1. The designed power is around $50 \mathrm{~kW}$. The coupled heat and water transport as well as sophisticated phase changes are all considered. Besides, the nitrogen crossover phenomenon is also taken into consideration. Instead of solving implicit conservation equations, the explicit formulation calculation method is adopted to enhance 
simulation efficiency. The membrane water, super-cooled/liquid water, ice, gas species, and temperature are calculated at the center of each layer with no further nodes divided. To better reflect water and temperature distribution along the flow direction, the single cell is further divided into several lumps. Gas temperature, concentration and velocity in flow channels are transmitted from the prior node to the posterior node. Heat exchange between adjacent cells is achieved by heat conduction and heat loss between endplate and surroundings is caused by heat convection. Besides, several important assumptions have been made as follows.

1. Reactant gases are assumed to be uniformly distributed into each individual fuel cell $[72,74,75]$.

2. Gas species are considered as ideal gas.

3. Mass transport process inside porous layer is assumed to be dominated by diffusion $[4,5]$.

4. Electrochemically generated water is assumed to be membrane water and it transforms into water vapor, super-cooled/liquid water through phase changes [76].

5. Homogeneous mist flow assumption is adopted in flow channels.

6. Coolant is assumed to flow through cooling channels uniformly in every bipolar layer.

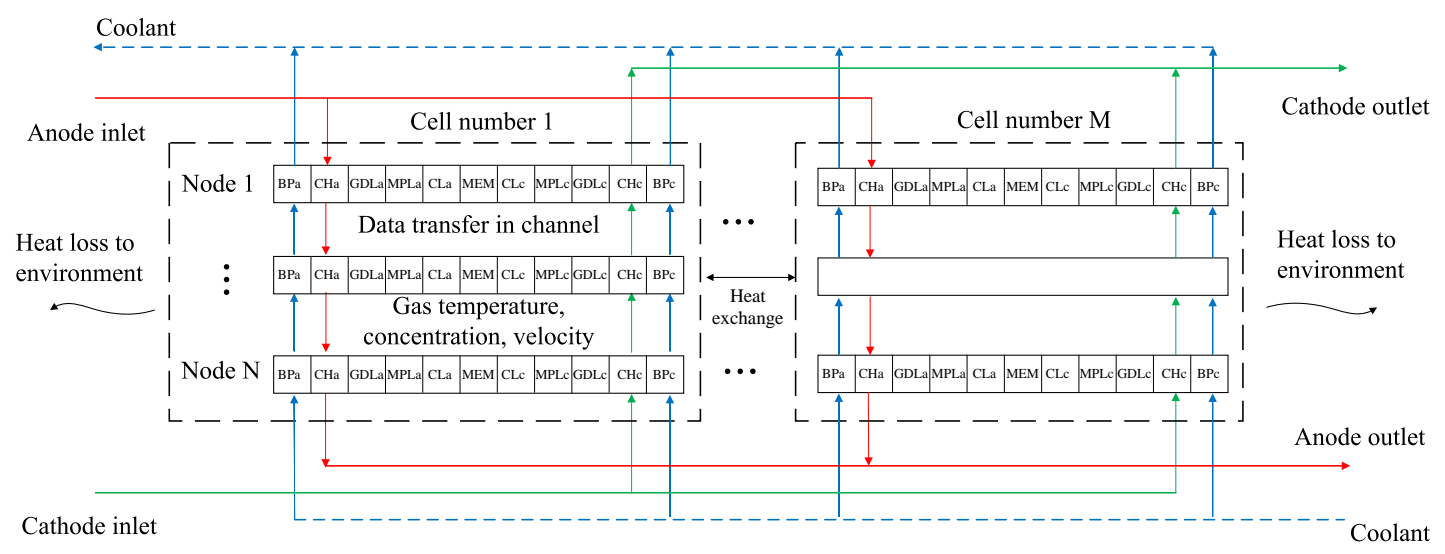

Fig. 2. Schematic diagram of a pseudo two-dimensional PEMFC stack model.

Table 1. Stack properties and operating conditions.

\begin{tabular}{ll}
\hline Parameter & Value \\
\hline
\end{tabular}


Number of single fuel cell

Effective area of single cell

Thickness of BP

Channel length, width, depth, rib width

Thickness of membrane, CL, MPL, $0.050 ; 0.01 ; 0.03 ; 0.2 \mathrm{~mm}$

GDL

Densities of membrane, CL, MPL, $\rho_{\text {mem,CL,MPL,GDL,BP }}=1980 ; 1000 ; 1000$;

GDL, BP $1000 ; 1000 \mathrm{~kg} \mathrm{~m}^{-3}$

Specific heat capacities of membrane, $\left(C_{\mathrm{p}}\right)_{\mathrm{mem}, \mathrm{CL}, \mathrm{MPL}, \mathrm{GDL}, \mathrm{BP}}=833 ; 3300 ; 568$;

CL, MPL, GDL, BP $2000 ; 1580 \mathrm{~J} \mathrm{~kg}^{-1} \mathrm{~K}^{-1}$

Thermal conductivities of membrane, $0.95 ; 1.0 ; 1.0 ; 1.0 ; 20 \mathrm{~W} \mathrm{~m}^{-1} \mathrm{~K}^{-1}$

CL, MPL, GDL, BP

Electric conductivities of $\mathrm{CL}, \mathrm{MPL}, \kappa_{\mathrm{CL}, \mathrm{MPL}, \mathrm{GDL}, \mathrm{BP}}=5000 ; 5000 ; 5000$;

GDL, BP $20000 \mathrm{~S} \mathrm{~m}^{-1}$

Ionomer volume fraction in $\mathrm{CL}$

$\omega=0.4$

Contact angles of CL, MPL, GDL

$\theta_{\mathrm{CL}, \mathrm{MPL}, \mathrm{GDL}}=100^{\circ} ; 120^{\circ} ; 120^{\circ}$

Porosities of CL, MPL, GDL

$\varepsilon_{\mathrm{CL}, \mathrm{MPL}, \mathrm{GDL}}=0.3 ; 0.4 ; 0.7$

Phase change rates

$\zeta_{\mathrm{m}-\mathrm{v}}, \zeta_{\mathrm{m}-\mathrm{l}}, \zeta_{\mathrm{l}-\mathrm{i}}, \zeta_{\mathrm{i}-\mathrm{l}}=1.0 \mathrm{~s}^{-1} ; \zeta_{\mathrm{v}-1}, \zeta_{\mathrm{l}-\mathrm{v}}=1000$ $\mathrm{s}^{-1}$

Requested stoichiometry ratio

$S T_{\mathrm{a}}^{\mathrm{eq}}=1.2, S T_{\mathrm{c}}^{\mathrm{rq}}=2.0$

Requested operating pressure

$p_{\mathrm{a}, \mathrm{c}}^{\mathrm{req}}=1.5 \mathrm{~atm}$

Heat transfer coefficient between $20 \mathrm{~W} \mathrm{~m}^{-2} \mathrm{~K}^{-1}$

endplate and surrounding

Heat transfer coefficient between fuel $200 \mathrm{~W} \mathrm{~m}^{-2} \mathrm{~K}^{-1}$

cell and coolant

Using the explicit formulation calculation method, membrane water contents at the center of anode CL, membrane, and cathode CL are updated directly at each time step. After discretization and transformation, the calculation equations are expressed as: 
where $\lambda_{\mathrm{CLa}}^{t-\Delta t}, \lambda_{\mathrm{MEM}}^{t-\Delta t}, \lambda_{\mathrm{CLc}}^{t-\Delta t}$ are the membrane water content at last time step, $\lambda_{\mathrm{CLa}}^{t}$, $\lambda_{\text {MEM }}^{t}, \lambda_{\text {CLC }}^{t}$ are the membrane water content at next time step, $D_{\text {MEM_CL }}^{\lambda, \text { eff }}\left(\mathrm{m}^{2} \mathrm{~s}^{-1}\right)$ represents the effective membrane water diffusivity between CL and membrane, $S_{\mathrm{mw}}$ $\left(\mathrm{kmol} \mathrm{m}^{-3} \mathrm{~s}^{-1}\right)$ is the membrane water source term (given in Table 2), $\Delta t$ (s) is the time step.

$$
D_{\mathrm{MEM} \_\mathrm{CL}}^{\lambda, \text { eff }}=\frac{\frac{\delta_{\mathrm{CL}}}{2}+\frac{\delta_{\mathrm{MEM}}}{2}}{\frac{\delta_{\mathrm{CL}}}{2} / D_{\mathrm{CL}}^{\lambda, \text { eff }}+\frac{\delta_{\mathrm{MEM}}}{2} / D_{\mathrm{MEM}}^{\lambda, \text { eff }}}
$$

During the cold start process, super-cooled water freezing mechanism is adopted which has been explained in the previous study [41]. The phase change functions, correlations for transport and electrochemical properties can be found in previous studies $[7,41]$.

Table 2. Source terms.

\begin{tabular}{ll}
\hline Source terms. & Unit \\
$S_{\mathrm{mw}}= \begin{cases}S_{\text {react }}-S_{\mathrm{m}-\mathrm{v}}-S_{\mathrm{m}-1}+S_{\text {EOD }} & \text { (in CLc) } \\
-S_{\mathrm{m}-\mathrm{v}}-S_{\mathrm{m}-1}-S_{\text {EOD }} & \text { (in CLa) }\end{cases}$ & $\mathrm{kmol} \mathrm{m}^{-3} \mathrm{~s}^{-1}$
\end{tabular}


$\mathrm{kg} \mathrm{m}^{-3} \mathrm{~s}^{-1}$ $\mathrm{kmol} \mathrm{m} \mathrm{s}^{-3}$ $\mathrm{kg} \mathrm{m}^{-3} \mathrm{~s}^{-1}$ $\mathrm{kg} \mathrm{m}^{-3} \mathrm{~s}^{-1}$ $\mathrm{kmol} \mathrm{m}^{-3} \mathrm{~s}^{-1}$ $\mathrm{kg} \mathrm{m}^{-3} \mathrm{~s}^{-1}$ (in CLa) (in CLc) (in MEM) (in GDL) $\quad \mathrm{W} \mathrm{m}^{-3}$ (in MPL) (in $\mathrm{CH}$ ) (in BP)

Liquid pressure is assumed to be continuous among porous layers since water saturation jump is observed at the interface of adjacent layers [41-44]. Liquid pressure at the center of CL, MPL and GDL are calculated in a similar way. 


$$
p_{1, \mathrm{GDL}}^{t}=p_{\mathrm{l}, \mathrm{GDL}}^{t-\Delta t}+\frac{d p_{1}}{d s_{\mathrm{lq}}}\left[\frac{\left(p_{1, \mathrm{MPL}}^{t-\Delta t}-p_{1, \mathrm{GDL}}^{t-\Delta t}\right) D_{\mathrm{MPL} \_\mathrm{GDL}}^{\mathrm{lq}, \text { eff }}}{\left(\frac{\delta_{\mathrm{MPL}}}{2}+\frac{\delta_{\mathrm{GDL}}}{2}\right) \delta_{\mathrm{GDL}}}-\frac{r_{\mathrm{CH}}\left(p_{1, \mathrm{GDL}}^{t-\Delta t}-p_{1, \mathrm{CH}}^{t-\Delta t}\right) D_{\mathrm{GDL}}^{\mathrm{lq}, \mathrm{eff}}}{\left(\frac{\delta_{\mathrm{GDL}}}{2}\right) \delta_{\mathrm{GDL}}}+S_{\mathrm{lq}}\right] \frac{\Delta t}{\rho_{\mathrm{lq}} \varepsilon_{\mathrm{GDL}}}
$$

where $p_{1, \mathrm{CL}}^{t-\Lambda t}, p_{1, \mathrm{MPL}}^{t-\Delta t}, p_{1, \mathrm{GLL}}^{t-\Delta t}(\mathrm{~Pa})$ are the liquid pressure of CL, MPL, GDL at last time step, $p_{\mathrm{l}, \mathrm{CL}}^{t}, p_{\mathrm{l}, \mathrm{MPL}}^{t}, p_{\mathrm{l}, \mathrm{GDL}}^{t}(\mathrm{~Pa})$ are that of CL, MPL, GDL at next time step, $s_{\mathrm{lq}}$ is the water volume fraction in porous layers, $D_{\text {CL_MPL }}^{\mathrm{lq} \text {, eff }}\left(\mathrm{m}^{2} \mathrm{~s}^{-1}\right)$ is the effective liquid water diffusivity between CL and MPL, $r_{\mathrm{CH}}$ is the ratio between channel area and cell area. If the channel width and the rib width are identical, $r_{\mathrm{CH}}$ is equal to $0.5 . S_{\mathrm{lq}}(\mathrm{kg}$ $\left.\mathrm{m}^{-3} \mathrm{~s}^{-1}\right)$ is the source term. $S_{\text {per }}\left(\mathrm{kg} \mathrm{m}^{-3} \mathrm{~s}^{-1}\right)$ represents the source term of hydraulic permeation caused by liquid pressure difference between anode CL and cathode CL. It should be noted that $S_{\mathrm{lq} \text { flow }}\left(\mathrm{kg} \mathrm{m}^{-3} \mathrm{~s}^{-1}\right)$ represents the amount of liquid water staying in flow channel, which is calculated by the difference of liquid water flowing in and flowing out. $A_{\text {in }}\left(\mathrm{m}^{2}\right)$ is cross-sectional area of channel. $\zeta_{\text {ratio }}$ is the velocity ratio between liquid water and gas in flow channels.

The water volume fraction can be obtained by Leverett-J function once the liquid pressure and the gas pressure are solved. 
$p_{\mathrm{c}}=p_{\mathrm{g}}-p_{1}$

$s_{\mathrm{lq}}^{t}=\frac{1}{1.417}\left[\frac{p_{\mathrm{c}}^{t}}{\sigma \cos (\theta)\left(\frac{\varepsilon}{K^{0}}\right)^{0.5}}+2.12\left(s_{\mathrm{lq}}^{t-\Delta t}\right)^{2}-1.26\left(s_{\mathrm{lq}}^{t-\Delta t}\right)^{3}\right]$

To illustrate liquid water removal process, it is necessary to consider the water volume fraction in flow channels. The capillary pressure in channel is also calculated based on Leverett-J function and it is used to calculate the diffusion term between GDL and channel to guarantee mass conservation. Detailed information about data exchange at GDL/channel interface can be found in previous studies [42-44].

$$
\begin{aligned}
& p_{\mathrm{c}, \mathrm{CHc}}^{t-\Delta t}=\sigma \cos (\theta)\left(\frac{\varepsilon}{K^{0}}\right)^{0.5}\left[1.42 s_{\mathrm{lq}, \mathrm{CHc}}^{t-\Delta t}-2.12\left(s_{\mathrm{lq}, \mathrm{CHc}}^{t-\Delta t}\right)^{2}+1.26\left(s_{\mathrm{lq}, \mathrm{CHc}}^{t-\Delta t}\right)^{3}\right] \\
& s_{\mathrm{lq}, \mathrm{CH}}^{t}=s_{\mathrm{lq}, \mathrm{CH}}^{t-\Delta t}+\left[\frac{\left(p_{\mathrm{l}, \mathrm{GDL}}^{t-\Delta t}-p_{\mathrm{l}, \mathrm{CH}}^{t-\Delta t}\right) D_{\mathrm{GDL}}^{\mathrm{lq}, \text { eff }}}{\left(\frac{\delta_{\mathrm{GDL}}}{2}\right) \delta_{\mathrm{CH}}}+S_{\mathrm{lq}}\right] \frac{\Delta t}{\rho_{\mathrm{lq}}}
\end{aligned}
$$

It is known that super-cooled/liquid water freezes under subzero temperatures, which will decrease effective reaction area and block gas transport passages, resulting in fuel cell performance degradation. During the cold start process, ice volume fraction in porous layers and gas channel are calculated as:

$$
s_{\text {ice }}^{t}=s_{\text {ice }}^{t-\Delta t}+\frac{S_{\text {ice }}}{\varepsilon \rho_{\text {ice }}} \Delta t
$$

where $s_{\text {ice }}^{t-\Delta t}$ is the ice volume fraction at last time step, $s_{\text {ice }}^{t}$ is the ice volume fraction at next time step, $S_{\text {ice }}\left(\mathrm{kg} \mathrm{m}^{-3} \mathrm{~s}^{-1}\right)$ is the source term (given in Table 2).

The gas species include water vapor, hydrogen, oxygen, and nitrogen, which are also updated using the explicit formulation calculation method.

$$
c_{\mathrm{i}, \mathrm{CL}}^{t}=c_{\mathrm{i}, \mathrm{CL}}^{t-\Delta t}+\left[-\frac{\left(c_{\mathrm{i}, \mathrm{CL}}^{t-\Delta t}-c_{\mathrm{i}, \mathrm{MPL}}^{t-\Delta t}\right) D_{\mathrm{CL} \_\mathrm{MPL}}^{\mathrm{i}, \text { eff }}}{\left(\frac{\delta_{\mathrm{CL}}}{2}+\frac{\delta_{\mathrm{MPL}}}{2}\right) \delta_{\mathrm{CL}}}+S_{\mathrm{i}}\right] \frac{\Delta t}{\varepsilon_{\mathrm{CL}}}
$$


where $c_{\mathrm{i}, \mathrm{CL}}^{t-\Delta t}, c_{\mathrm{i}, \mathrm{MPL}}^{t-\Delta t}, c_{\mathrm{i}, \mathrm{GDL}}^{t-\Delta t}, c_{\mathrm{i}, \mathrm{CH}}^{t-\Delta t}\left(\mathrm{~mol} \mathrm{~m} \mathrm{~m}^{-3}\right)$ represent the gas concentration of CL, MPL, GDL, CH at last time step, $c_{\mathrm{i}, \mathrm{CL}}^{t}, c_{\mathrm{i}, \mathrm{MPL}}^{t}, c_{\mathrm{i}, \mathrm{GDL}}^{t}, c_{\mathrm{i}, \mathrm{CH}}^{t}\left(\mathrm{~mol} \mathrm{~m}^{-3}\right)$ represent that of CL, MPL, GDL, $\mathrm{CH}$ at next time step ( $\mathrm{i}=\mathrm{H}_{2}, \mathrm{O}_{2}, \mathrm{~N}_{2}$, water vapor), $S_{\mathrm{i}}\left(\mathrm{mol} \mathrm{m}^{-3} \mathrm{~s}^{-1}\right)$ is the source term of gas species. The effective gas diffusivity between GDL and gas channel $D_{\mathrm{GDL} \_\mathrm{CH}}^{\mathrm{i} \text {, eff }}\left(\mathrm{m}^{2} \mathrm{~s}^{-1}\right)$ is calculated as:

$$
D_{\mathrm{GDL} \_\mathrm{CH}}^{\mathrm{i} \text {,eff }}=\frac{\frac{\delta_{\mathrm{GDL}}}{2}+\frac{\delta_{\mathrm{CH}}}{2}}{\left(\frac{\delta_{\mathrm{GDL}}}{2}\right) / D_{\mathrm{GDL}}^{\mathrm{i} \text {,eff }}+\left(\frac{\delta_{\mathrm{CH}}}{2}\right) /\left(\text { Sher } \cdot D_{\mathrm{CH}}^{\mathrm{i}, \text { eff }}\right)}
$$

where Sher refers to Sherwood number.

Nitrogen crossover phenomenon results from the partial pressure gradient between cathode side and anode side, which may decrease fuel cell performances after long-term operation [49-52]. The nitrogen crossover rate $D_{\mathrm{N}_{2}, \mathrm{MEM}}\left(\mathrm{mol} \mathrm{m}^{-1} \mathrm{~s}^{-1} \mathrm{~Pa}^{-1}\right)$ is calculated as [53]:

$$
D_{\mathrm{N}_{2}, \mathrm{MEM}}=\alpha_{N_{2}}\left(0.0295+1.21 \psi-1.93 \psi^{2}\right) \exp \left[\frac{19830}{R}\left(\frac{1}{303}-\frac{1}{T_{\mathrm{MEM}}}\right)\right]
$$




$$
\psi=\frac{\lambda_{\mathrm{MEM}} V_{\mathrm{H}_{2} \mathrm{O}}}{V_{\mathrm{MEM}}+\lambda_{\mathrm{MEM}} V_{\mathrm{H}_{2} \mathrm{O}}}
$$

where $\psi$ is the water volume fraction in the hydrated membrane. The coefficient $\alpha_{N_{2}}\left(\mathrm{~mol} \mathrm{~m}^{-1} \mathrm{~s}^{-1} \mathrm{~Pa}^{-1}\right)$ is set as $1 \times 10^{-15}$ after validating against the experimental data [54].

Since an air compressor is considered in the system model, it is essential to describe pressure drops in every component. The pressure drop in stack consists of two parts: pressure drop of gas distribution passage inside stack manifolds and pressure drop of straight flow channels in single cell [77].

$$
\frac{\mathrm{d} p}{\mathrm{~d} x}=\frac{4}{D_{h}} f \frac{1}{2} \rho \bar{u}^{2}=\frac{4}{D_{h}} \frac{f \mathrm{Re}_{h}}{\frac{\rho \bar{u} D_{h}}{\mu}} \frac{1}{2} \rho \bar{u}^{-2}=\frac{2}{D_{h}^{2}} f \operatorname{Re}_{h} \mu \bar{u}
$$

where $\mathrm{d} x(\mathrm{~m})$ is the channel length, $D_{h}(\mathrm{~m})$ is the hydraulic diameter, $\bar{u}\left(\mathrm{~m} \mathrm{~s}^{-1}\right)$ is the average velocity, $f$ is the friction factor, $\operatorname{Re}_{h}$ is the Reynolds number. For rectangular flow channels, $f \operatorname{Re}_{h}$ can be calculated as [55]:

$$
f \cdot \operatorname{Re}_{h}=24\left(1-1.3553 \alpha+1.9467 \alpha^{2}-1.7012 \alpha^{3}+0.9564 \alpha^{4}-0.2537 \alpha^{5}\right)
$$

where $\alpha$ represents the length-width ratio of the cross-sectional area.

The temperatures at the center of all layers are updated at each time step.

$$
\begin{aligned}
T_{\mathrm{BP}}^{t}=T_{\mathrm{BP}}^{t-\Delta t}+\left[\frac{\left(T_{\mathrm{CH}}^{t-\Delta t}-T_{\mathrm{BP}}^{t-\Delta t}\right) k_{\mathrm{BP} \_\mathrm{CH}}^{\mathrm{eff}}}{\left(\frac{\delta_{\mathrm{BP}}}{2}+\frac{\delta_{\mathrm{CH}}}{2}\right) \delta_{\mathrm{BP}}}-\frac{h_{\text {cool }}\left(T_{\mathrm{BP}}^{t-\Delta t}-T_{\text {cool }}\right)}{\delta_{\mathrm{BP}}}+S_{\mathrm{T}}\right] \frac{\Delta t}{\rho c_{\mathrm{p}}} \\
T_{\mathrm{CH}}^{t}=T_{\mathrm{CH}}^{t-\Delta t}+\left[\frac{\left(T_{\mathrm{GDL}}^{t-\Delta t}-T_{\mathrm{CH}}^{t-\Delta t}\right) k_{\mathrm{GD} \_\mathrm{CH}}^{\mathrm{eff}}}{\left(\frac{\delta_{\mathrm{CH}}}{2}+\frac{\delta_{\mathrm{GDL}}}{2}\right) \delta_{\mathrm{CH}}}-\frac{\left(T_{\mathrm{CH}}^{t-\Delta t}-T_{\mathrm{BP}}^{t-\Delta t}\right) k_{\mathrm{BP} \_\mathrm{CH}}^{\mathrm{eff}}}{\left(\frac{\delta_{\mathrm{BP}}}{2}+\frac{\delta_{\mathrm{CH}}}{2}\right) \delta_{\mathrm{CH}}}+S_{\mathrm{T}}\right] \frac{\Delta t}{\rho c_{\mathrm{p}}}
\end{aligned}
$$


where $T_{\mathrm{BP}}^{t-\Delta t}, T_{\mathrm{CH}}^{t-\Delta t}, T_{\mathrm{MEM}}^{t-\Delta t}(\mathrm{~K})$ are the temperature of $\mathrm{BP}, \mathrm{CH}, \mathrm{MEM}$ at last time step, $T_{\mathrm{BP}}^{t}, T_{\mathrm{CH}}^{t}, T_{\mathrm{MEM}}^{t}(\mathrm{~K})$ are the temperature of $\mathrm{BP}, \mathrm{CH}, \mathrm{MEM}$ at next time step, $k_{\mathrm{BP} \_\mathrm{CH}}^{\text {eff }}\left(\mathrm{W} \mathrm{m}^{-1} \mathrm{~K}^{-1}\right)$ is the effective thermal conductivity between $\mathrm{BP}$ and flow channel, $h_{\text {cool }}\left(\mathrm{W} \mathrm{m} \mathrm{m}^{-2} \mathrm{~K}^{-1}\right)$ is the heat transfer coefficient between BP and coolant, $S_{\mathrm{T}}\left(\mathrm{W} \mathrm{m}^{-3}\right)$ is the heat source term. $Q_{\text {flow }}\left(\mathrm{W} \mathrm{m}^{-3}\right)$ is the heating/cooling effect since the inlet gas temperature may differ from the fuel cell temperature.

$Q_{\text {flow }}=\frac{A_{\text {in }} \sum_{\mathrm{i}}\left(c_{p} u_{\text {in }} c_{\text {in }} M\left(T_{\mathrm{CH}}-T_{\text {in }}\right)\right)_{\mathrm{i}}}{A_{\text {cell }} \delta_{\mathrm{CH}}}\left(\mathrm{i}=\mathrm{H}_{2}, \mathrm{O}_{2}, \mathrm{~N}_{2}, \mathrm{vp}\right)$

where $u_{\mathrm{in}}\left(\mathrm{m} \mathrm{s}^{-1}\right)$ is the inlet gas velocity, $T_{\text {in }}(\mathrm{K})$ is the inlet gas temperature. It should be noted that the gas temperature is assumed identical as the local layer temperature.

Instead of solving ionic and electronic conservations, the output voltage is calculated based on Tafel equations for simplification. Detailed calculation equations for polarization losses can be found in the reference [7].

$$
\begin{aligned}
& V_{\text {out }}=V_{\text {Nernst }}+V_{\text {act }}+V_{\text {ohmic }}+V_{\text {conc }} \\
& V_{\text {Nernst }}=\frac{\Delta G}{2 F}+\frac{\Delta S}{2 F}\left(T-T_{\text {ref }}\right)+\frac{R T}{2 F}\left[\ln \left(\frac{c_{\mathrm{H}_{2}, \text { CLa }}}{c_{\mathrm{H}_{2}, \text { ref }}}\right)+\frac{1}{2} \ln \left(\frac{c_{\mathrm{O}_{2}, \text { CLC }}}{c_{\mathrm{O}_{2}, \text { ref }}}\right)\right]
\end{aligned}
$$

\subsection{Membrane humidifier model}

The schematic diagram of a planar membrane humidifier is illustrated in Fig.3, consisting of wet/dry channel and proton exchange membrane. Hot and wet exhausted gases from the stack flow into the wet channel while cold and dry reactant gases flow into the dry channel. Water contents on two sides of membrane are influenced by 
water vapor concentration and phase changes. However, phase changes are rarely considered in previous numerical studies [63-65,67], which is important for predicting humidification performances when the inlet vapor concentration is changed. The water transport is coupled with the heat transport, and it is found that the heat transport contributes to the water transport $[63,64]$. The membrane humidifier properties are given in the Appendix A, Table A.1. The governing equations include membrane water, water vapor, and temperature, which are solved using the same method as the PEMFC stack model.

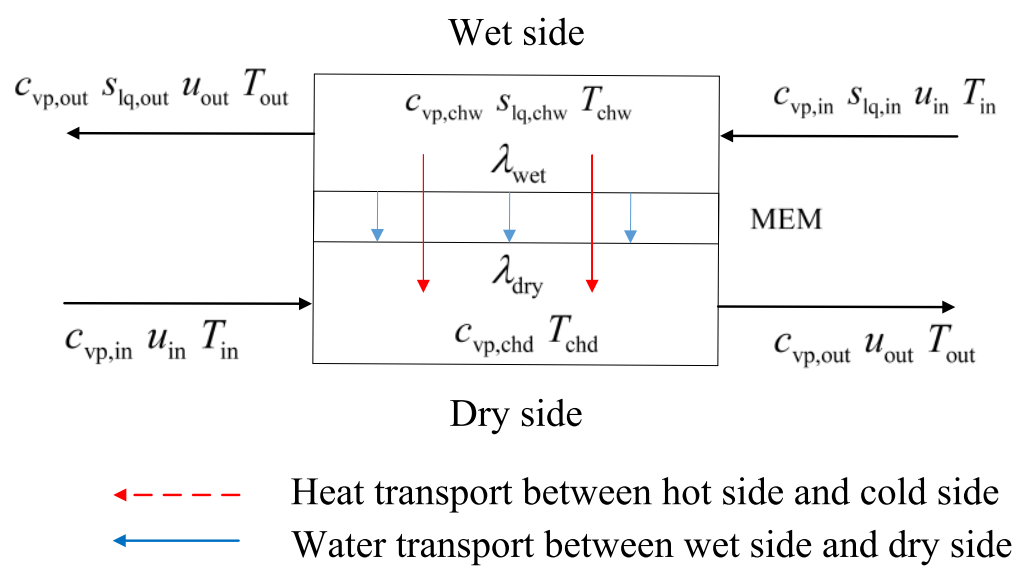

Fig. 3. Schematic diagram of a planar membrane humidifier model.

After discretization and transformation, the membrane water contents at two sides of membrane are calculated as:

$$
\begin{aligned}
& \lambda_{\mathrm{wet}}^{t}=\lambda_{\mathrm{wet}}^{t-\Delta t}+\left[-\frac{\left(\lambda_{\mathrm{wet}}^{t-\Delta t}-\lambda_{\mathrm{dry}}^{t-\Delta t}\right) D_{\mathrm{m}}^{\mathrm{eff}}}{\left(\frac{\delta_{\mathrm{MEM}}}{2}\right) \frac{\delta_{\mathrm{MEM}}}{2}}+S_{\mathrm{MH}, \mathrm{mw}} \frac{E W}{\rho_{\mathrm{MEM}}}\right] \Delta t \\
& \lambda_{\mathrm{dry}}^{t}=\lambda_{\mathrm{dry}}^{t-\Delta t}+\left[\frac{\left(\lambda_{\mathrm{wet}}^{t-\Delta t}-\lambda_{\mathrm{dry}}^{t-\Delta t}\right) D_{\mathrm{m}}^{\mathrm{eff}}}{\left(\frac{\delta_{\mathrm{MEM}}}{2}\right) \frac{\delta_{\mathrm{MEM}}}{2}}+S_{\mathrm{MH}, \mathrm{mw}} \frac{E W}{\rho_{\mathrm{MEM}}}\right] \Delta t
\end{aligned}
$$

where $\lambda_{\text {wet }}^{t-\Delta t}, \lambda_{\mathrm{dry}}^{t-\Delta t}$ are the membrane water content at last time step, $\lambda_{\text {wet }}^{t}, \lambda_{\mathrm{dry}}^{t}$ are membrane water content at next time step, $D_{\mathrm{m}}^{\text {eff }}\left(\mathrm{m}^{2} \mathrm{~s}^{-1}\right)$ is the effective membrane water diffusivity. $S_{\mathrm{MH}, \mathrm{mw}}\left(\mathrm{kmol} \mathrm{m}^{-3} \mathrm{~s}^{-1}\right)$ is the source term (see Appendix A, Table 
The water vapor concentrations in channels are calculated as:

$c_{\mathrm{vp}}^{t}=c_{\mathrm{vp}}^{t-\Delta t}+\left(S_{\mathrm{MH}, \mathrm{vp}}\right) \Delta t$

where $c_{\mathrm{vp}}^{t-\Delta t}\left(\mathrm{~mol} \mathrm{~m}^{-3}\right)$ is the water vapor concentration at last time step, $c_{\mathrm{vp}}^{t}\left(\mathrm{~mol} \mathrm{~m}^{-3}\right)$ is that at next time step, $S_{\mathrm{MH}, \mathrm{vp}}\left(\mathrm{mol} \mathrm{m} \mathrm{m}^{-3} \mathrm{~s}^{-1}\right)$ is the water vapor source term (see Appendix A, Table A.2).

The liquid water volume fraction in the wet channel is calculated as:

$s_{\mathrm{lq}, \mathrm{CHw}}^{t}=s_{\mathrm{lq}, \mathrm{CHw}}^{t-\Delta t}+\left(S_{\mathrm{MH}, \mathrm{lq}}\right) \frac{\Delta t}{\rho_{\mathrm{lq}}}$

where $s_{\mathrm{lq}, \mathrm{CHw}}^{t-\Delta t}$ is the liquid water volume fraction in wet channel at last time step, $S_{\mathrm{lq}, \mathrm{CHw}}^{t}$ is that of the wet channel at next time step, $S_{\mathrm{MH}, \mathrm{lq}}\left(\mathrm{kg} \mathrm{m}^{-3} \mathrm{~s}^{-1}\right)$ is the source term (see Appendix A, Table A.2). It should be noted that the liquid water in dry channel is not considered since the water vapor concentration is hard to reach saturation.

The temperatures at center of channels and membrane are calculated as:

$$
\begin{aligned}
& T_{\mathrm{CHw}}^{t}=T_{\mathrm{CHw}}^{t-\Delta t}+\left(-\frac{\left(T_{\mathrm{CHw}}^{t-\Delta t}-T_{\mathrm{MEM}}^{t-\Delta t}\right) k_{\mathrm{CHw} \_\mathrm{MEM}}^{\text {eff }}}{\left(\frac{\delta_{\mathrm{CHw}}}{2}+\frac{\delta_{\mathrm{MEM}}}{2}\right) \delta_{\mathrm{CHw}}}-\frac{h_{\text {surr }}\left(T_{\mathrm{CHw}}^{t-\Delta t}-T_{\text {surr }}\right)}{\delta_{\mathrm{CHw}}}+S_{\mathrm{T}}\right) \frac{\Delta t}{\rho c_{\mathrm{p}}} \\
& T_{\mathrm{MEM}}^{t}=T_{\mathrm{MEM}}^{t-\Delta t}+\left(\frac{\left(T_{\mathrm{CHw}}^{t-\Delta t}-T_{\mathrm{MEM}}^{t-\Delta t}\right) k_{\mathrm{CHw} \_\mathrm{MEM}}^{\text {eff }}}{\left(\frac{\delta_{\mathrm{CHw}}}{2}+\frac{\delta_{\mathrm{MEM}}}{2}\right) \delta_{\mathrm{MEM}}}-\frac{\left(T_{\mathrm{MEM}}^{t-\Delta t}-T_{\mathrm{CHd}}^{t-\Delta t}\right) k_{\mathrm{MEM} \_\mathrm{CHd}}^{\text {eff }}}{\left(\frac{\delta_{\mathrm{MEM}}}{2}+\frac{\delta_{\mathrm{CHd}}}{2}\right) \delta_{\mathrm{MEM}}}+S_{\mathrm{T}}\right) \frac{\Delta t}{\rho c_{\mathrm{p}}} \\
& T_{\mathrm{CHd}}^{t}=T_{\mathrm{CHd}}^{t-\Delta t}+\left(\frac{\left(T_{\mathrm{MEM}}^{t-\Delta t}-T_{\mathrm{CHd}}^{t-\Delta t}\right) k_{\mathrm{MEM} \_\mathrm{CHd}}^{\mathrm{eff}}}{\left(\frac{\delta_{\mathrm{MEM}}}{2}+\frac{\delta_{\mathrm{CHd}}}{2}\right) \delta_{\mathrm{CHd}}}\right)
\end{aligned}
$$


where $T_{\mathrm{CHw}}^{t-\Delta t}, T_{\mathrm{MEM}}^{t-\Delta t}, T_{\mathrm{CHd}}^{t-\Delta t}(\mathrm{~K})$ are the temperature of wet channel, membrane and dry channel at last time step, $T_{\mathrm{CHw}}^{t}, T_{\mathrm{MEM}}^{t}, T_{\mathrm{CHd}}^{t}(\mathrm{~K})$ are the temperature at next time step, $S_{\mathrm{T}}\left(\mathrm{W} \mathrm{m}^{-3}\right)$ is the heat source term (see Appendix A, Table A.2), $h_{\text {surr }}\left(\mathrm{W} \mathrm{m}^{-2}\right.$ $\mathrm{s}^{-1}$ ) is the heat transfer coefficient between membrane humidifier and surroundings.

\subsection{Electrochemical hydrogen pump model}

The structure of electrochemical hydrogen pump is similar to PEMFC, consisting of $\mathrm{BP}, \mathrm{CH}, \mathrm{GDL}, \mathrm{CL}$, and membrane. The low concentration hydrogen from the stack anode exhausted gases turns into protons and electrons at the three-phase boundary in anode CL. By applying extra voltage, protons are driven to cross the membrane. Subsequently, protons combine with electrons from the external circuit to generate hydrogen in cathode CL. The water vapor is also recirculated owing to phase changes between membrane water and water vapor. The corresponding structural properties are set identical as the stack, and the explicit formulation calculation method is adopted. The governing equations include membrane water, hydrogen, water vapor, and temperature. Detailed calculation methods are given in Appendix B.

The drive voltage of electrochemical hydrogen pump is calculated as:

$$
\begin{aligned}
& V_{\mathrm{HP}, \text { Nernst }}=\frac{R T}{2 F} \ln \left(\frac{p_{\mathrm{HP}, \mathrm{c}}}{p_{\mathrm{HP}, \mathrm{a}}}\right) \\
& V_{\mathrm{HP}}=V_{\mathrm{HP}, \text { Nernst }}+V_{\mathrm{HP}, \text { act }}+V_{\mathrm{HP}, \text { ohmic }}
\end{aligned}
$$

where $\frac{p_{\mathrm{HP}, \mathrm{c}}}{p_{\mathrm{HP}, \mathrm{a}}}$ is the hydrogen pressure ratio between cathode and anode. The real drive voltage is higher than Nernst voltage since activation voltage loss and ohmic voltage loss are inevitable $[57,58]$.

\subsection{Centrifugal air compressor model}

The centrifugal air compressor is commonly adopted in real PEMFC systems owing 
to its high specific power and efficiency. The compressor model consists of two parts: characteristics of compressor and inertance of drive motor. The Rotrex C15-16 centrifugal air compressor is adopted, and the corresponding parameters are taken from reference [62]. Note that the compressor characteristics from the manufacturer is tested at specific operating conditions which may differ from real working conditions, making it necessary to conduct calibrations for better accuracy (see Appendix C).

It is known that the air mass flow rate is determined by both rotating speed and pressure ratio. By applying polynomial fitting method, the function among mass flow rate, pressure ratio, and rotating speed is derived based on a large number of sample data. The multinomial coefficients are given in Appendix C, Table C.1.

$$
\begin{aligned}
& x=\frac{N_{\mathrm{cp}}-1.444 \times 10^{5}}{4.808 \times 10^{4}}, y=\frac{p_{\text {ratio }}-1.726}{0.4504} \\
& m_{\mathrm{air}}=\mathrm{p}_{00}+\mathrm{p}_{10} x+\mathrm{p}_{01} y+\mathrm{p}_{20} x^{2}+\mathrm{p}_{11} x y+\mathrm{p}_{02} y^{2}+\mathrm{p}_{30} x^{3}+\mathrm{p}_{24} x^{2} y+\mathrm{p}_{12} x y^{2}+\mathrm{p}_{03} y^{3} \\
& +\mathrm{p}_{40} x^{4}+\mathrm{p}_{31} x^{3} y+\mathrm{p}_{22} x^{2} y^{2}+\mathrm{p}_{13} x y^{3}+\mathrm{p}_{04} y^{4}+\mathrm{p}_{50} x^{5}+\mathrm{p}_{41} x^{4} y+\mathrm{p}_{32} x^{3} y^{2}+\mathrm{p}_{23} x^{2} y^{3}+\mathrm{p}_{14} x y^{4}+\mathrm{p}_{05} y^{5}
\end{aligned}
$$

However, the surging region and the region exceeding maximum flow rate are also included. Using the same method, the surging line and the maximum flow rate line are acquired.

$$
\begin{aligned}
& p_{\text {surging }}=1.009 \times 10^{4} m_{\text {air }}{ }^{3}+264.5 m_{\text {air }}{ }^{2}+2.469 m_{\text {air }}+1.032 \\
& p_{\text {maxrate }}=445.9 m_{\text {air }}{ }^{3}-68.58 m_{\text {air }}{ }^{2}+5.975 m_{\text {air }}+0.9028
\end{aligned}
$$

The compressor is driven by motor and the inertance of drive motor is calculated as:

$$
\begin{aligned}
& J_{\mathrm{cp}} \frac{d \omega_{\mathrm{cp}}}{d t}=\tau_{\mathrm{cm}}-\tau_{\mathrm{cp}} \\
& \tau_{\mathrm{cm}}=\eta_{\mathrm{cm}} \frac{\kappa_{\mathrm{t}}}{R_{\mathrm{cm}}}\left(\nu_{\mathrm{cm}}-\kappa_{\mathrm{v}} \omega_{\mathrm{cm}}\right) \\
& \tau_{\mathrm{cp}}=\frac{P_{\mathrm{cp}}}{\omega_{\mathrm{cp}}}
\end{aligned}
$$


$P_{\mathrm{cp}}=c_{\mathrm{p}} \frac{T_{\mathrm{p} p, \text { in }}}{\eta_{\mathrm{cp}}}\left[\left(\frac{p_{\mathrm{cp}, \text { out }}}{p_{\mathrm{cp}, \text { in }}}\right)^{\frac{\gamma-1}{\gamma}}-1\right] m_{\mathrm{cp}}$

where $J_{\mathrm{cp}}\left(\mathrm{kg} \mathrm{m}^{2}\right)$ is the inertia of compressor, $\omega_{\mathrm{cp}}\left(\mathrm{rad} \mathrm{s}^{-1}\right)$ is the compressor rotation angular frequency, $\tau_{\mathrm{cm}}(\mathrm{N} \mathrm{m})$ is the drive torque, $\tau_{\mathrm{cp}}(\mathrm{N} \mathrm{m})$ is load torque, $\omega_{\mathrm{cm}}\left(\mathrm{rad} \mathrm{s}^{-1}\right)$ is the rotation angular frequency of drive motor, $v_{\mathrm{cm}}(\mathrm{V})$ is the drive terminal voltage, $P_{\mathrm{cp}}(\mathrm{W})$ is the compressor power consumption.

A simple proportion-integral-derivative (PID) control strategy is adopted to satisfy the required mass flow rate under both steady-state and transient operating conditions. Detailed information about the control strategy and the corresponding calculation procedure is presented in Appendix C. One group of PID parameters is adopted by trial and error: $K_{\mathrm{p}}=1.2, K_{\mathrm{I}}=20, K_{\mathrm{D}}=20$, which shows good performances under both steady-state and transient operating conditions.

\subsection{Ribbon-tubular fin radiator model}

The schematic diagram of a ribbon-tubular fin radiator is shown in Fig. D.1, and the detailed radiator structural properties are given in Appendix D and Table D.1. The effectiveness-NTU method is adopted to calculate outlet temperature since it requires less iteration than the logarithmic mean temperature method. It should be noted that the radiator is simplified into a zero-dimensional model, which focuses on heat transfer processes. The same method has been widely adopted when it comes to the energy analysis of complicated thermal systems $[79,80]$.

The amount of heat released by coolant is equal to that absorbed by air when the radiator is under steady-state operating condition.

$Q=m_{\mathrm{lq}}\left(c_{p}\right)_{\mathrm{lq}}\left(T_{\mathrm{lq}, \text { in }}-T_{\mathrm{lq}, \text { out }}\right)=m_{\text {air }}\left(c_{p}\right)_{\text {air }}\left(T_{\text {air,out }}-T_{\text {air,in }}\right)=A K \Delta t_{\mathrm{m}}$

where $m_{\mathrm{lq}}\left(\mathrm{kg} \mathrm{s}^{-1}\right)$ represents the coolant flow rate, $m_{\text {air }}\left(\mathrm{kg} \mathrm{s}^{-1}\right)$ represents the air 
flow rate, $T_{\mathrm{lq}, \mathrm{in}}(\mathrm{K}), T_{\mathrm{lq}, \mathrm{out}}(\mathrm{K})$ are the inlet and outlet temperature of coolant, $A$ $\left(\mathrm{m}^{2}\right)$ is the overall heat transfer area, $K\left(\mathrm{~W} \mathrm{~m}{ }^{-2} \mathrm{~K}^{-1}\right)$ is the overall heat transfer coefficient which is related to radiator structural properties, $\Delta t_{\mathrm{m}}(\mathrm{K})$ is the average temperature difference, which is determined by the effectiveness of radiator and the maximum temperature difference between coolant and air.

The effectiveness of radiator is defined as the real heat flow rate divided by the theoretically maximum heat flow rate.

$$
\eta=\frac{Q}{Q_{\max }}=\frac{Q}{\operatorname{MIN}\left\{\left(m_{\mathrm{lq}}\left(c_{p}\right)_{\mathrm{lq}}\right),\left(m_{\text {air }}\left(c_{p}\right)_{\text {air }}\right)\right\}\left(T_{\mathrm{lq}, \mathrm{in}}-T_{\text {air,in }}\right)}
$$

In the radiator, two types of fluids move in a cross-flow pattern and there exists no mixture process. The effectiveness is thus calculated as [81]:

$$
\begin{aligned}
& \eta=1-\exp \left\{\frac{N T U^{0.22}}{C^{*}}\left[\exp \left(-C^{*} N T U^{0.78}\right)-1\right]\right\} \\
& N T U=\frac{A K}{\operatorname{MIN}\left\{\left(m_{\mathrm{lq}}\left(c_{p}\right)_{\mathrm{lq}}\right),\left(m_{\mathrm{air}}\left(c_{p}\right)_{\text {air }}\right)\right\}} \\
& C^{*}=\frac{\operatorname{MIN}\left\{\left(m_{\mathrm{lq}}\left(c_{p}\right)_{\mathrm{lq}}\right),\left(m_{\text {air }}\left(c_{p}\right)_{\text {air }}\right)\right\}}{\operatorname{MAX}\left\{\left(m_{\mathrm{lq}}\left(c_{p}\right)_{\mathrm{lq}}\right),\left(m_{\text {air }}\left(c_{p}\right)_{\text {air }}\right)\right\}}
\end{aligned}
$$

The overall heat transfer coefficient consists of three parts, including heat convection between coolant and tube, heat conduction inside tube wall and heat convection between tube and air.

$$
\frac{1}{A K}=\frac{1}{h_{1} A_{1}}+\frac{\delta}{\lambda_{\mathrm{t}} A_{1}}+\frac{1}{h_{\mathrm{a}} A_{\mathrm{a}} \eta_{0}}
$$

where $h_{1}\left(\mathrm{~W} \mathrm{~m}^{-2} \mathrm{~K}^{-1}\right), A_{1}\left(\mathrm{~m}^{2}\right)$ are the heat transfer coefficient and effective area between coolant and tube, $\lambda_{\mathrm{t}}\left(\mathrm{W} \mathrm{m} \mathrm{m}^{-1} \mathrm{~K}^{-1}\right)$ is the heat conduction coefficient of tube wall, $h_{\mathrm{a}}\left(\mathrm{W} \mathrm{m} \mathrm{K}^{-1}\right), A_{\mathrm{a}}\left(\mathrm{m}^{2}\right)$ are the heat transfer coefficient and effective area between tube and air, respectively. Detailed calculation methods of the above 
coefficients are presented in Appendix D.

\subsection{Boundary and initial conditions}

In the study, the ambient temperature and pressure are $25^{\circ} \mathrm{C}, 101325 \mathrm{~Pa}$. The required air and hydrogen mass flow rate are calculated based on Faraday's law.

$$
m_{\text {air }}^{\text {req }}=\frac{N_{\text {stack }} I A_{\text {cell }} \xi_{\mathrm{c}} M_{\text {air }}}{4 F \times 0.21 \times 1000}, \quad m_{\mathrm{H}_{2}}^{\text {req }}=\frac{N_{\text {stack }} I A_{\text {cell }} \xi_{\mathrm{a}} M_{\mathrm{H}_{2}}}{2 F \times 1000}
$$

where $N_{\text {stack }}$ is the number of single fuel cells, $\xi_{\mathrm{a}}, \xi_{\mathrm{c}}$ are the anode and cathode stoichiometry, respectively.

The stack is operated under the constant current mode, indicating that each individual fuel cell is operated with the same current. In a single cell, local current density varies in the flow direction because reactant concentrations keep decreasing from upstream towards downstream. Since bipolar plate has good electrical conductivity, it is more reasonable to assume that voltage among different nodes are identical rather than assuming uniform current density distribution. The local current density is obtained by solving the system of nonlinear equations.

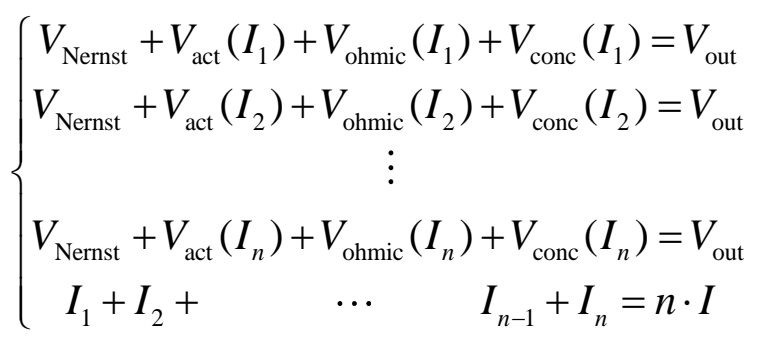

where $n$ represents the node number in the flow direction.

It should be noted that the boundary conditions of all sub-models are interrelated, including temperature, pressure, and mass flow rate. The stack cathode inlet gases are set the same as the humidifier dry channel outlet gases. The hydrogen temperature after pressure regulating valve is set identical as surrounding temperature. The stack anode inlet gas temperature is calculated as the mixing temperature between pure hydrogen from the high-pressure tank and cathode outlet gases from the 
As for membrane humidifier, the wet channel inlet gases and water saturation are set the same as that of stack cathode exhaust. The real air mass flow rate and pressure flowing into humidifier dry channel are determined by the air compressor model. The high-temperature air after compression needs to be cooled down before it enters the humidifier to avoid membrane dehydration. Thus, the air temperature after radiator is set as $30^{\circ} \mathrm{C}$. The heat loss to environment is also considered since there is no assisted equipment to maintain its operating temperature in the study.

$Q_{\mathrm{MH}, \text { loss }}=h_{\text {surr }} A_{\mathrm{MH}}\left(T_{\mathrm{MH}}-T_{\text {surr }}\right)$

As for hydrogen pump, the anode inlet gases are set identical as the stack anode exhausted gases. Convective heat loss to environment is taken into account.

$$
Q_{\mathrm{HP}, \text { loss }}=h_{\text {surr }} A_{\mathrm{HP}}\left(T_{\mathrm{HP}, \mathrm{BP}}-T_{\text {surr }}\right)
$$

For stack, membrane humidifier, and hydrogen pump, the explicit formulation calculation equations are updated with a time step of $1 \times 10^{-6} \mathrm{~s}$ to simultaneously guarantee accuracy and calculation efficiency. Increasing the time step leads to calculation divergence of gas species, and further decreasing the time step contributes negligibly.

The initial liquid water volume fraction is zero and the initial membrane water content is set as 6.0. The initial temperatures of all subsystems are set as surrounding temperature. The air filter causes 5\% atmospheric pressure drop. For air compressor model, the response interval of drive motor is set as $0.1 \mathrm{~s}$ and the time delay of PID control signal is not considered. For radiator model, the inlet air temperature and initial coolant temperature are set the same as environment. The total coolant and air 
mass flow rate are set as $1.5,2.0 \mathrm{~kg} \mathrm{~s}^{-1}$, respectively. The water tank temperature is assumed to be the same as coolant temperature because heat capacity of tank is not considered. All sub-models are developed in Matlab 2018a with user defined function files and a powerful workstation is adopted to conduct simulations.

\section{Results and discussion}

\subsection{Model validation}

To guarantee the system model accuracy, all sub-models have been rigorously validated against experimental data. However, it is impractical to validate the whole system model because such complicated and detailed PEMFC system is rarely presented in literature. As regards proton exchange membrane fuel cell (PEMFC) stack model, grid independence study is firstly conducted to show influences of the node number in the flow direction. The main simulation results such as output voltage, water volume fraction in cathode catalyst layer (CL), and cathode outlet gas velocity are compared (shown in Fig. 4(a)). It is found that three nodes are enough to guarantee the calculation accuracy (within $\pm 0.5 \%$ when compared with ten nodes). To reflect more transport details from the channel upstream to downstream, the node number is eventually set as 5 in the study. Furthermore, the stack model has been validated against experimental data under both steady-state and transient operating conditions. In Fig. 4(b), the output voltage and ohmic voltage are compared simultaneously under various cathode RH cases $(66 \%, 100 \%)$ [27], which shows good agreement. The inlet gas temperature, fuel cell temperature, and anode relative humidity (RH) are given at $80^{\circ} \mathrm{C}, 80{ }^{\circ} \mathrm{C}, 100 \%$. In Fig. 4(c), the simulation results are compared with experimental data from authors' laboratory during the startup from $-10{ }^{\circ} \mathrm{C}$ and $-5{ }^{\circ} \mathrm{C}$, which also demonstrates reasonable agreement. The effective cell area is $25 \mathrm{~cm}^{2}$, membrane thickness is $50.8 \mu \mathrm{m}$, operating current is $2.5 \mathrm{~A}$, anode and cathode operating pressure are $1.0 \mathrm{~atm}$, dry hydrogen and air are supplied at $0.5,1.5$ SLPM. The initial membrane water content is set according to high frequency resistance measurement. It should be noted that the output voltage varies from 
experimental data although the ohmic voltage matches well in the beginning, which indicates that the voltage difference comes from the activation voltage loss. It is inferred that the effective cell area may increase with the membrane becoming wetter during the cold start process. In other words, the effective area could be much smaller than the nominal cell area since the membrane is initially dry after the long-term purging, which leads to larger current density and lower output voltage in reality.

The planar membrane humidifier $(\mathrm{MH})$ model has also been compared with experimental data in literature $[63,68]$. In Fig. 4(d), the water recovery ratio under various operating temperatures and pressures are presented [63]. The inlet RH of wet channel is $100 \%$ and the corresponding flow rate is 100 SLPM. In Fig. 4(e), the water vapor transfer rate is compared under various air mass flow rates [68]. The inlet gas temperature of wet channel is given at $70{ }^{\circ} \mathrm{C}$. The inlet $\mathrm{RH}$ of wet channel and dry channel are $100 \%, 60 \%$, respectively. The validation of electrochemical hydrogen pump against experimental data [58] is shown in Fig. 4(f), where polarization curves at different $\mathrm{CO}_{2} / \mathrm{H}_{2}$ ratios are compared. The membrane surface area is $1.9 \mathrm{~cm}^{2}$. Fully humidified $\mathrm{CO}_{2} / \mathrm{H}_{2}$ gas is fed into the anode gas channel at $50{ }^{\circ} \mathrm{C}$. Fig. $4(\mathrm{~g})$ shows the steady-state performance and dynamic response of the air compressor model under the aforementioned PID control strategy, indicating that the compressor model is capable of satisfying the required air mass flow rate. In Fig. 4(h), the coolant outlet temperature with different air mass flow rates is compared with the experimental data in [78]. The coolant is supplied at 1.00,1.33, $1.67 \mathrm{~kg} \mathrm{~s}^{-1}$ with an inlet temperature of $92{ }^{\circ} \mathrm{C}$, and the inlet air temperature is given at $32{ }^{\circ} \mathrm{C}$. 


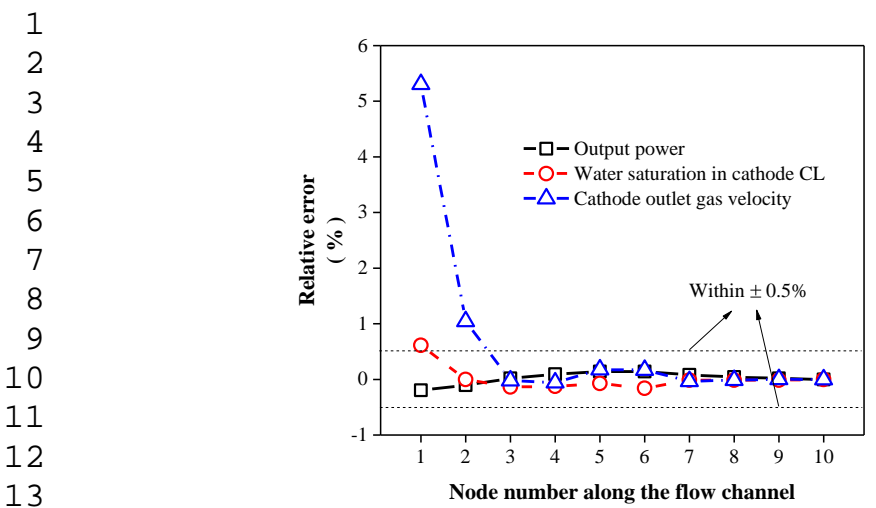

(a)

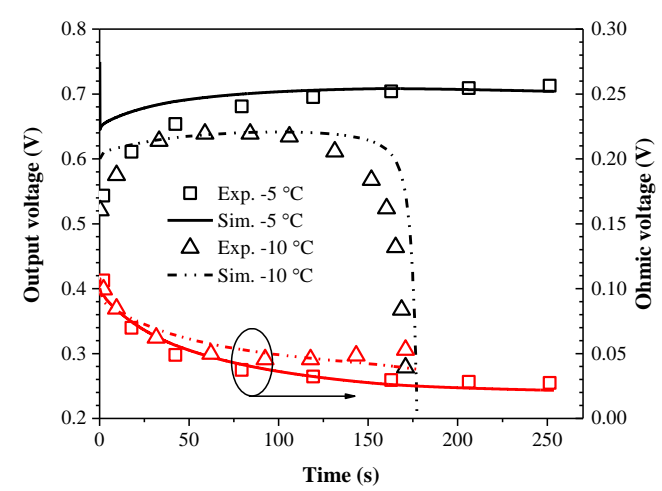

(c)

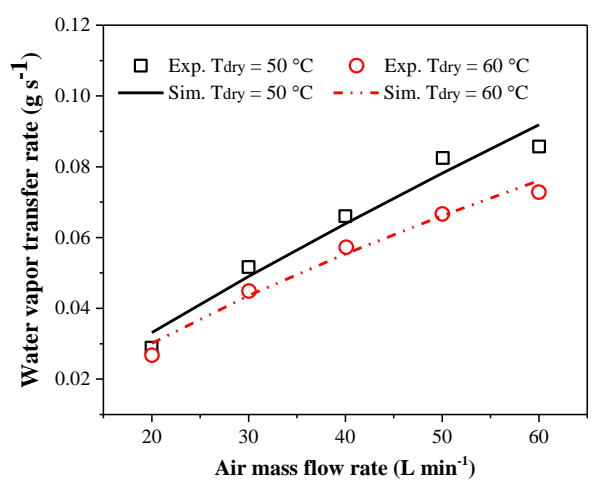

(e)

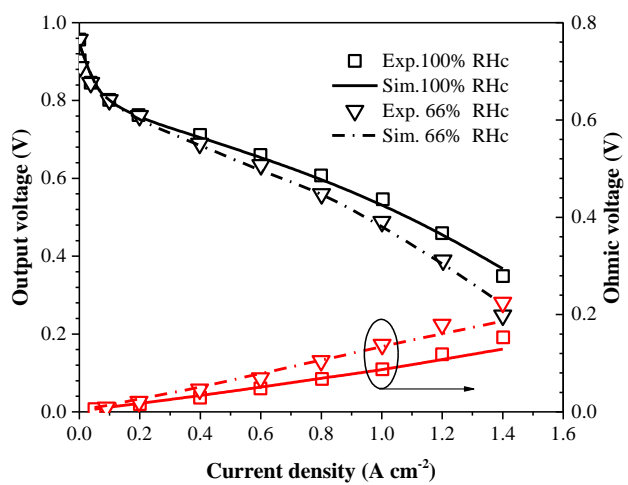

(b)

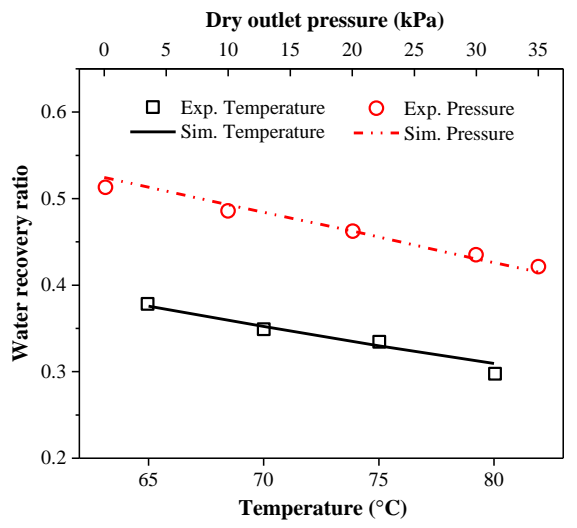

(d)

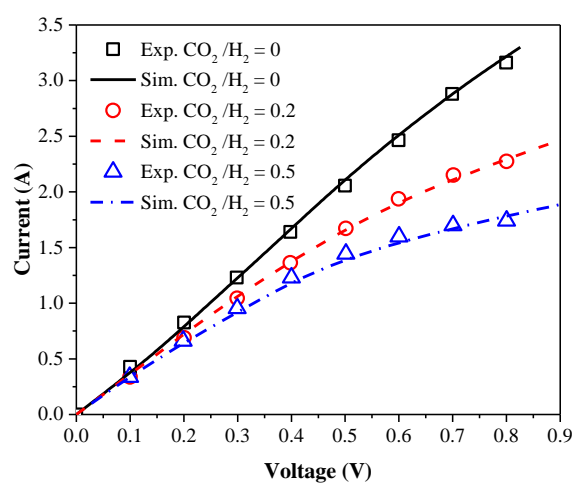

(f) 


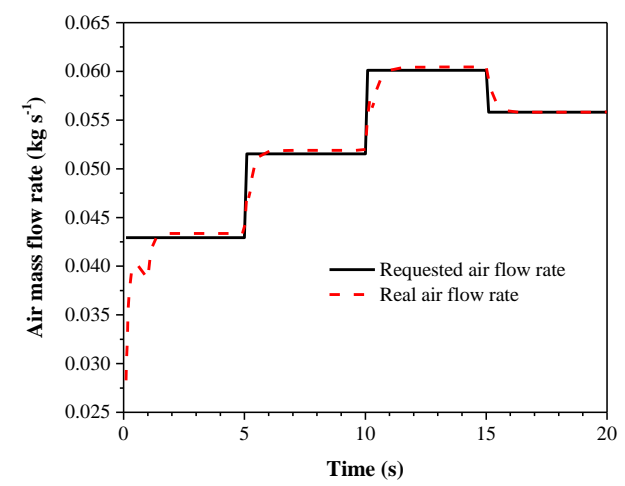

(g)

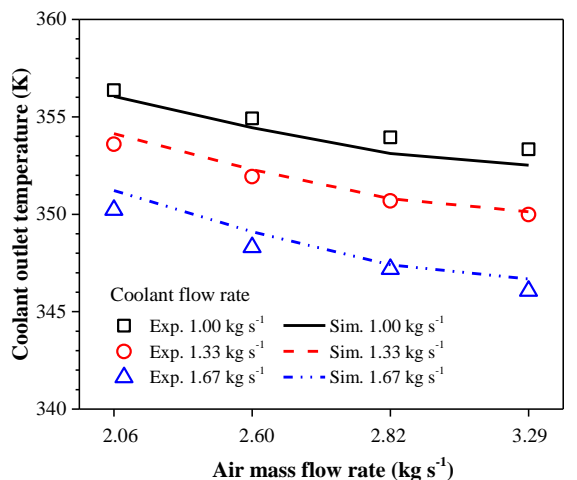

(h)

Fig. 4. Comparison between simulation results and experimental data. (a) PEMFC. Grid independence study. (b) PEMFC. Output voltage and ohmic voltage under different cathode humidification [27]. (c) PEMFC. Cold start performance under different subzero temperatures. (d) MH. Water recovery ratio with different operating conditions [63]. (e) MH. Water transfer rate with various inlet gas temperatures [68]. (f) HP. Polarization curve with different $\mathrm{CO}_{2} / \mathrm{H}_{2}$ ratios [58]. (g) Air compressor. Dynamic response and steady-state performance under the PID control strategy. (h) Radiator. Coolant outlet temperature with various air mass flow rates [78].

\subsection{Effects of stack operating temperature}

Unless otherwise noted, the current density is $1.2 \mathrm{~A} \mathrm{~cm}^{-2}$ and counter-current flow is adopted for the PEMFC stack. Since reactant gases and coolant are assumed to be uniformly distributed, there exists negligible performance differences among individual fuel cells in the simulation results. In the following results, the output performance and parameter distribution of the middle fuel cell in the stack is presented for comparison. Several typical cases are chosen to demonstrate the novelty of system model. Fig. 5 shows the cell voltage under different stack operating temperatures $\left(60^{\circ} \mathrm{C}, 70^{\circ} \mathrm{C}, 80^{\circ} \mathrm{C}\right)$. It should be noted that the required operating temperature is guaranteed by the heat management subsystem, in which a temperature trigger is set. Coolant pump works when the maximum cathode CL temperature exceeds the upper limit, and it stops when the maximum cathode CL temperature 
drops below the lower limit. To avoid large temperature fluctuation and frequent coolant pump switch, the trigger is set as $\pm 0.5{ }^{\circ} \mathrm{C}$. In Fig. 5 , there is a sharp voltage drop in the first $5 \mathrm{~s}$, which is caused by the electro-osmotic drag effect. The output voltage increases gradually as the membrane electrode assembly (MEA) gets wetter owing to the electrochemically generated water. Besides, the rising cell temperature also contributes to performance improvement since the initial stack temperature is set identical as surroundings. During the temperature increment period, there exists no apparent cell voltage difference. However, the output voltage varies drastically after $40 \mathrm{~s}$. Higher voltage drop is observed when it comes to higher operating temperature, which is consistent with the previous study [82]. It can be inferred that there must be negative conditions which decreases stack performances since increasing operating temperature is beneficial to the electrochemical reactions.

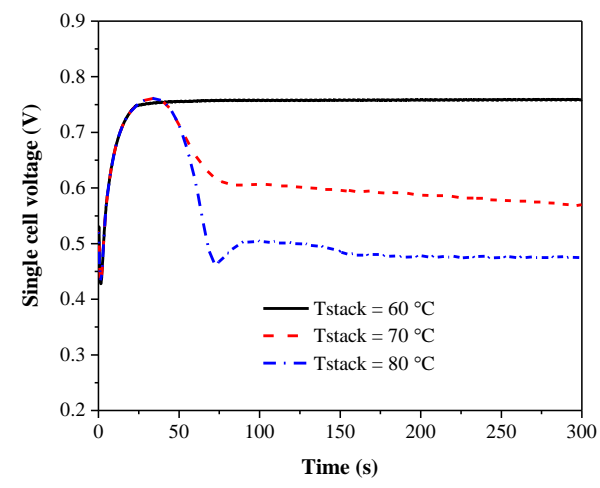

Fig. 5. Single cell output voltage under different stack operating temperatures.

Fig. 6 depicts the membrane water distribution inside fuel cell and membrane humidifier. It can be noticed that the membrane begins to dehydrate at approximately $40 \mathrm{~s}$ when the stack is operated at $70^{\circ} \mathrm{C}$ and $80^{\circ} \mathrm{C}$ (shown in Fig. 6(a)), indicating that the stack is likely to suffer from membrane dehydration. Poor membrane hydration reduces the ionic conductivity, resulting in more ohmic voltage loss and less output voltage. The membrane is better hydrated in the anode downstream in the case of $60^{\circ} \mathrm{C}$ while it is wetter in the anode upstream in the case of $70{ }^{\circ} \mathrm{C}$, indicating that the membrane water distribution depends on operating conditions. The fuel cell cathode 


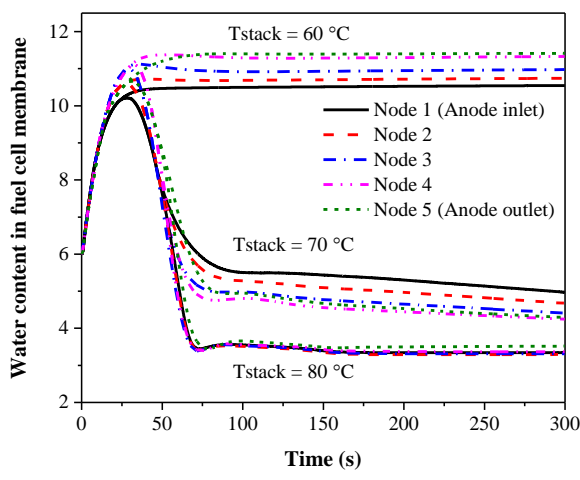

(a)

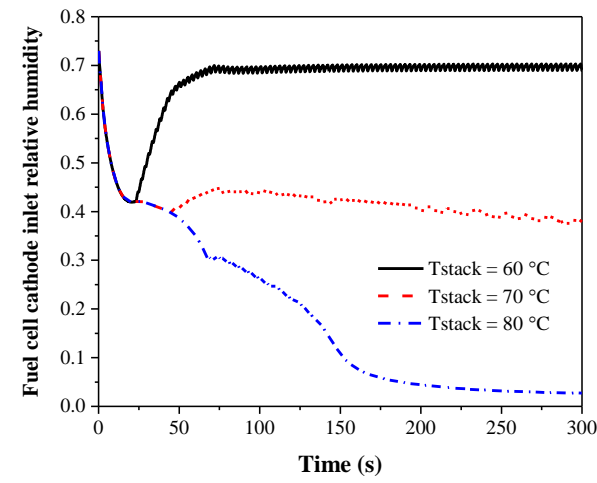

(b) 


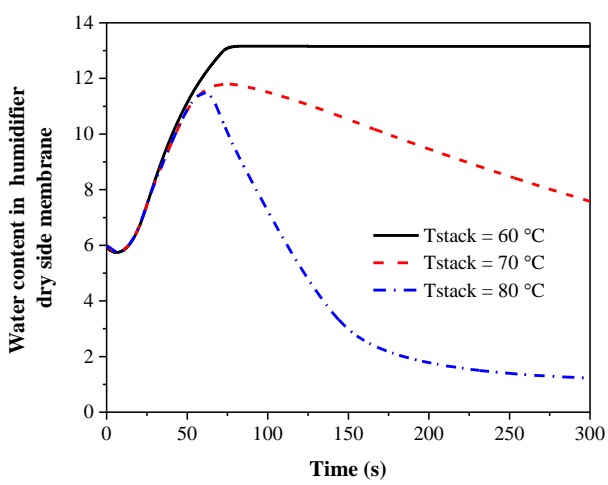

(c)

Fig. 6. Water distribution inside fuel cell and membrane humidifier under various stack operating temperatures. (a) Water content in fuel cell membrane. (b) Fuel cell cathode inlet relative humidity. (c) Water content in humidifier dry side membrane.

Fig. 7 shows the temperature distribution inside fuel cell and membrane humidifier under various stack operating temperatures. The cathode CL temperature is presented because it is usually the highest among all layers. In Fig. 7(a), it can be observed that the highest CL temperature slightly fluctuates around the required operating temperature, indicating good accuracy and reliability of the aforementioned temperature control strategy. The local CL temperature varies from the channel upstream to downstream, which is mainly caused by the uneven local current density distribution. The humidifier membrane temperature is presented in Fig. 7(b). When the stack is operated at higher temperatures, the humidifier is also stabilized at higher temperatures as a consequence of the inlet gas heating effect. The temperature increment of humidifier is much slower than the stack, indicating a longer startup period. Besides, the stabilized humidifier temperature is much lower than the stack since there exist no electrochemical reactions. It can be inferred that assisted heating method may be necessary to reduce temperature differences between the membrane humidifier and the stack. 


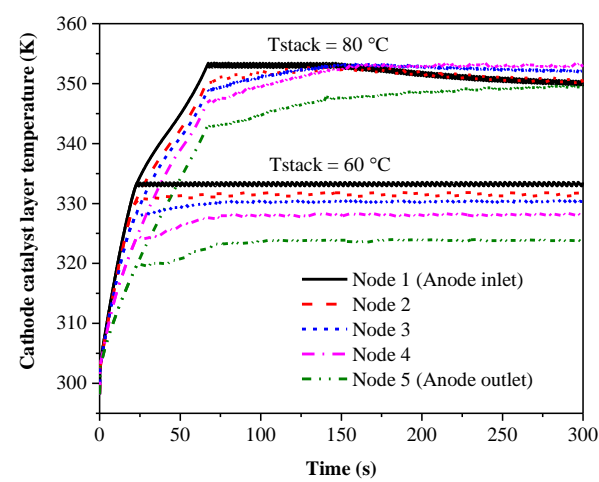

(a)

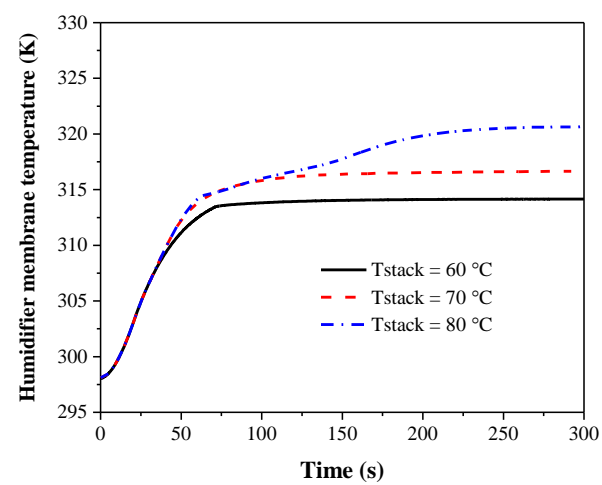

(b)

Fig. 7. Temperature distribution inside fuel cell and membrane humidifier under various stack operating temperatures. (a) Cathode catalyst layer temperature. (b) Humidifier membrane temperature.

\subsection{Effects of gas flow pattern}

Co-current flow and counter-current flow of the PEMFC stack are compared, including output performance, cathode inlet $\mathrm{RH}$, temperature, and water vapor distribution. The single fuel cell voltage is presented in Fig. 8(a). When the stack is operated at $60{ }^{\circ} \mathrm{C}$ and $80^{\circ} \mathrm{C}$, counter-current flow results in slightly better performance, however, co-current flow leads to $0.1 \mathrm{~V}$ higher output voltage at $70{ }^{\circ} \mathrm{C}$. To illustrate voltage differences, the fuel cell cathode inlet RH is demonstrated in Fig. 8(b) since it has great influences on stack performances. It can be clearly observed that co-current flow contributes to higher inlet RH under various temperatures. The increase in the inlet RH leads to significant voltage improvement at $70{ }^{\circ} \mathrm{C}$, however, it does not result in further performance enhancement at $60{ }^{\circ} \mathrm{C}$. It can be inferred that the stack becomes less dependent on reactant gases humidification as the operating temperature decreases. Further increasing the inlet RH contributes negligibly once it has met the requirement of keeping the membrane hydrated. Similar results about humidification level have also been observed in the previous study [82]. Meanwhile, slightly increment of gas humidification results in negligible improvement since it is woefully inadequate at $80{ }^{\circ} \mathrm{C}$. The reason why counter-current flow still behaves better with lower inlet RH is because counter-current flow may improve the heat and mass 


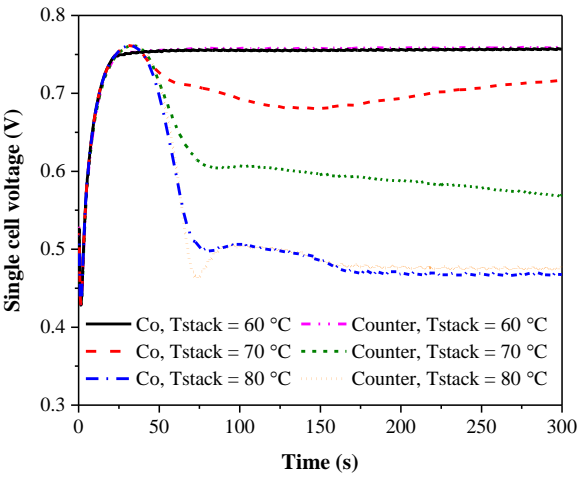

(a)

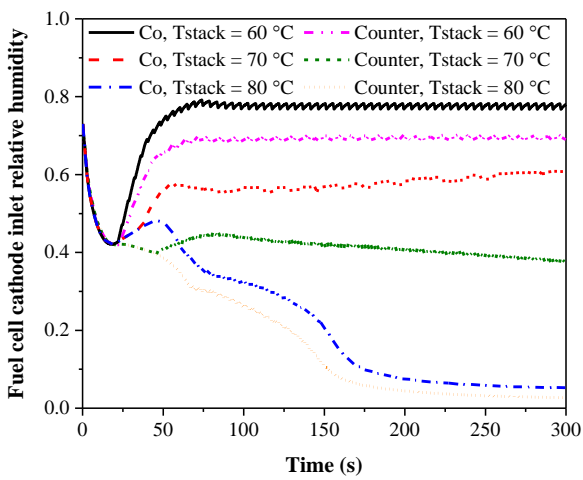

(b)

Fig. 8. Effects of gas flow pattern on system performances. (a) Output voltage. (b)

Fuel cell cathode inlet relative humidity.

Fig. 9 shows the cathode water vapor concentration and temperature distribution at $80{ }^{\circ} \mathrm{C}$, and the contour maps are plotted at $300 \mathrm{~s}$. It should be noticed that component layer thicknesses in the figure are not to scale as reality. As shown in Fig. 9(a), the largest temperature difference reaches appropriately $20^{\circ} \mathrm{C}$ in the co-current flow mode while it is about $10{ }^{\circ} \mathrm{C}$ in the counter-current mode. As stated previously, the inlet reactant temperatures are decided by the corresponding auxiliary sub-models. The temperature of membrane humidifier is much lower than the stack as shown in Fig. 7(b), indicating that the humidified air has cooling effects on the stack temperature. Therefore, the cell temperature at the inlet region of gas channel in the co-current flow mode is obviously lower. Counter-current flow is more beneficial since it significantly contributes to temperature uniformity from the channel upstream to downstream, which is of great importance for fuel cell durability. The cathode water vapor distribution in porous layers and flow channel is presented in Fig. 9(b). Not only does it illustrate the effects of gas flow pattern on the water vapor transport inside fuel cell, it also reveals the effects on water utilization in the whole system. In 
co-current flow mode, the water vapor accumulation phenomenon is obvious since hydrogen and air move in the same direction, which results in higher outlet water vapor concentration. The water vapor concentration in the counter-current flow is smaller than that in the co-current flow mode, however, it is more evenly distributed, which reflects better membrane hydration uniformity. In the system, the water transport and utilization are fully coupled. Lower cathode outlet vapor concentration results in lower inlet RH of the humidifier wet channel, thus decreasing the humidifier dry channel outlet water vapor concentration. Consequently, the cathode inlet RH of the stack is reduced, which results in more severe membrane dehydration. In general, counter-current flow has positive effects on the distribution uniformity inside fuel cell while co-current flow contributes to better water utilization at a system level. Note that only a few cases are presented in the study. Once the insufficient reactant gases humidification problem is solved, counter-current flow of the PEMFC stack may generate better output voltage than co-current flow mode.

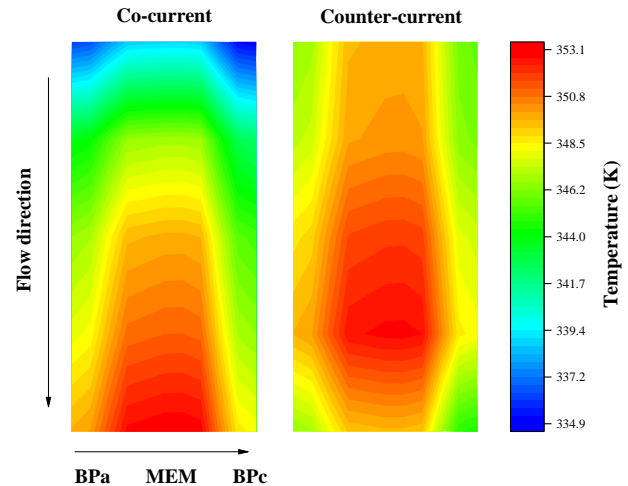

(a)

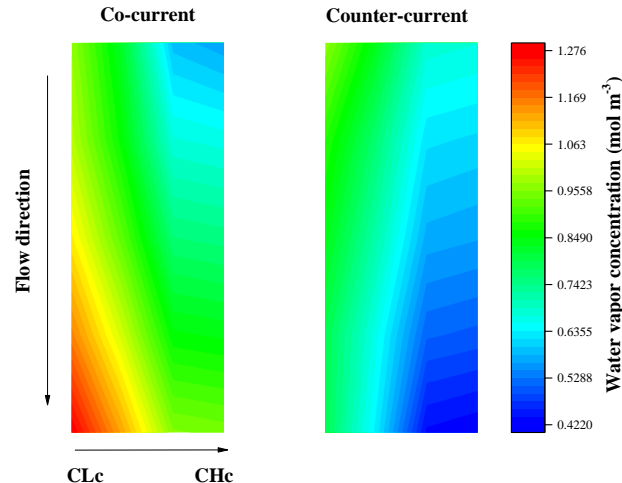

(b)

Fig. 9. Effects of gas flow pattern on temperature and water vapor distribution, $T_{\text {stack }}=$ $80{ }^{\circ} \mathrm{C}, t=300 \mathrm{~s}$. (a) Temperature. (b) Cathode water vapor concentration.

\subsection{Effects of membrane humidifier design}

The effects of membrane humidifier design are investigated since the stack is likely to suffer from membrane dehydration at high operating temperatures. Improving the humidifier performance may help alleviate the fuel cell dehydration phenomenon. Fig. 
10(a) shows the single cell voltage under various membrane humidifier areas. It is observed that doubling or halving humidifier area has negligible influences on stack performances at $60{ }^{\circ} \mathrm{C}$ while it results in significant performance variations at $70{ }^{\circ} \mathrm{C}$ When the stack operating temperature is further increased to $80^{\circ} \mathrm{C}$, the influences of humidifier area become less conspicuous. The water vapor transfer rate is demonstrated in Fig. 10(b) with the operating temperature equal to $60^{\circ} \mathrm{C}$. In a system model, the water transfer in membrane humidifier is coupled with cathode outlet vapor concentration of the stack. It is necessary to keep the inlet gases unchanged to investigate the humidifier design on its humidification performance and that is the reason why $60{ }^{\circ} \mathrm{C}$ is selected. Extended gas resident time in flow channels is the reason that larger humidifier area enhances the water vapor transfer rate after long-term operation, which is consistent with the previous study [68]. However, the transfer rate rises more rapidly with smaller humidifier area as indicated by larger curve slopes in Fig. 10(b). To reflect the water absorption and desorption process inside humidifier, phase changes between vapor and membrane water are considered by assuming reasonable phase change rates. It is the reason why longer time is taken to reach the same water vapor transfer rate with a larger humidifier area. It is found that optimizing membrane humidifier area does not fundamentally solve the membrane dehydration problem under high operating temperatures, indicating that further investigation should be conducted for better understanding.

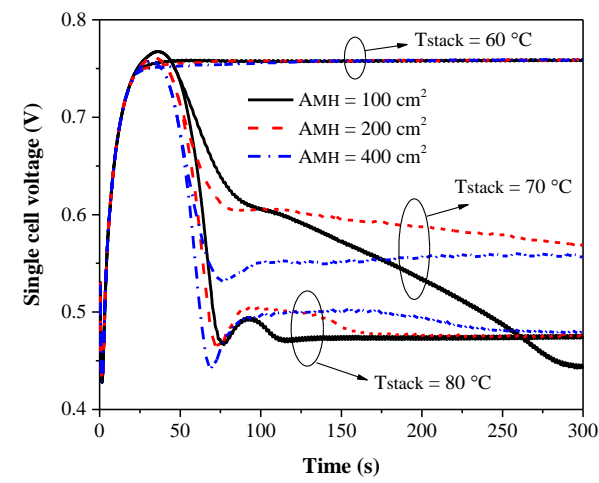

(a)

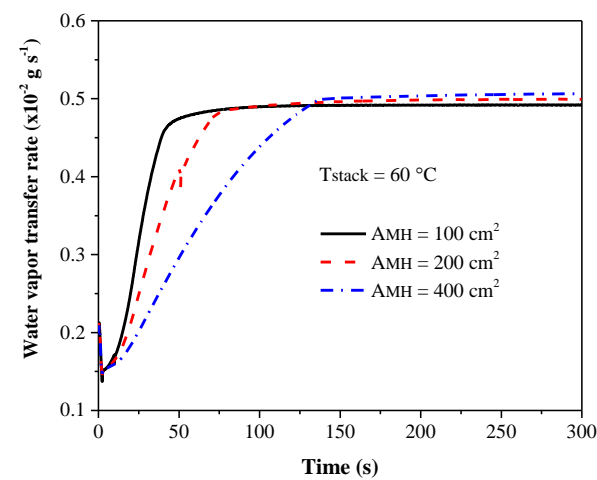

(b)

Fig. 10. Effects of membrane humidifier design on system performance. (a) Single cell voltage under various humidifier area. (b) Water vapor transfer rate, $T_{\text {stack }}=60^{\circ} \mathrm{C}$. 


\section{Conclusion}

A comprehensive proton exchange membrane fuel cell (PEMFC) system model, consisting of stack, membrane humidifier, electrochemical hydrogen pump, air compressor and radiator, is developed under both steady-state and transient operating conditions. Nitrogen crossover, water saturation in flow channels, and phase changes among water/ice/vapor are integrated in the stack model. The governing equations about auxiliary subsystems are also explained in detail. All sub-models have been rigorously validated against experimental data to guarantee the system model accuracy. The effects of stack operating temperature, gas flow pattern, and humidifier structural design are investigated at a system level to study the interaction among the stack and auxiliary subsystems. The results indicate that the stack is successfully maintained at required operating temperatures $\left(60{ }^{\circ} \mathrm{C}, 70^{\circ} \mathrm{C}, 80^{\circ} \mathrm{C}\right)$ with help of the radiator when the whole system starts from ambient temperature $\left(25^{\circ} \mathrm{C}\right)$. However, over $20{ }^{\circ} \mathrm{C}$ temperature difference is observed between the membrane humidifier and the stack, indicating that assisted heating methods may be necessary for humidifier during long-term operation. The PEMFC stack is likely to suffer from membrane dehydration when the operating temperature is $70{ }^{\circ} \mathrm{C}$, and the problem becomes more severe at $80{ }^{\circ} \mathrm{C}$. The water content in stack is strongly affected by the inlet gases humidification. Meanwhile, the membrane humidifier relies on stack cathode exhaust gases to humidify dry inlet gases, leading to the coupled water management issue at a system level. In comparison, the counter-current flow pattern has positive effects on reducing temperature gradient inside the fuel cell while the co-current flow pattern contributes to better water utilization of the whole system, which may lead to higher output performances. As regards the membrane dehydration under high operating temperatures, it is found that optimizing membrane humidifier area does not fundamentally solve the problem. Increasing humidifier area contributes to higher water vapor transfer rate, however, it results in much slower humidification responses.

\section{Acknowledgements}


This work is supported by the National Key Research and Development Program of China (2018YFB0105500), the National Natural Science Foundation of China (grant No. 51976138), and the China-UK International Cooperation and Exchange Project (Newton Advanced Fellowship) jointly supported by the National Natural Science Foundation of China (grant No. 51861130359) and the UK Royal Society (grant No. NAF\R1\180146).

\section{References}

[1] Ellis M W, Von Spakovsky M R, Nelson D J. Fuel cell systems: efficient, flexible energy conversion for the 21st century. Proc IEEE, 2001, 89(12): 1808-1818. doi:10.1109/5.975914.

[2] Wu H W. A review of recent development: Transport and performance modeling of PEM fuel cells. Appl Energy, 2016, 165: 81-106. https://doi.org/10.1016/j.apenergy.2015.12.075

[3] Ji M, Wei Z. A review of water management in polymer electrolyte membrane fuel cells. Energies, 2009, 2(4): 1057-1106. https://doi.org/10.3390/en20401057

[4] Jiao K, Li X. Water transport in polymer electrolyte membrane fuel cells. Prog Energy Combust Sci, 2011, 37(3): 221-291. https://doi.org/10.1016/j.pecs.2010.06.002

[5] Spiegel C. PEM fuel cell modeling and simulation using MATLAB. Elsevier, 2011.

[6] Dicks A, Rand D A J. Fuel cell systems explained. Wiley, 2018.

[7] Yang Z, Du Q, Jia Z, et al. Effects of operating conditions on water and heat management by a transient multi-dimensional PEMFC system model. Energy, 2019. https://doi.org/10.1016/j.energy.2019.06.148

[8] Kim M, Sohn Y J, Cho C W, et al. Customized design for the ejector to recirculate a humidified hydrogen fuel in a submarine PEMFC. J Power Sources, 2008, 176(2): 529-533. https://doi.org/10.1016/j.jpowsour.2007.08.069

[9] Yin Y, Fan M, Jiao K, et al. Numerical investigation of an ejector for anode recirculation in proton exchange membrane fuel cell system. Energy Convers 
Manag, 2016, 126: 1106-1117. https://doi.org/10.1016/j.enconman.2016.09.024

[10]Barbir F, Görgün H. Electrochemical hydrogen pump for recirculation of hydrogen in a fuel cell stack. J appl electrochem, 2007, 37(3): 359-365. doi:10.1007/s10800-006-9266-0.

[11] Onda K, Araki T, Ichihara K, et al. Treatment of low concentration hydrogen by electrochemical pump or proton exchange membrane fuel cell. J Power Sources, 2009, 188(1): 1-7. https://doi.org/10.1016/j.jpowsour.2008.11.135

[12]Cheng X, Shi Z, Glass N, et al. A review of PEM hydrogen fuel cell contamination: Impacts, mechanisms, and mitigation. J Power Sources, 2007, 165(2): 739-756. https://doi.org/10.1016/j.jpowsour.2006.12.012

[13]Nagahara Y, Sugawara S, Shinohara K. The impact of air contaminants on PEMFC performance and durability. J Power Sources, 2008, 182(2): 422-428. https://doi.org/10.1016/j.jpowsour.2007.12.091

[14]Zamel N, Li X. Effect of contaminants on polymer electrolyte membrane fuel cells. Prog Energy Combust Sci, 2011, 37(3): 292-329. https://doi.org/10.1016/j.pecs.2010.06.003

[15]Zhang J, Tang Y, Song C, et al. PEM fuel cell relative humidity (RH) and its effect on performance at high temperatures. Electrochim Acta, 2008, 53(16): 5315-5321. https://doi.org/10.1016/j.electacta.2008.02.074

[16]Jian Q, Ma G, Qiu X. Influences of gas relative humidity on the temperature of membrane in PEMFC with interdigitated flow field. Renew Energy, 2014, 62: 129-136. https://doi.org/10.1016/j.renene.2013.06.046

[17] Yan Q, Toghiani H, Causey H. Steady state and dynamic performance of proton exchange membrane fuel cells (PEMFCs) under various operating conditions and load changes. J Power Sources, 2006, 161(1): 492-502. https://doi.org/10.1016/j.jpowsour.2006.03.077

[18]Chang Y, Qin Y, Yin Y, et al. Humidification strategy for polymer electrolyte membrane fuel cells-A review. Appl energy, 2018, 230: 643-662. https://doi.org/10.1016/j.apenergy.2018.08.125

[19]Li Y, Pei P, Wu Z, et al. Approaches to avoid flooding in association with pressure 
drop in proton exchange membrane fuel cells. Appl Energy, 2018, 224: 42-51. https://doi.org/10.1016/j.apenergy.2018.04.071

[20] Wu J, Yuan X Z, Martin J J, et al. A review of PEM fuel cell durability: Degradation mechanisms and mitigation strategies. J Power Sources, 2008, 184(1): 104-119. https://doi.org/10.1016/j.jpowsour.2008.06.006

[21]Pei P, Chen H. Main factors affecting the lifetime of Proton Exchange Membrane fuel cells in vehicle applications: A review. Appl Energy, 2014, 125: 60-75. https://doi.org/10.1016/j.apenergy.2014.03.048

[22] Islam M R, Shabani B, Rosengarten G, et al. The potential of using nanofluids in PEM fuel cell cooling systems: A review. Renew Sustain Energy Rev, 2015, 48: 523-539. https://doi.org/10.1016/j.rser.2015.04.018

[23] Ehsani M, Gao Y, Longo S, et al. Modern electric, hybrid electric, and fuel cell vehicles. CRC press, 2018.

[24] Kim S, Hong I. Effects of humidity and temperature on a proton exchange membrane fuel cell (PEMFC) stack. J Ind Eng Chem, 2008, 14(3): 357-364. https://doi.org/10.1016/j.jiec.2008.01.007

[25] Iranzo A, Boillat P, Biesdorf J, et al. Investigation of the liquid water distributions in a $50 \mathrm{~cm}^{2}$ PEM fuel cell: Effects of reactants relative humidity, current density, and cathode stoichiometry. Energy, 2015, 82: 914-921. https://doi.org/10.1016/j.energy.2015.01.101

[26]Devrim Y, Albostan A. Enhancement of PEM fuel cell performance at higher temperatures and lower humidities by high performance membrane electrode assembly based on Nafion/zeolite membrane. Int J Hydrogen Energy, 2015, 40(44): 15328-15335. https://doi.org/10.1016/j.ijhydene.2015.02.078

[27]Ozen D N, Timurkutluk B, Altinisik K. Effects of operation temperature and reactant gas humidity levels on performance of PEM fuel cells. Renew Sustain Energy Rev, 2016, 59: 1298-1306. https://doi.org/10.1016/j.rser.2016.01.040

[28] Wang Y J, Long W, Wang L, et al. Unlocking the door to highly active ORR catalysts for PEMFC applications: polyhedron-engineered Pt-based nanocrystals. Energy Environ Sci, 2018, 11(2): 258-275. DOI: 10.1039/C7EE02444D 
[29]Ratso S, Sahraie N R, Sougrati M T, et al. Synthesis of highly-active Fe-N-C catalysts for PEMFC with carbide-derived carbons. J Mater Chem A, 2018, 6(30): 14663-14674. DOI: 10.1039/C8TA02325E

[30]Liu M, Zhao Z, Duan X, et al. Nanoscale Structure Design for High Performance Pt - Based ORR Catalysts. Adv Mater, 2019, 31(6): 1802234. https://doi.org/10.1002/adma.201802234

[31]Zhao J, Shahgaldi S, Alaefour I, et al. Pore structure and effective diffusion coefficient of catalyzed electrodes in polymer electrolyte membrane fuel cells. Int J Hydrogen Energy, 2018, 43(7): 3776-3785. https://doi.org/10.1016/j.ijhydene.2018.01.019

[32]Zhao J, Shahgaldi S, Ozden A, et al. Geometric pore surface area and fractal dimension of catalyzed electrodes in polymer electrolyte membrane fuel cells. Int J Energy Research, 2019, 43(7): 3011-3019. https://doi.org/10.1002/er.4260

[33] Ashrafi M, Kanani H, Shams M. Numerical and experimental study of two-phase flow uniformity in channels of parallel PEM fuel cells with modified Z-type flow-fields. Energy, 2018, 147: 317-328. https://doi.org/10.1016/j.energy.2018.01.064

[34]Pekula N, Heller K, Chuang P A, et al. Study of water distribution and transport in a polymer electrolyte fuel cell using neutron imaging. Nucl. Instruments Methods Phys. Res. Sect. A Accel. Spectrometers, Detect. Assoc. Equip., 2005, 542(1-3): 134-141. https://doi.org/10.1016/j.nima.2005.01.090

[35] Tsushima S, Hirai S. In situ diagnostics for water transport in proton exchange membrane fuel cells. Prog Energy Combust Sci, 2011, 37(2): 204-220. https://doi.org/10.1016/j.pecs.2010.06.001

[36]Xie X, Zhang G, Zhou J, et al. Experimental and theoretical analysis of ionomer/carbon ratio effect on PEM fuel cell cold start operation. Int J Hydrogen Energy, 2017, 42(17): 12521-12530. https://doi.org/10.1016/j.ijhydene.2017.02.183

[37] Ishikawa Y, Shiozawa M, Kondo M, et al. Theoretical analysis of supercooled states of water generated below the freezing point in a PEFC. Int J Heat Mass 
Trans, 2014, 74: 215-227.

https://doi.org/10.1016/j.ijheatmasstransfer.2014.03.038

[38]Plazanet M, Sacchetti F, Petrillo C, et al. Water in a polymeric electrolyte membrane: Sorption/desorption and freezing phenomena. J Mem Sci, 2014, 453: 419-424. https://doi.org/10.1016/j.memsci.2013.11.026

[39]Jiao K, Li X. Effects of various operating and initial conditions on cold start performance of polymer electrolyte membrane fuel cells. Int J Hydrogen Energy, 2009, 34(19): 8171-8184. https://doi.org/10.1016/j.ijhydene.2009.07.102

[40]Jeon D H, Kim K N, Baek S M, et al. The effect of relative humidity of the cathode on the performance and the uniformity of PEM fuel cells. Int J Hydrogen Energy, 2011, 36(19): 12499-12511. https://doi.org/10.1016/j.ijhydene.2011.06.136

[41] Yang Z, Du Q, Huo S, et al. Effect of membrane electrode assembly design on the cold start process of proton exchange membrane fuel cells. Int J Hydrogen Energy, 2017, 42(40): 25372-25387. https://doi.org/10.1016/j.ijhydene.2017.08.106

[42]Fan L, Zhang G, Jiao K. Characteristics of PEMFC operating at high current density with low external humidification. Energy Convers Manag, 2017, 150: 763-774. https://doi.org/10.1016/j.enconman.2017.08.034

[43]Zhang G, Fan L, Sun J, et al. A 3D model of PEMFC considering detailed multiphase flow and anisotropic transport properties. Int J Heat Mass Trans, 2017, 115: 714-724. https://doi.org/10.1016/j.ijheatmasstransfer.2017.07.102

[44]Zhang G, Xie X, Xie B, et al. Large-scale multi-phase simulation of proton exchange membrane fuel cell. Int J Heat Mass Trans, 2019, 130: 555-563. https://doi.org/10.1016/j.ijheatmasstransfer.2018.10.122

[45] Tolj I, Bezmalinovic D, Barbir F. Maintaining desired level of relative humidity throughout a fuel cell with spatially variable heat removal rates. Int J Hydrogen Energy, 2011, 36(20): 13105-13113.

\section{https://doi.org/10.1016/j.ijhydene.2011.07.078}

[46]Jiang Y, Yang Z, Jiao K, et al. Sensitivity analysis of uncertain parameters based on an improved proton exchange membrane fuel cell analytical model. Energy 
Convers Manag, 2018, 164: 639-654.

https://doi.org/10.1016/j.enconman.2018.03.002

[47]Pei P, Wu Z, Li Y, et al. Improved methods to measure hydrogen crossover current in proton exchange membrane fuel cell. Appl Energy, 2018, 215: 338-347. https://doi.org/10.1016/j.apenergy.2018.02.002

[48]He J, Ahn J, Choe S Y. Analysis and control of a fuel delivery system considering a two-phase anode model of the polymer electrolyte membrane fuel cell stack. J Power Sources, 2011, 196(10): 4655-4670. https://doi.org/10.1016/j.jpowsour.2011.01.019

[49]Promislow K, St-Pierre J, Wetton B. A simple, analytic model of polymer electrolyte membrane fuel cell anode recirculation at operating power including nitrogen crossover. J Power Sources, 2011, 196(23): 10050-10056. https://doi.org/10.1016/j.jpowsour.2011.08.070

[50] Rabbani A, Rokni M. Effect of nitrogen crossover on purging strategy in PEM fuel cell systems. Appl energy, 2013, 111: 1061-1070. https://doi.org/10.1016/j.apenergy.2013.06.057

[51]Chen Y S, Yang C W, Lee J Y. Implementation and evaluation for anode purging of a fuel cell based on nitrogen concentration. Appl Energy, 2014, 113: 1519-1524. https://doi.org/10.1016/j.apenergy.2013.09.028

[52]Hwang J J. Effect of hydrogen delivery schemes on fuel cell efficiency. J Power Sources, 2013, 239: 54-63. https://doi.org/10.1016/j.jpowsour.2013.03.090

[53]Rabbani A, Rokni M. Effect of nitrogen crossover on purging strategy in PEM fuel cell systems. Appl energy, 2013, 111: 1061-1070. https://doi.org/10.1016/j.apenergy.2013.06.057

[54]Chen Y S, Yang C W, Lee J Y. Implementation and evaluation for anode purging of a fuel cell based on nitrogen concentration. Appl Energy, 2014, 113: 1519-1524. https://doi.org/10.1016/j.apenergy.2013.09.028

[55]Ryan O. Fuel Cell Fundamentals. Publishing house of electronics industry, 2007.

[56]Dadvar M, Afshari E. Analysis of design parameters in anodic recirculation system based on ejector technology for PEM fuel cells: A new approach in 
designing. Int J Hydrogen Energy, 2014, 39(23): 12061-12073.

https://doi.org/10.1016/j.ijhydene.2014.06.046

[57] Onda K, Araki T, Ichihara K, et al. Treatment of low concentration hydrogen by electrochemical pump or proton exchange membrane fuel cell. J Power Sources, 2009, 188(1): 1-7. https://doi.org/10.1016/j.jpowsour.2008.11.135

[58] Abdulla A, Laney K, Padilla M, et al. Efficiency of hydrogen recovery from reformate with a polymer electrolyte hydrogen pump. AIChE J, 2011, 57(7): 1767-1779. https://doi.org/10.1002/aic.12406

[59]Becherif M, Hissel D. MPPT of a PEMFC based on air supply control of the motocompressor group. Int J Hydrogen Energy, 2010, 35(22): 12521-12530. https://doi.org/10.1016/j.ijhydene.2010.06.094

[60] Matraji I, Laghrouche S, Jemei S, et al. Robust control of the PEM fuel cell air-feed system via sub-optimal second order sliding mode. Appl Energy, 2013, 104: 945-957. https://doi.org/10.1016/j.apenergy.2012.12.012

[61] Wang Y X, Xuan D J, Kim Y B. Design and experimental implementation of time delay control for air supply in a polymer electrolyte membrane fuel cell system. Int J Hydrogen Energy, 2013, 38(30): 13381-13392. https://doi.org/10.1016/j.ijhydene.2013.06.040

[62] Liu Z, Li L, Ding Y, et al. Modeling and control of an air supply system for a heavy duty PEMFC engine. Int J Hydrogen Energy, 2016, 41(36): 16230-16239. https://doi.org/10.1016/j.ijhydene.2016.04.213

[63] Kadylak D, Mérida W. Experimental verification of a membrane humidifier model based on the effectiveness method. J Power Sources, 2010, 195(10): 3166-3175. https://doi.org/10.1016/j.jpowsour.2009.12.005

[64] Yu S, Im S, Kim S, et al. A parametric study of the performance of a planar membrane humidifier with a heat and mass exchanger model for design optimization. Int J Heat Mass Trans, 2011, 54(7-8): 1344-1351. https://doi.org/10.1016/j.ijheatmasstransfer.2010.11.054

[65]Bhatia D, Sabharwal M, Duelk C. Analytical model of a membrane humidifier for polymer electrolyte membrane fuel cell systems. Int J Heat Mass Trans, 2013, 
58(1-2): 702-717. https://doi.org/10.1016/j.ijheatmasstransfer.2012.11.033

[66]Park S, Jung D. Effect of operating parameters on dynamic response of water-to-gas membrane humidifier for proton exchange membrane fuel cell vehicle. Int J Hydrogen Energy, 2013, 38(17): 7114-7125.

https://doi.org/10.1016/j.ijhydene.2013.03.170

[67]Afshari E, Houreh N B. Performance analysis of a membrane humidifier containing porous metal foam as flow distributor in a PEM fuel cell system. Energy Convers Manag, 2014, 88: 612-621. https://doi.org/10.1016/j.enconman.2014.08.067

[68]Chen C Y, Yan W M, Lai C N, et al. Heat and mass transfer of a planar membrane humidifier for proton exchange membrane fuel cell. Int J Heat Mass Trans, 2017, 109: 601-608. https://doi.org/10.1016/j.ijheatmasstransfer.2017.02.045

[69] Kandlikar S G, Lu Z. Thermal management issues in a PEMFC stack-A brief review of current status. Appl Therm Eng, 2009, 29(7): 1276-1280. https://doi.org/10.1016/j.applthermaleng.2008.05.009

[70]Zhang G, Kandlikar S G. A critical review of cooling techniques in proton exchange membrane fuel cell stacks. Int J Hydrogen Energy, 2012, 37(3): 2412-2429. https://doi.org/10.1016/j.ijhydene.2011.11.010

[71] Gwak G, Ju H. A rapid start-up strategy for polymer electrolyte fuel cells at subzero temperatures based on control of the operating current density. Int J Hydrogen Energy, 2015, 40(35): 11989-11997. https://doi.org/10.1016/j.ijhydene.2015.05.179

[72] Guo Q, Luo Y, Jiao K. Modeling of assisted cold start processes with anode catalytic hydrogen-oxygen reaction in proton exchange membrane fuel cell. Int J Hydrogen Energy, 2013, 38(2): 1004-1015. https://doi.org/10.1016/j.ijhydene.2012.10.067

[73]Luo Y, Jiao K. Cold start of proton exchange membrane fuel cell. Prog Energy Combust Sci, 2017. https://doi.org/10.1016/j.pecs.2017.10.003

[74] Yang S, Chellali R, Lu X, et al. Modeling and optimization for proton exchange membrane fuel cell stack using aging and challenging $\mathrm{P}$ systems based 
Table A.1. Planar membrane humidifier properties.

\begin{tabular}{ll}
\hline Parameter & Value \\
\hline Number of membranes & 300 \\
Membrane area & $200 \mathrm{~cm}^{2}$ \\
Channel length; width; depth; rib width & $200 ; 1.0 ; 1.0 ; 1.0 \mathrm{~mm}$ \\
Membrane thickness & $0.050 \mathrm{~mm}$ \\
Heat transfer coefficient $\quad$ between & $h_{\text {surr }}=20 \mathrm{~W} \mathrm{~m}^{-2} \mathrm{~K}^{-1}$ \\
humidifier and surrounding & \\
\hline
\end{tabular}

Table A.2. Source terms.

\begin{tabular}{|c|c|}
\hline Source terms & Unit \\
\hline$S_{\mathrm{MH}, \mathrm{mw}}= \begin{cases}-S_{\mathrm{m}-\mathrm{v}} & \text { (in wet side) } \\
-S_{\mathrm{m}-\mathrm{v}} & \text { (in dry side) }\end{cases}$ & $\mathrm{kmol} \mathrm{m}^{-3} \mathrm{~s}^{-1}$ \\
\hline$S_{\mathrm{MH}, \mathrm{vp}}= \begin{cases}1000 S_{\mathrm{m}-\mathrm{v}}-S_{\mathrm{v}-1}+S_{\mathrm{vp}, \text { flow }} & \text { (in wet channel) } \\
1000 S_{\mathrm{m}-\mathrm{v}}+S_{\mathrm{vp}, \text { flow }} & \text { (in dry channel) }\end{cases}$ & $\mathrm{mol} \mathrm{m}{ }^{-3} \mathrm{~s}^{-1}$ \\
\hline$S_{\mathrm{vp}, \mathrm{flow}}=\frac{\left(c_{\mathrm{vp}, \mathrm{in}} u_{\mathrm{in}}-c_{\mathrm{vp}, \mathrm{out}} u_{\mathrm{out}}\right) A_{\mathrm{MH}, \mathrm{in}}}{r_{\mathrm{MH}, \mathrm{CH}} A_{\mathrm{MH}} \delta_{\mathrm{CH}}}$ & $\mathrm{mol} \mathrm{m}{ }^{-3} \mathrm{~s}^{-1}$ \\
\hline$S_{\mathrm{MH}, \mathrm{lq}}=\frac{S_{\mathrm{v}-1} M_{\mathrm{H} 2 \mathrm{O}}}{1000}+\frac{\left(s_{\mathrm{lq}, \mathrm{in}} u_{\mathrm{in}}-s_{\mathrm{lq}, \mathrm{out}} u_{\mathrm{out}}\right) \zeta_{\mathrm{rati}} \rho_{\mathrm{lq}} A_{\mathrm{MH}, \text { in }}}{r_{\mathrm{MH}, \mathrm{CH}} A_{\mathrm{MH}} \delta_{\mathrm{CH}}}$ & $\mathrm{kg} \mathrm{m}^{-3} \mathrm{~s}^{-1}$ \\
\hline$S_{\mathrm{T}}=\left\{\begin{array}{lr}Q_{\mathrm{gas}} & \text { (in dry channel) } \\
h_{\mathrm{cond}}\left(-S_{\mathrm{m}-\mathrm{v}} M_{\mathrm{H}_{2} \mathrm{O}}\right) & \text { (in membrane) } \\
Q_{\mathrm{gas}}+h_{\text {cond }} S_{\mathrm{v}-1} & \text { (in wet channel) }\end{array}\right.$ & $\mathrm{W} \mathrm{m} \mathrm{m}^{-3}$ \\
\hline
\end{tabular}

\section{Appendix B}

This appendix presents the calculation equations for the electrochemical hydrogen 
pump model, including membrane water, hydrogen, water vapor, and temperature.

Membrane water content is calculated at the center of catalyst layer (CL) and membrane.

$$
\begin{aligned}
& \lambda_{\mathrm{HP}, \mathrm{CLa}}^{t}=\lambda_{\mathrm{HP}, \mathrm{CLa}}^{t-\Delta t}+\left[\frac{\left(\lambda_{\mathrm{HP}, \mathrm{MEM}}^{t-\Delta t}-\lambda_{\mathrm{HP}, \mathrm{CLa}}^{t-\Delta t}\right) D_{\mathrm{HP}, \mathrm{MEM} \_\mathrm{CLa}}^{\lambda, \mathrm{ef}}}{\left(\frac{\delta_{\mathrm{HP}, \mathrm{CLa}}}{2}+\frac{\delta_{\mathrm{HP}, \mathrm{MEM}}}{2}\right) \delta_{\mathrm{HP}, \mathrm{CLa}}}+S_{\mathrm{HP}, \mathrm{mw}} \frac{E W_{\mathrm{HP}}}{\rho_{\mathrm{HP}, \mathrm{MEM}}}\right] \frac{\Delta t}{\omega_{\mathrm{HP}, \mathrm{CLa}}} \\
& \lambda_{\mathrm{HP}, \mathrm{MEM}}^{t}=\lambda_{\mathrm{HP}, \mathrm{MEM}}^{t-\Delta t}+\left[\frac{\left(\lambda_{\mathrm{HP}, \mathrm{CLc}}^{t-\Delta t}-\lambda_{\mathrm{HP}, \mathrm{MEM}}^{t-\Delta t}\right) D_{\mathrm{HP}, \mathrm{MEM} \_\mathrm{CLc}}^{\lambda, \text { ef }}}{\left(\frac{\delta_{\mathrm{HP}, \mathrm{CLc}}}{2}+\frac{\delta_{\mathrm{HP}, \mathrm{MEM}}}{2}\right) \delta_{\mathrm{HP}, \mathrm{MEM}}}-\frac{\left(\lambda_{\mathrm{HP}, \mathrm{MEM}}^{t-\Delta t}-\lambda_{\mathrm{HP}, \mathrm{CLa}}^{t-\Delta t}\right) D_{\mathrm{HP}, \mathrm{MEM} \_\mathrm{CLa}}^{\lambda, \text { eff }}}{\left(\frac{\delta_{\mathrm{HP}, \mathrm{CLa}}}{2}+\frac{\delta_{\mathrm{HP}, \mathrm{MEM}}}{2}\right) \delta_{\mathrm{HP}, \mathrm{MEM}}}\right] \Delta t \\
& \lambda_{\mathrm{HP}, \mathrm{CLc}}^{t}=\lambda_{\mathrm{HP}, \mathrm{CLc}}^{t-\Delta t}+\left[-\frac{\left(\lambda_{\mathrm{HP}, \mathrm{CLc}}^{t-\Delta t}-\lambda_{\mathrm{HP}, \mathrm{MEM}}^{t-\Delta t}\right) D_{\mathrm{HP}, \mathrm{MEM} \_\mathrm{CLc}}^{\lambda}}{\left(\frac{\delta_{\mathrm{HP}, \mathrm{CLc}}}{2}+\frac{\delta_{\mathrm{HP}, \mathrm{MEM}}}{2}\right) \delta_{\mathrm{HP}, \mathrm{CLc}}}+S_{\mathrm{HP}, \mathrm{mw}} \frac{E W_{\mathrm{HP}}}{\rho_{\mathrm{HP}, \mathrm{MEM}}}\right] \frac{\Delta t}{\omega_{\mathrm{HP}, \mathrm{CLc}}}
\end{aligned}
$$

where $\lambda_{\mathrm{HP}, \mathrm{CLa}}^{t-\Delta t}, \lambda_{\mathrm{HP}, \mathrm{MEM}}^{t-\Delta t}, \lambda_{\mathrm{HP}, \mathrm{CLc}}^{t-\Delta t}$ are the membrane water content of CLa, membrane, CLc at last time step, $\lambda_{\mathrm{HP}, \mathrm{CLa}}^{t}, \lambda_{\mathrm{HP}, \mathrm{MEM}}^{t}, \lambda_{\mathrm{HP}, \mathrm{CL} c}^{t}$ are that of CLa, membrane, CLc at next time step, $S_{\mathrm{HP}, \mathrm{mw}}\left(\mathrm{kmol} \mathrm{m} \mathrm{m}^{-3}\right)$ is the membrane water source term, which includes the electro-osmotic drag effect and phase changes.

Gas concentration at the center of CL, GDL, and gas channel $(\mathrm{CH})$ are calculated as:

$$
\begin{aligned}
& c_{\mathrm{HP}, \mathrm{i} \_\mathrm{CLc}}^{t}=c_{\mathrm{HP}, \mathrm{i} \_\mathrm{CLc}}^{t-t}+\left[S_{\mathrm{HP}, \mathrm{i}}-\frac{\left(c_{\mathrm{HP}, \mathrm{i} \_\mathrm{CLc}}^{t-t}-c_{\mathrm{HP}, \mathrm{i} \_\mathrm{GDLc}}^{t-\Delta t}\right) D_{\mathrm{HP}, \mathrm{CLc} \_\mathrm{GDLc}}^{\mathrm{i}, \text { eff }}}{\left(\frac{\delta_{\mathrm{HP}, \mathrm{CLc}}}{2}+\frac{\delta_{\mathrm{HP}, \mathrm{GDLc}}}{2}\right) \delta_{\mathrm{HP}, \mathrm{CLc}}}\right] \frac{\Delta t}{\varepsilon_{\mathrm{HP}, \mathrm{CLc}}} \\
& c_{\mathrm{HP}, \mathrm{i}_{-} \mathrm{GDLc}}^{t}=c_{\mathrm{HP}, \mathrm{i} \_\mathrm{GDLc}}^{t-\Delta t}+ \\
& {\left[\frac{\left(c_{\mathrm{HP}, \mathrm{i} \_\mathrm{CLc}}^{t-t}-c_{\mathrm{HP}, \mathrm{i} \_\mathrm{GDLc}}^{t-\Delta t}\right) D_{\mathrm{HP}, \mathrm{CLc} \_\mathrm{GDLc}}^{\mathrm{i} \text { eff }}}{\left(\frac{\delta_{\mathrm{HP}, \mathrm{CLc} c}}{2}+\frac{\delta_{\mathrm{HP}, \mathrm{GDLc}}}{2}\right) \delta_{\mathrm{HP}, \mathrm{GDLc}}}-\frac{r_{\mathrm{HP}, \mathrm{CH}}\left(c_{\mathrm{HP}, \mathrm{i}, \mathrm{GDLc}}^{t-\Delta t}-c_{\mathrm{HP}, \mathrm{i} \_\mathrm{CHc}}^{t-\Delta t}\right) D_{\mathrm{HP}, \mathrm{GDLc}}^{\mathrm{i}, \text { eff }}}{\left(\frac{\delta_{\mathrm{HP}, \mathrm{GDLc}}}{2}\right) \delta_{\mathrm{HP}, \mathrm{GDLc}}}\right] \frac{\Delta t}{\varepsilon_{\mathrm{HP}, \mathrm{GDLc}}}}
\end{aligned}
$$


where $c_{\mathrm{HP}, i \mathrm{CL}}^{t-\Delta t}, c_{\mathrm{HP}, i \in \mathrm{GDLc}}^{t-\Delta t}, c_{\mathrm{HP}, i \_\mathrm{CHc}}^{t-\Delta t}\left(\mathrm{~mol} \mathrm{~m}^{-3}\right)$ represent the gas concentration of $\mathrm{CL}$, GDL, $\mathrm{CH}$ at last time step, $c_{\mathrm{HP}, \mathrm{i}, \mathrm{CL}}^{t}, c_{\mathrm{HP}, \mathrm{i}, \mathrm{GDLc}}^{t}, c_{\mathrm{HP}, \mathrm{i} \_\mathrm{CHc}}^{t}\left(\mathrm{~mol} \mathrm{~m}^{-3}\right)$ represent the gas concentration of $\mathrm{CL}, \mathrm{GDL}, \mathrm{CH}$ at next time step $\left(\mathrm{i}=\mathrm{H}_{2}, \mathrm{vp}\right), S_{\mathrm{HP}, \_ \text {fllow }}\left(\mathrm{kmol} \mathrm{m}^{-3} \mathrm{~s}^{-1}\right)$ is the source term of gas species.

Temperature at the center of each layer is calculated in the same way.

$$
\begin{aligned}
& T_{\mathrm{HP}, \mathrm{BP}}^{t}=T_{\mathrm{HP}, \mathrm{BP}}^{t-\Delta t}+\left[\frac{\left(T_{\mathrm{HP}, \mathrm{CH}}^{t-\Delta t}-T_{\mathrm{HP}, \mathrm{BP}}^{t-\Delta t}\right) k_{\mathrm{HP}, \mathrm{BP} \_\mathrm{CH}}^{\text {eff }}}{\left(\frac{\delta_{\mathrm{HP}, \mathrm{BP}}}{2}+\frac{\delta_{\mathrm{HP}, \mathrm{CH}}}{2}\right) \delta_{\mathrm{HP}, \mathrm{BP}}}-\frac{h_{\text {surr }}\left(T_{\mathrm{HP}, \mathrm{BP}}^{t-\Delta t}-T_{\text {surr }}\right)}{\delta_{\mathrm{HP}, \mathrm{BP}}}+S_{\mathrm{HP}, \mathrm{T}}\right] \frac{\Delta t}{\rho c_{\mathrm{p}}} \\
& T_{\mathrm{HP}, \mathrm{CH}}^{t}=T_{\mathrm{HP}, \mathrm{CH}}^{t-\Delta t}+\left[\frac{\left(T_{\mathrm{HP}, \mathrm{GDL}}^{t-\Delta t}-T_{\mathrm{HP}, \mathrm{CH}}^{t-\Delta t}\right) k_{\mathrm{HP}, \mathrm{GDL} \_\mathrm{CH}}^{\mathrm{eff}}}{\left(\frac{\delta_{\mathrm{HP}, \mathrm{CH}}}{2}+\frac{\delta_{\mathrm{HP}, \mathrm{GDL}}}{2}\right) \delta_{\mathrm{HP}, \mathrm{CH}}}-\frac{\left(T_{\mathrm{HP}, \mathrm{CH}}^{t-\Delta t}-T_{\mathrm{HP}, \mathrm{BP}}^{t-\Delta t}\right) k_{\mathrm{HP}, \mathrm{BP} \_\mathrm{CH}}^{\text {eff }}}{\left(\frac{\delta_{\mathrm{HP}, \mathrm{BP}}}{2}+\frac{\delta_{\mathrm{HP}, \mathrm{CH}}}{2}\right) \delta_{\mathrm{HP}, \mathrm{CH}}}+S_{\mathrm{HP}, \mathrm{T}}\right] \frac{\Delta t}{\rho c_{\mathrm{p}}}
\end{aligned}
$$

$T_{\mathrm{HP}, \mathrm{MEM}}^{t}=T_{\mathrm{HP}, \mathrm{MEM}}^{t-\Delta t}+$ $\left[\frac{\left(T_{\mathrm{HP}, \mathrm{CLc}}^{t}-T_{\mathrm{HP}, \mathrm{MEM}}^{t}\right) k_{\mathrm{HPP}, \mathrm{CL} \_ \text {MEM }}^{\text {eff }}}{\left(\frac{\delta_{\mathrm{HP}, \mathrm{CLc}}}{2}+\frac{\delta_{\mathrm{HP}, \mathrm{MEM}}}{2}\right) \delta_{\mathrm{HP}, \mathrm{MEM}}}-\frac{\left(T_{\mathrm{HP}, \mathrm{MEM}}^{t-\Delta t}-T_{\mathrm{H}, \mathrm{CLa}}^{t-\Delta t}\right) k_{\mathrm{HP}, \mathrm{MEM} \_\mathrm{eLa}}^{\text {eff }}}{\left(\frac{\delta_{\mathrm{HP}, \mathrm{MEM}}}{2}+\frac{\delta_{\mathrm{HP}, \mathrm{CLa}}}{2}\right) \delta_{\mathrm{HP}, \mathrm{MEM}}}+S_{\mathrm{HP}, \mathrm{T}}\right] \frac{\Delta t}{\rho c_{\mathrm{p}}}$

where $T_{\mathrm{HP}, \mathrm{BP}}^{t-\Delta t}, T_{\mathrm{HP}, \mathrm{CH}}^{t-\Delta t}, T_{\mathrm{HP}, \mathrm{MEM}}^{t-\Delta t}(\mathrm{~K})$ are the temperature of $\mathrm{BP}, \mathrm{CH}, \mathrm{MEM}$ at last time step, $T_{\mathrm{HP}, \mathrm{BP}}^{t}, T_{\mathrm{HP}, \mathrm{CH}}^{t}, T_{\mathrm{HP}, \mathrm{MEM}}^{t}(\mathrm{~K})$ are the temperature at next time step. $S_{\mathrm{HP}, \mathrm{T}}(\mathrm{W}$ $\mathrm{m}^{-3}$ ) is the heat source term.

\section{Appendix C}


This appendix lists the calibration process of the compressor characteristics. The multinomial coefficients of curving fitting results, the proportion-integral-derivative control strategy, and the corresponding calculation procedure are also presented.

The air mass flow rate and rotating speed are calibrated as:

$$
\begin{aligned}
& m_{\text {air,cr }}=\frac{m_{\mathrm{cp}} \sqrt{\theta_{\mathrm{f}}}}{\delta_{\mathrm{f}}}, N_{\mathrm{cr}}=\frac{N_{\mathrm{cp}}}{\sqrt{\theta_{\mathrm{f}}}} \\
& \theta_{\mathrm{f}}=\frac{T_{\mathrm{cp}, \mathrm{in}}}{288}, \delta_{\mathrm{f}}=\frac{p_{\mathrm{cp}, \mathrm{in}}}{101325}
\end{aligned}
$$
where $m_{\mathrm{cp}}\left(\mathrm{kg} \mathrm{s}^{-1}\right)$ is the mass flow rate, $N_{\mathrm{cp}}(\mathrm{RPM})$ is the rotating speed, $m_{\text {air,cr }}$ $\left(\mathrm{kg} \mathrm{s}^{-1}\right)$ is the corrected mass flow rate, $N_{\mathrm{cr}}$ (RPM) is the corrected rotating speed, $T_{\text {cp,in }}(\mathrm{K})$ is the air inlet temperature, $p_{\mathrm{cp}, \text { in }}(\mathrm{Pa})$ is the air inlet pressure, $\theta_{\mathrm{f}}, \delta_{\mathrm{f}}$ are the temperature and pressure calibration factor, respectively.

Table C.1. Multinomial coefficients of curving fitting results.

\begin{tabular}{llllllll}
\hline Parameter & Value & Parameter & Value & Parameter & Value & Parameter & Value \\
\hline $\mathrm{p}_{00}$ & 0.0483 & $\mathrm{p}_{30}$ & 0.806 & $\mathrm{p}_{40}$ & -0.603 & $\mathrm{p}_{50}$ & 0.214 \\
$\mathrm{p}_{10}$ & 0.361 & $\mathrm{p}_{21}$ & -2.70 & $\mathrm{p}_{31}$ & 3.017 & $\mathrm{p}_{41}$ & -1.448 \\
$\mathrm{p}_{01}$ & -0.297 & $\mathrm{p}_{12}$ & 2.696 & $\mathrm{p}_{22}$ & -5.12 & $\mathrm{p}_{32}$ & 3.663 \\
$\mathrm{p}_{20}$ & -0.682 & $\mathrm{p}_{03}$ & -0.819 & $\mathrm{p}_{13}$ & 3.578 & $\mathrm{p}_{23}$ & -4.324 \\
$\mathrm{p}_{11}$ & 1.352 & & & $\mathrm{p}_{04}$ & -0.883 & $\mathrm{p}_{14}$ & 2.435 \\
$\mathrm{p}_{02}$ & -0.617 & & & & & $\mathrm{p}_{05}$ & -0.536 \\
\hline
\end{tabular}

Note: The sum of squares due to error (SSE) is 0.008865 , and the coefficient of determination (R-square) is 0.9805 , indicating good curve fitting results.

As stated in Subsection 2.4, the terminal voltage determines the rotating speed of drive motor, thus determining the mass flow rate of compressor. The variance of real/required mass flow rate is set as the control deviation, and the controlled terminal 
vage is calculated.

$$
\begin{aligned}
& e(t)=m_{\mathrm{air}}^{\mathrm{req}}-m_{\mathrm{air}}^{\mathrm{real}} \\
& u(t)=K_{\mathrm{p}} e(t)+K_{\mathrm{I}} \int e(t) d t+K_{\mathrm{D}} \frac{d e(t)}{d t} \\
& v_{\mathrm{cm}}^{\mathrm{PID}}=v_{\mathrm{cm}}+u(t)
\end{aligned}
$$

The calculation procedure of the air compressor model is explained as follows. Firstly, the required air mass flow rate and pressure ratio are calculated according to stack operating conditions. After the temperature and pressure calibration, the specific working point in characteristics of air compressor is determined. If the point locates in surging region or exceeds maximum flow rate, it is adjusted to ensure normal operation of compressor. Given temporary compressor rotating speed, the real mass flow rate is obtained based on aforementioned polynomial fitting results. Then, the control variance is calculated and the corresponding motor terminal voltage is acquired. The new rotating speed is subsequently calculated based on the inertance of drive motor. Finally, the new air mass flow rate is obtained. The above procedure continues until the required air mass flow rate and pressure ratio are simultaneously reached.

\section{Appendix D}

This appendix gives the schematic diagram of a ribbon-tubular fin radiator and the corresponding structural properties. The calculation equations for heat transfer coefficients are also presented. 

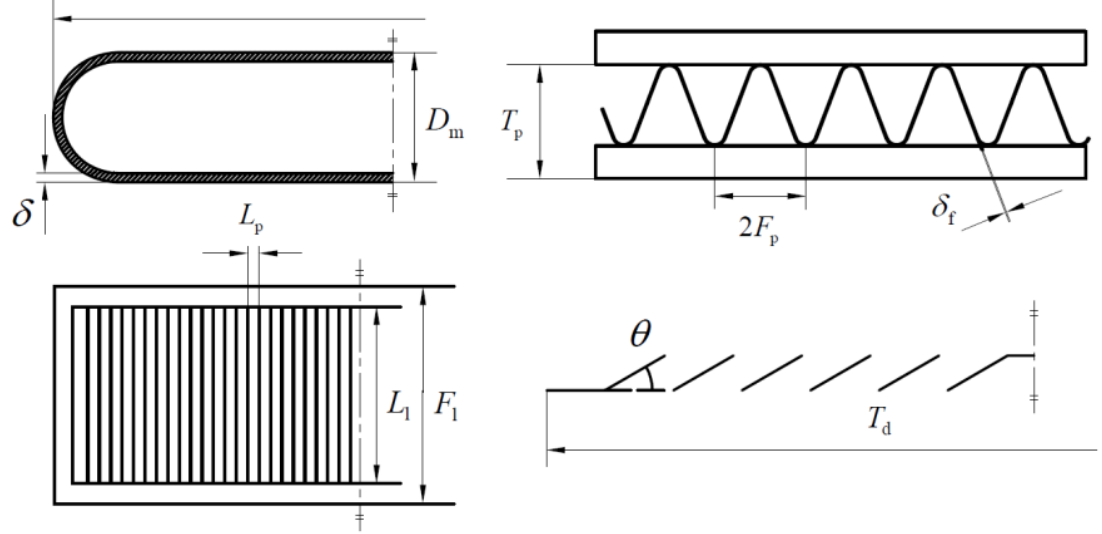

Fig. D.1. Schematic diagram of a ribbon-tubular fin radiator [78].

Table D.1. Radiator structural properties [78].

\begin{tabular}{llll}
\hline Parameter & Value & Parameter & Value $(\mathrm{mm})$ \\
\hline Tube length $L$ & 600 & Fin thickness $\delta_{\mathrm{f}}$ & $0.06 \mathrm{~mm}$ \\
Tube width $D_{\mathrm{m}}$ & $1.5 \mathrm{~mm}$ & Fin pitch $F_{\mathrm{p}}$ & $1.115 \mathrm{~mm}$ \\
Tube length $T_{\mathrm{d}}$ & $16 \mathrm{~mm}$ & Fin number $n_{\mathrm{f}}$ & 266 \\
Tube thickness $\delta$ & $0.25 \mathrm{~mm}$ & Louver pitch $L_{\mathrm{p}}$ & $0.805 \mathrm{~mm}$ \\
Tube pitch $T_{\mathrm{p}}$ & $6.5 \mathrm{~mm}$ & Louver length $L_{1}$ & $4.56 \mathrm{~mm}$ \\
Tube number $n_{\mathrm{t}}$ & 58 & Louver angle $\theta$ & $30^{\circ}$ \\
Fin length $F_{1}$ & $5 \mathrm{~mm}$ & & \\
\hline
\end{tabular}

As previously stated, the overall heat transfer coefficient consists of three parts, including heat convection between coolant and tube, heat conduction inside tube wall and heat convection between tube and air. The heat transfer coefficient between coolant and tube is calculated as:

$h_{l}=\frac{N u \lambda_{1}}{l_{1}}$

where $N u$ is the Nusselt number, $\lambda_{1}\left(\mathrm{~W} \mathrm{~m}^{-1} \mathrm{~K}^{-1}\right)$ is the conductive heat transfer 
coefficient of coolant, $l_{1}(\mathrm{~m})$ is the characteristic length. Based on tube structures shown in Fig. D.1, the sectional area and perimeter are calculated as:

$l_{1}=\frac{4 A_{\mathrm{t}}}{P_{\mathrm{t}}}$

$A_{\mathrm{t}}=\left(T_{\mathrm{d}}-D_{\mathrm{m}}\right)\left(D_{\mathrm{m}}-2 \delta\right)+\pi\left(\frac{D_{\mathrm{m}}-2 \delta}{2}\right)^{2}$

$P_{\mathrm{t}}=2\left[\left(T_{\mathrm{d}}-D_{\mathrm{m}}\right)-\pi\left(D_{\mathrm{m}}-2 \delta\right) / 2\right]$

The Nusselt number is determined by coolant flow condition inside tube and it is calculated based on empirical equations [81].

$N u=\left\{\begin{array}{lr}6.49 & \left(R e_{1}<2300\right) \\ \frac{\left(R e_{1}-1000\right) P r_{1}\left(f_{1} / 2\right)}{1.07+12.7 \sqrt{f_{1} / 2}\left(P r_{1}^{2 / 3}-1\right)} & \left(3000 \leq R e_{1}<5 \times 10^{6}\right)\end{array}\right.$

$f_{1}=\left(1.58 \ln R e_{1}-3.28\right)^{-2}$

where $P r_{1}$ is the Prandtl number, $f_{1}$ is the friction factor.

Heat is absorbed from coolant, then it is released to air through louver. The heat transfer coefficient between tube and air is calculated as [78]:

$$
\begin{aligned}
& j=R_{\text {air }}^{-0.49}\left(\frac{\theta}{90}\right)^{0.27}\left(\frac{F_{\mathrm{p}}}{L_{\mathrm{p}}}\right)^{-0.14}\left(\frac{F_{1}}{L_{\mathrm{p}}}\right)^{-0.29}\left(\frac{T_{\mathrm{d}}}{L_{\mathrm{p}}}\right)^{-0.23}\left(\frac{L_{1}}{L_{\mathrm{p}}}\right)^{0.68}\left(\frac{T_{\mathrm{p}}}{L_{\mathrm{p}}}\right)^{-0.28}\left(\frac{\delta_{\mathrm{f}}}{L_{\mathrm{p}}}\right)^{-0.05} \\
& h_{\mathrm{a}}=\frac{j\left(c_{\mathrm{p}}\right)_{\text {air }} G_{\text {air }}}{\mathrm{Pr}_{\text {air }}^{/ 23}} \\
& G_{\text {air }}=\frac{m_{\text {air }}}{2 n_{\mathrm{t}} n_{\mathrm{f}} A_{\mathrm{a}, \text { min }}}
\end{aligned}
$$

where $j$ is the heat transfer factor and it is related to the louver structure. $G_{\text {air }}(\mathrm{kg}$ $\left.\mathrm{m}^{-2} \mathrm{~s}^{-1}\right)$ is the air mass flow rate per effective flow area. $A_{\mathrm{a}, \mathrm{min}}\left(\mathrm{m}^{2}\right)$ is the sectional area encircled by adjacent tubes and fins. Since there are fins on the surface of each tube to enhance heat transfer, it is necessary to take fin efficiency into consideration. 


$$
\begin{aligned}
& \eta_{0}=\frac{A_{\mathrm{f}, 1}+\eta_{\mathrm{f}} A_{\mathrm{f}, 2}}{A_{\mathrm{f}, 1}+A_{\mathrm{f}, 2}}, \quad \eta_{\mathrm{f}}=\frac{\operatorname{th}(m l)}{m l} \\
& m=\sqrt{\frac{2 h_{\mathrm{a}}\left(F_{\mathrm{d}}+\delta_{\mathrm{f}}\right)}{\lambda F_{\mathrm{d}} \delta_{\mathrm{f}}}}, \quad l=\sqrt{F_{\mathrm{p}}^{2}+F_{1}^{2}}
\end{aligned}
$$

where $\eta_{0}$ is the overall heat transfer efficiency, $\eta_{\mathrm{f}}$ is the fin efficiency, $A_{\mathrm{f}, 1}, A_{\mathrm{f}, 2}$ $\left(\mathrm{m}^{2}\right)$ are the fin base area and fin surface area, respectively. 